\title{
IS THE GRASS REALLY GREENER? A QUALITATIVE STUDY OF TEACHER REFLECTIONS ON THEIR DECISION TO MIGRATE FROM SMALL RURAL DISTRICTS TO LARGER SCHOOL DISTRICTS
}

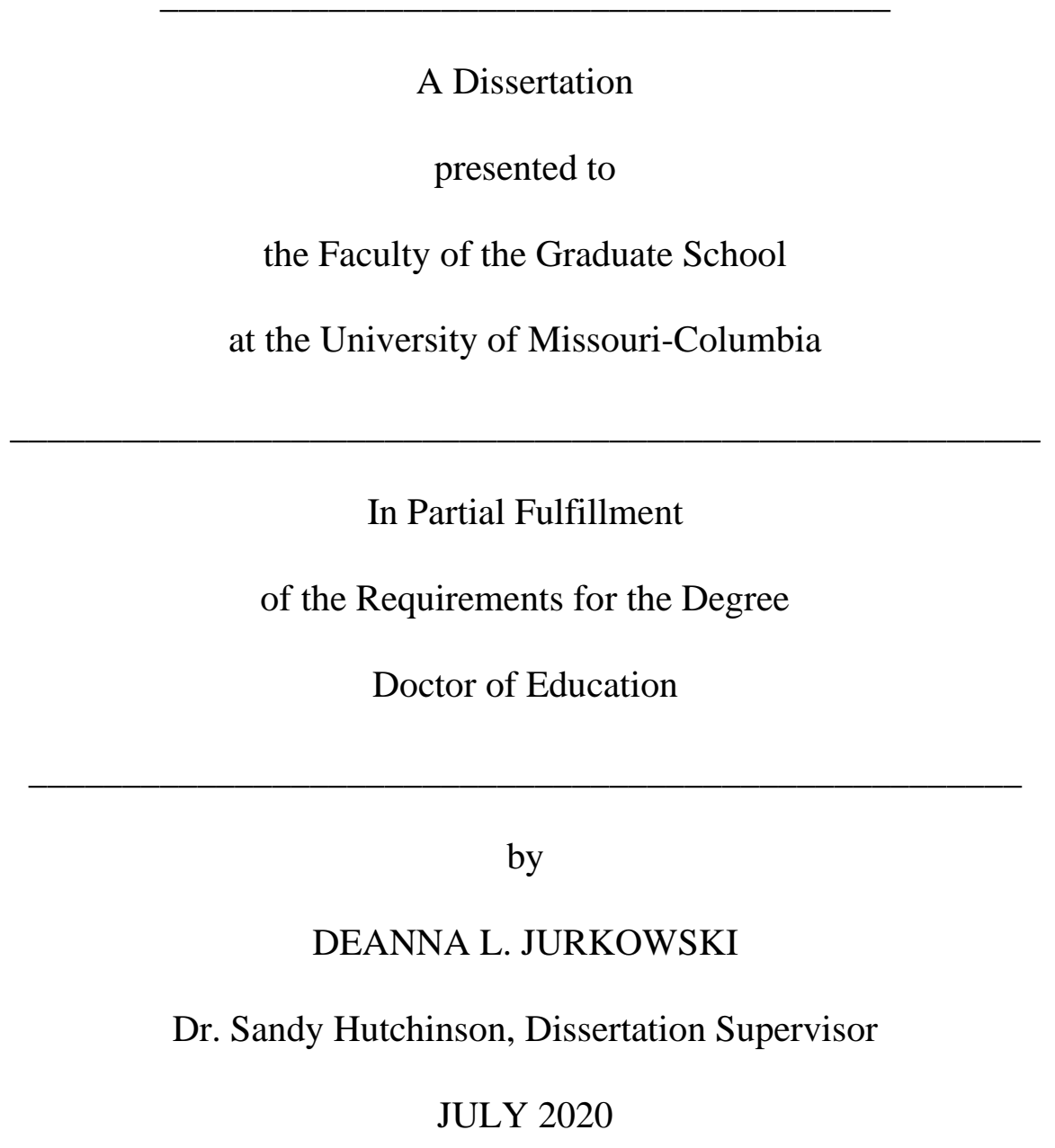


(C) Copyright by Deanna L. Jurkowski 2020

All Rights Reserved 
The undersigned, appointed by the dean of the Graduate School, have examined the dissertation entitled

IS THE GRASS REALLY GREENER? A QUALITATIVE STUDY OF TEACHER REFLECTIONS ON THEIR DECISION TO MIGRATE FROM SMALL RURAL DISTRICTS TO LARGER SCHOOL DISTRICTS

presented by Deanna L. Jurkowski, a candidate for the degree of doctor of education, and hereby certify that, in their opinion, it is worthy of acceptance.

Dr. Sandy Hutchinson

Dr. Barbara N. Martin

Dr. Doug Thomas

Dr. Steve Ritter 


\section{DEDICATION}

An endeavor of this magnitude is not accomplished in isolation. Simply put, while my name may be the one on the diploma, many people kept me moving toward the goal of finishing this dissertation. From the reboot of my educational journey in 2009, my family has supported me $100 \%$. I feel as if Odin knew what I needed to do even before I did and gave me the not so gentle shove into the educational abyss out of which I am climbing. He has supported me from the day we met and knew that while my education was important, there was a time our children took priority. He saw that I was not happy defining myself as a college dropout (multiple times over), and when our family was complete, he took on more of the home tasks to support me as I went back to school. There are no words to describe how much I love this man who loves me enough to keep me focused on my goals. Throughout this journey, Odin has been my hero. He has balanced his career, our large family, and his crazy wife, who works out of town and is always taking another class, working on homework, or staying until closing time at the library.

Our children also have had to deal with another parent taking on the insane task of writing a dissertation, and for that I am both sorry and proud. They were so young when their father completed his dissertation and did not see the sleepless nights, the frustration when something did not go just right, and the physical and emotional demands of this process. While I am sorry they had to deal with a mom who is busy, tired, and emotional as the end is getting near, I am proud to set the example for them. I know they are strong young men and women who will take on the world and change it for the better. Had they been unsupportive of my pursuit at any time, I do not think I could have managed to go 
on. Instead, they let me know which events were important to them so I could make those a priority. They were gracious and understanding that I could not be at everything, and they know that I love them.

Others that need to be mentioned are both my parents and my in-laws. Both my parents and Odin's parents have been supportive of me as I pursue this degree. I have not always wanted to talk about it, especially when things were not going well. Many phone calls would end with, "we aren't talking about that today," in response to them asking how I was doing regarding my research. I knew I could always share the highs and lows with them, but mostly chose to share the highs. I have no doubt my parents wanted to see me reach my goal and their love and support was unconditional.

Finally, I could not have made it through this process without the support of my co-workers and friends. My co-workers in both school districts have been understanding when I could not stay late due to class or research. They kept me on track and were willing to send me gentle reminders knowing that at times my mind may be focused elsewhere. My friends, particularly those on this same journey, have been an invaluable asset. They understand the specifics of this program, the excitement and frustration that happens during the research process, and the physical and emotional toll of the entire EdD experience. These are the people who have seen me at my best and my worst and still care for me anyway. 


\section{ACKNOWLEDGMENTS}

There are several important people whom I would like to acknowledge. My dissertation committee has been extremely supportive throughout this process by providing guidance and insight along the way through coursework, the design of my study, and ultimately the presentation of my findings. This group of professionals encouraged me to view my research as important and helped me take steps toward sharing my preliminary findings with the world. Thank you, Dr. Sandy Hutchinson, Dr. Barbara N. Martin, Dr. Doug Thomas, and Dr. Steve Ritter for the gift of your time and expertise.

I have a special place in my heart for Dr. Sandy Hutchinson, the Chair of my dissertation committee. I am lucky to call her a friend as well as an advisor. Without her encouragement, I do not know if I would have ever found it in myself to not only call myself a leader but to endeavor to answer some of my many questions about rural education through a research study. Dr. Hutchinson celebrated milestones with me, encouraged me through the rough patches, and more than once told me to trust my instincts because I was ready. There are not enough ways in the world to say thank you. I hope to pay your gift of generosity, encouragement, leadership, and support on to others throughout my lifetime.

Finally, those who chose to answer the email in the affirmative when asked to participate in this study should be acknowledged. Without their candor, I would continue to wonder, "but why, really." These individuals shared their time and stories with me, trusting a stranger to share their secrets without sharing their names. These individuals are brave and should be recognized for their contribution to education in rural schools across Missouri. 


\section{TABLE OF CONTENTS}

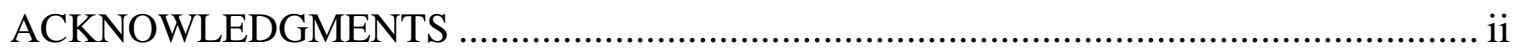

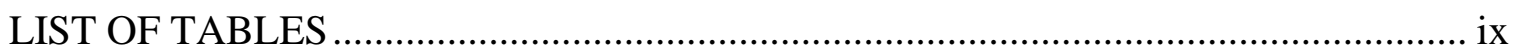

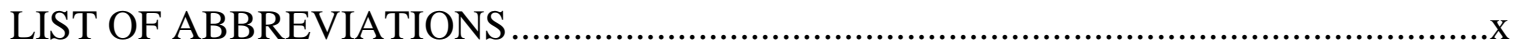

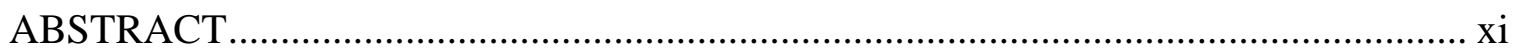

\section{SECTION}

1. INTRODUCTION TO THE DISSERTATION-IN-PRACTICE .........................1

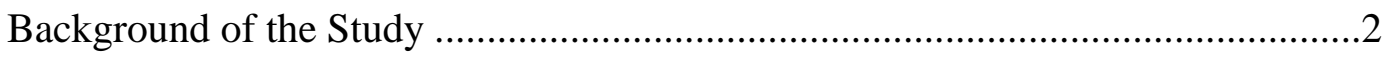

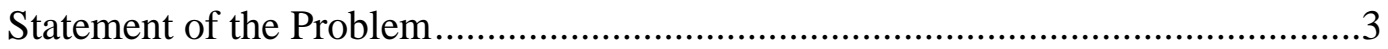

Problem of Practice ...................................................................... 3

Existing Gap in the Literature ........................................................4

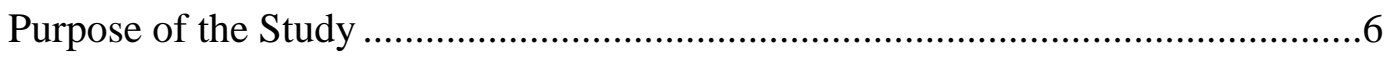

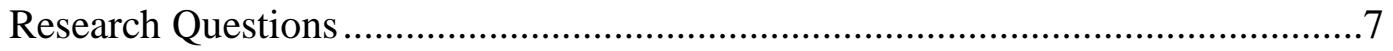

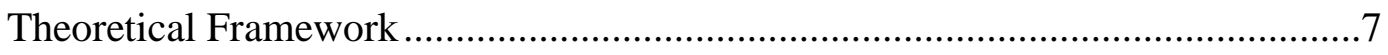

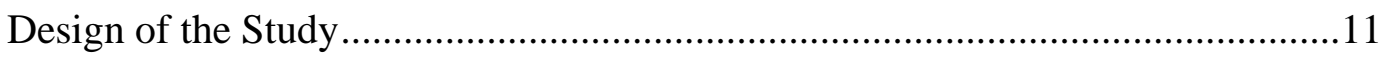

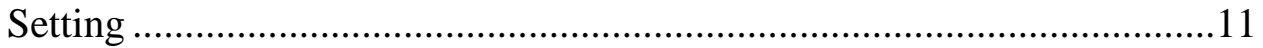

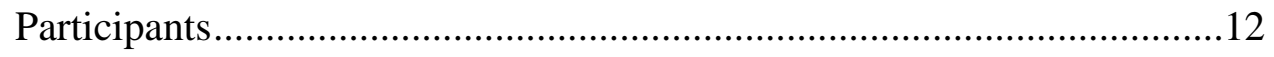

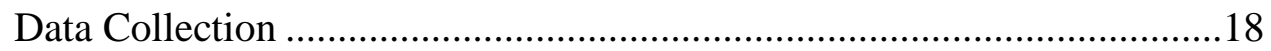

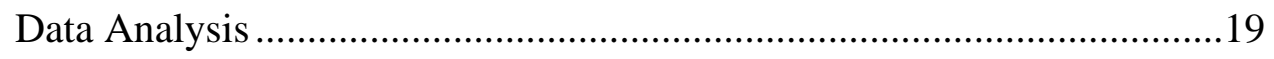

Limitations, Assumptions, and Design Controls ...........................................21

Limitations ............................................................................. 21

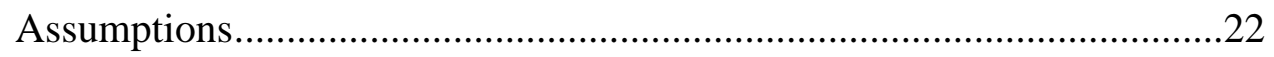

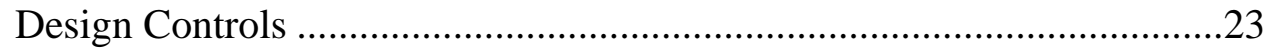


Research Questions Answered.......................................................................25

Research Question One: Why Do Teachers Leave Rural School Districts to Teach in Larger School Districts? ................................................25

Money and Finances ............................................................25

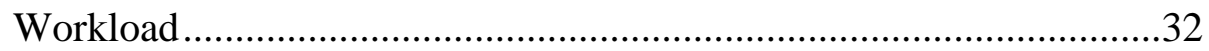

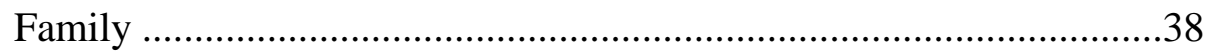

Administration and Support ...................................................41

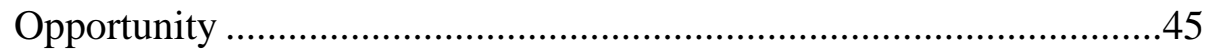

Inevitable Migration...........................................................4 47

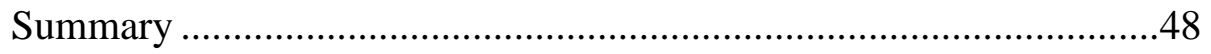

Research Question Two: How Do Teachers View Their Experience

Teaching in a Small, Rural School District?......................................48

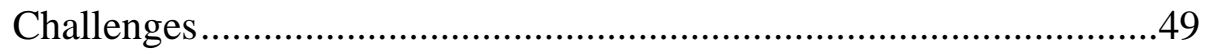

Positive Experience..................................................................56

Negative Experience ................................................................68

Recommend Other Teachers Should Have This Experience ..............73

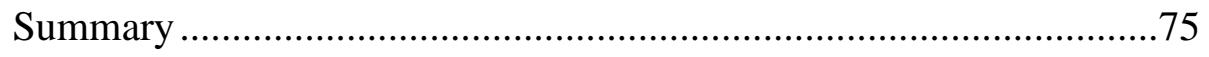

Research Question Three 3: What Do Teachers Perceive to be the

Differences Between Rural School Districts and Larger School

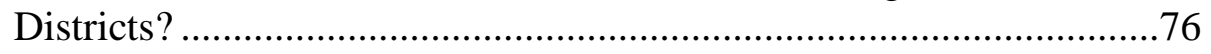

Hiring Practices and Orientation...............................................76

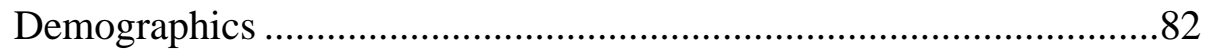

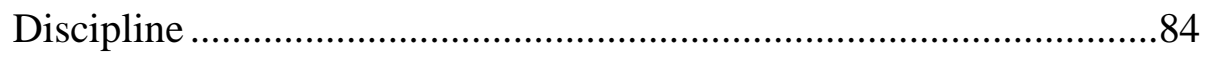

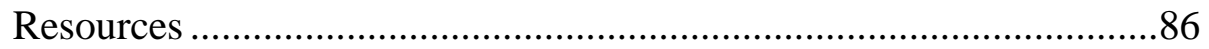




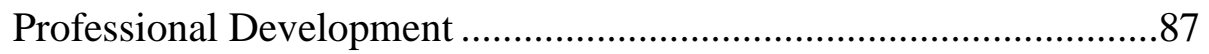

Instructional Practices ................................................................. 90

Workload.............................................................................. 91

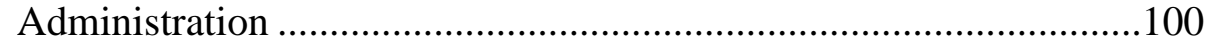

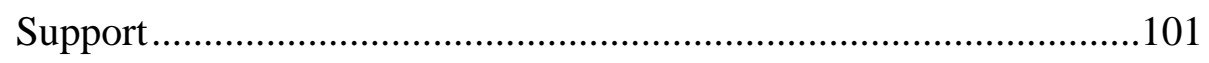

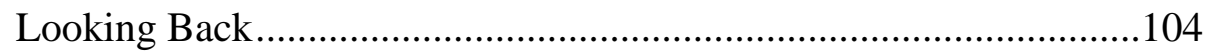

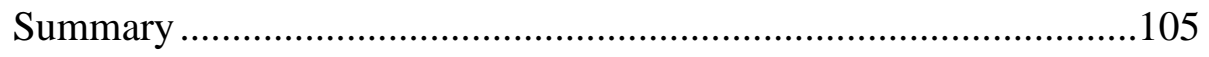

Research Question Four: What Do Teachers Perceive to be the Similarities

Between Rural School Districts and Larger School Districts? ..........105

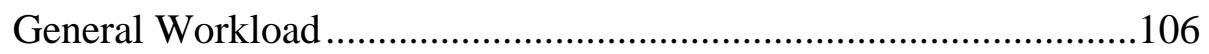

Professional Development .....................................................107

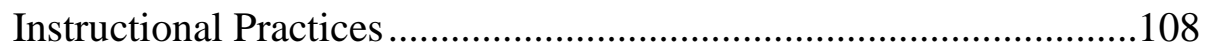

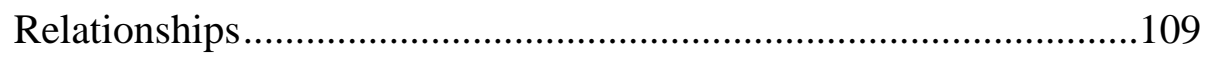

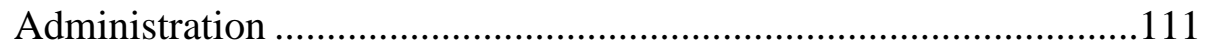

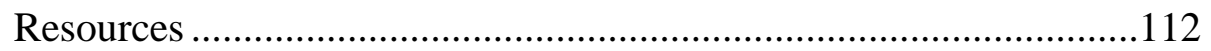

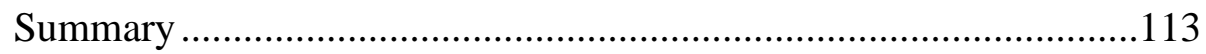

Research Question Five: How Do These Teachers View Their Decision to

Leave a Rural School District for a Larger District? .......................114

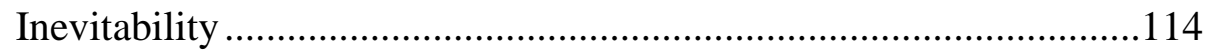

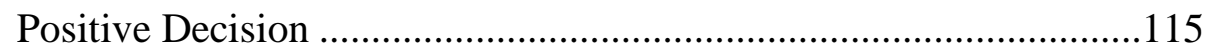

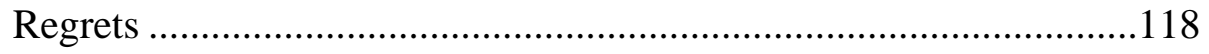

Looking Back .....................................................................119

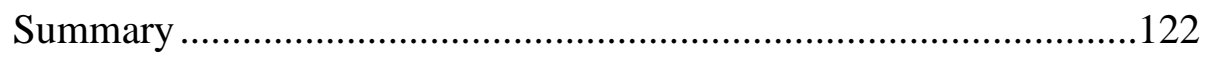


Research Question Six: What Motivation and Hygiene Factors do

Teachers Reference When They Discuss Their Experiences in a Rural

School District?

Discussion

Why Teachers Leave Small, Rural School Districts

Teachers Reflections on Teaching in a Small, Rural School District 131

Similarities and Differences.

Recommendations

Recruitment, Hiring, Orientation, and Induction

Administration 135

Financial Compensation. 136

Workload.

Support

Advocate 138

Significance of the Study 138

Recommendations for Further Research. 140

Summary

2. PRACTITIONER SETTING FOR THE STUDY

Introduction to Practitioner Setting for the Study. 144

History of the Organization 144

History of Education in the United States. 144

History of Education in Missouri 147

Organizational Analysis

Structural Frame

.151 
Human Resource Frame.

Political Frame

Symbolic Frame .155

Leadership Analysis 156

Implications for Research in the Practitioner Setting 158

Summary 160

3. SCHOLARLY REVIEW FOR THE STUDY 162

Introduction .163

History and Characteristics of Rural Schools 164

History of Rural Education in Missouri. 164

Characteristics of Rural Schools 168

Review of the Extant Scholarship ............................................................. 170

Teacher Retention ..................................................................... 170

Student Achievement ...................................................................173

Challenges for Rural Teachers......................................................174

Challenges for Rural Districts......................................................178

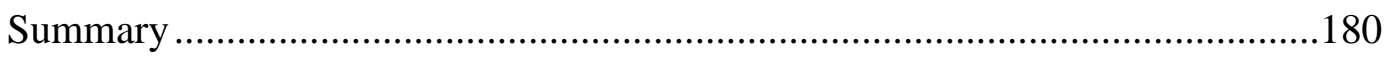

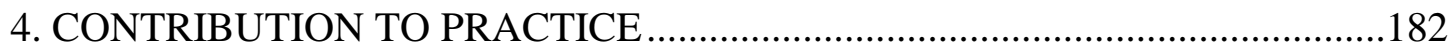

Dissemination of Practitioner Contribution .................................................. 183

National Rural Education Association...............................................183

Missouri Association of Rural Education ...........................................183

Presentation for Dissemination at Conferences ............................................184

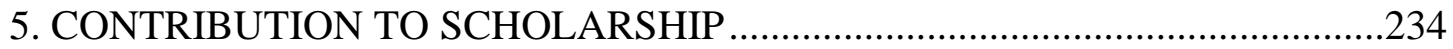


Target Journal

Rationale for this Target ............................................................................23

Journal Article .....................................................................................236

6. SCHOLARLY PRACTITIONER REFLECTION .............................................263

Influence of Dissertation on Researcher's Practice as an Educational Leader.....264

Influence of Dissertation Process on Researcher as a Scholar ..........................267

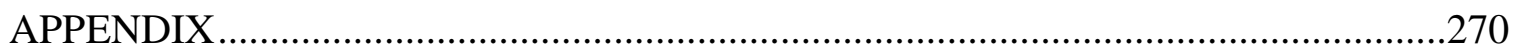

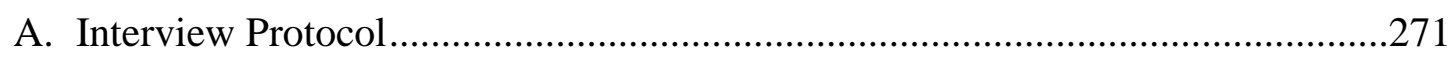

B. Interview Questions Linked to Research Questions .......................................273

C. Individual Interview Consent Form ...........................................................274

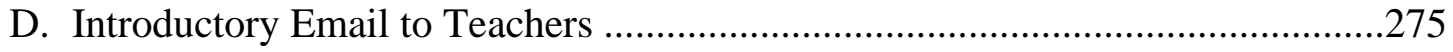

E. Introductory Email to Administrators in the CRPDC Region and CRPDC Employees...................................................................................276

F. Institutional Review Board (IRB) Approval..............................................27

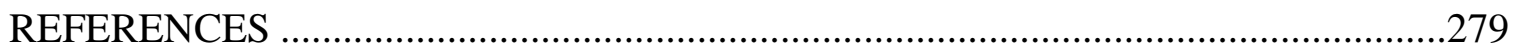

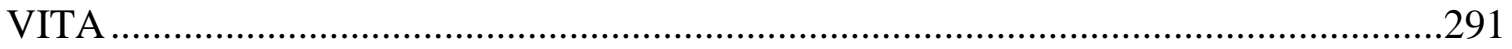




\section{LIST OF TABLES}

Table $\quad$ Page

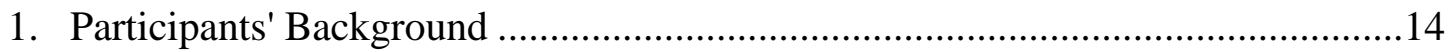

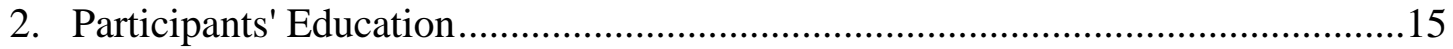

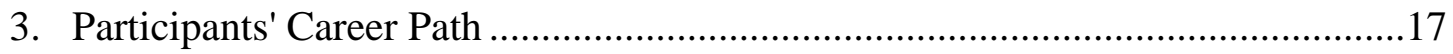

4. Motivation and Hygiene Factors Referenced by Participants.............................123 


\title{
LIST OF ABBREVIATIONS
}

\author{
Alliance for Excellent Education (AEE) \\ Behavior Intervention Support Team (BIST) \\ Central Regional Professional Development Center (CRPDC) \\ Comprehensive School Improvement Plan (CSIP) \\ Every Student Succeeds Act (ESSA) \\ Family Educational Rights and Privacy Act (FERPA) \\ Future Business Leaders of America (FBLA) \\ Local Education Agencies (LEA) \\ Missouri Association of Rural Education (MARE) \\ Missouri Department of Elementary and Secondary Education (DESE) \\ Missouri National Education Association (MNEA) \\ Missouri State Teachers Association (MSTA) \\ National Center for Education Statistics (NCES) \\ National Rural Education Association (NREA) \\ No Child Left Behind Act (NCLB) \\ Parent Teacher Organization (PTO) \\ Positive Behavioral Interventions and Supports (PBIS) \\ Professional Development (PD) \\ University of Central Missouri (UCM)
}




\begin{abstract}
Teacher retention in rural schools continues to be an area of concern. This qualitative study examines why teachers migrate from small, rural school districts to teach in larger districts by interviewing teachers who have already made the move and who have taught in both environments. It also shares the perceptions of teachers as they reflect on their experience in the small district as well as how they now feel about their decision to leave the small rural district. Findings indicate that teachers look back fondly at their time in small rural schools and, while they do not regret their decision to leave, they do think more teachers should have that experience. Teachers discussed the similarities and differences of the district sizes and gave their personal reasons for leaving. Findings reveal teachers primarily leave small rural districts for financial concerns and enjoy a smaller workload at the secondary level in the larger districts. Workload at the elementary level seemed to be similar. Recommendations for small rural school district leaders are presented.
\end{abstract}




\section{SECTION ONE}

INTRODUCTION TO THE DISSERTATION-IN-PRACTICE 


\section{Background of the Study}

Education continues to be a much-discussed topic in the news. With the confirmation of Betsy DeVos as the United States Secretary of Education in 2017, the public has been promised, " 'the president believes strongly that our nation's success depends on education of our students ... [DeVos] will ensure that every student has

access to a good school..."' (Spangler, 2017, par. 3). Now, more than ever, research is needed to ensure students have access to a quality education whether they live in an urban, suburban, or rural area.

Parents in the United States have several options for educating their children (Flavin, 2016). The options vary based on where a family lives and include options such as traditional public schools, charter schools, private schools, parochial schools, and virtual schools (Flavin, 2016). Students living in rural areas do not always have the same options as a student living in a more populated area. However, their education is still a priority as evidenced by DeVos' statements.

Presently, research indicates teachers in rural schools face different challenges than in suburban or urban schools (Beesley, Atwill, Blair, \& Barley, 2010; Monk, 2007). Consequently, the research on teacher retention conducted using participants in suburban or urban schools cannot be generalized to fit the rural context (Burton et al., 2013). For example, teachers in rural schools face isolation when compared to those in larger schools, and this isolation is often geographic as well as professional (Burton et al., 2013; Fishman, 2009; Monk, 2007). At the same time, the workload in rural schools can be difficult to manage (Monk, 2007). A secondary teacher will find having more than four 
preps daily is typical in a rural school, and it is not uncommon to have added to this extra duties including lunch, committee work, and other meetings (Barley, 2009).

\section{Statement of the Problem}

\section{Problem of Practice}

Of the 3.4 million public school teachers in the United States, each year approximately 12 percent move to a new position or leave teaching altogether (Alliance for Excellent Education, 2008; Alliance for Excellent Education, 2014). It is estimated that annually, one million teachers begin teaching careers, move out of the profession, or migrate to a new school or position (Alliance for Excellent Education, 2014). Unfortunately, the research emphasis for teacher retention and turnover has been placed on teachers leaving the profession rather than on teachers migrating from one school or district to another (Ingersoll, 2001). Those who move to a new district or position are often seeking better working conditions which may be found in districts considered to be wealthy and high-performing (Alliance for Excellent Education, 2008). It is estimated that "more than one million teachers, including new hires, transition into, between, or out of schools annually" (Alliance for Excellent Education, 2014, p. 2). The impact of this teacher attrition and migration has a significant impact on student achievement and has serious financial implications for school districts (Alliance for Excellent Education, 2014; Ingersoll \& Smith, 2003).

When discussing rural teacher retention, the research specific to teacher recruitment and retention in rural districts is limited (Beesley et al., 2010; Ulferts, 2016). The literature states teacher shortages are a problem for rural districts, and vacancies in rural districts happen at a higher rate (Monk, 2007; Ulferts, 2016). In fact, teacher 
vacancies in rural districts are "4\% higher than city, suburban or urban" (Barley, 2009, p. 10), and districts with less than 300 students have the highest turnover rate (Ingersoll, 2001). These teacher vacancies "may negatively impact a small or rural school more than a larger school” (Beesley, Atwill, Blair, \& Barley, 2010, p. 1). As it is difficult for districts to find teachers to fill vacancies, rural districts may hire teachers who are less than qualified for the content or grade (Beesley et al., 2010; Berry et al., 2011; Monk, 2007). This practice of assigning courses to less than qualified teachers can create a selfperpetuating cycle leading to further attrition (Berry et al., 2011).

\section{Existing Gap in the Literature}

In the United States, during the 2008-2009 school year, approximately $20 \%$ of students attended a rural school (Strange, Johnson, Showalter, \& Klein, 2012). However, the number of journals specific to rural education number just three: Journal of Research in Rural Education, The Rural Educator, and Rural Special Education Quarterly. Since the 1970s, over half of the articles included in a narrative analysis of qualitative research conducted specifically on rural teachers were published in these three journals, with just nine being found in general education journals (Burton, Brown, \& Johnson, 2013). Burton, Brown, and Johnson (2013) contended the lack of research focused on rural teachers in general education journals is of concern, leaving "many education researchers... unaware of issues related to rural education and research in this field" (p. 8). Hardre (2008) reported as little as six percent of the empirical research in the field of education focuses on rural education.

A clear example of the considerable lack of empirical research specific to rural education is evidenced when reviewing the literature on teacher retention. In general 
education journals, teacher retention is a common discussion. A quick search in Education Research Complete using the term teacher retention returns over 4,000 items. When that search is narrowed to articles in peer reviewed journals, there are still nearly 3,000 items returned. However, narrowing the search to return items that specifically discuss teacher retention in rural school districts within the United States of America significantly drops the number of items returned to less than 100 . These studies specific to rural teacher retention often discuss components related to teacher satisfaction. However, it is unclear if the challenges for teacher retention in rural districts are similar to the challenges in suburban and urban districts. Granted, this is a simple search limited to one database, but the results of a preliminary review of the literature seem to indicate this is the case across this field of study.

More research specific to rural teachers and schools is needed. As stated above, data in this area are limited not only due to a small number of journals specific to rural education, but also as articles specific to rural schools in general education journals appear infrequently (Burton et al., 2013; Hardre, 2008). Recently, Ulferts (2016) investigated why teachers stay in the smallest rural districts in Illinois. While this study provided current data, Ulferts did not find out why teachers originally chose to work in rural districts and then leave the district. Admittedly, both quantitative and qualitative research has been conducted targeting the challenges of teaching in rural schools as well as teacher induction and retention. Research cited in the literature review for this study regarding rural teacher retention often discuss components related to teacher satisfaction. However, there is a lack of evidence and discussion as to why teachers choose to teach in a rural school only later to decide to leave that position to teach in a larger school district. 
It is unclear if the challenges regarding teacher retention in rural districts are similar to the challenges in suburban and urban districts. Even with Ulferts' (2016) recent study, research specific to rural school teacher retention and recruitment is quite limited.

\section{Purpose of the Study}

The purpose of this study was to gain an understanding of why teachers leave small, rural schools to teach in larger school districts. By interviewing teachers who have experienced working in a rural district and who then chose to continue their teaching career in a larger school district, the researcher hoped to change the conversation from being just about the challenges and benefits to teaching in a rural district to one that looks at perspectives of those who have worked in both environments (Colquitt \& George, 2011). Ideally, the researcher thought an understanding of why teachers migrate to a larger district and their subsequent feelings about their choice would give insight to small, rural district administrators. In turn, rural districts may be able to adjust their hiring practices to better recruit teachers who are likely to remain in a small, rural district. Additionally, understanding why teachers are leaving rural districts may also allow rural districts to examine their current working conditions, employment policies, and climate to retain teachers currently employed.

Generalizable, quantitative data are not sufficient in this case to truly understand the problem of retaining rural teachers. Information beyond what can be gathered in a quantitative analysis is required to understand the perceptions of these teachers.

Considering $20 \%$ of students across the nation attend rural schools (Strange et al., 2012), research in this area was needed to assist school leaders in the examination of their 
current practices in the areas of recruitment and retention and make adjustments as needed.

\section{Research Questions}

The research questions guiding this study are:

1. Why do teachers leave rural school districts to teach in larger school districts?

2. How do these teachers view their experience teaching in a rural school district?

3. What do teachers perceive to be the differences between rural school districts and larger school districts?

4. What do teachers perceive to be the similarities between rural school districts and larger school districts?

5. How do these teachers view their decision to leave a rural school district for a larger school district?

6. What motivation and hygiene factors do teachers reference when they discuss their experience in a rural school district?

\section{Theoretical Framework}

Based on the literature, it could be stated that teachers leave rural districts because they are not satisfied with their current position (Huysman, 2008). As such, job satisfaction may be the key to why teachers leave rural districts to teach in larger districts. Herzberg, Mausner, and Snyderman (1959) sought to determine "whether the worker's attitude toward his job makes any difference in the way he works on in his willingness to stick with it" (p. 7). They hypothesized job satisfaction is not on a simple continuum but is instead a two-factor theory, in contrast to Maslow's hierarchy of needs (Maslow, 
1943). While both theorists agree individuals seek happiness and self-actualization, Herzberg (1966) theorized "man has two sets of needs: his need as an animal to avoid pain and his need as a human to grow psychologically" (p.71). Maslow's pyramid, in contrast, requires all other needs to be met first (Maslow, 1943).

When developing their study, Herzberg, Mausner, and Snyderman (1959) based their hypothesis on the idea there are factors relating to job satisfaction that are considered satisfiers and other factors that are considered to be dissatisfiers. From their perspective, an individual could be both satisfied and dissatisfied or not dissatisfied and not satisfied at the same time. Other combinations of the factors are also described, creating a more complex lens through which to view job satisfaction. In his two-factor motivation-hygiene theory, Herzberg (1966) found "five factors stand out as strong determiners of job satisfaction - achievement, recognition, work itself, responsibility and advancement - the last three being of greater importance for lasting change of attitude" (p. 72-73). These more intrinsic factors relating to job satisfaction are also referred to as motivators. On the other side, Herzberg (1966) referred to hygiene issues or factors that are more extrinsic and causes of dissatisfaction, which include "company policy and administration, supervision, salary, interpersonal relations, and working conditions" ( $\mathrm{p}$. 72).

At first glance, it may be difficult to connect the terms motivator and hygiene to the factors of satisfaction and dissatisfaction; however, Herzberg, Mausner, and Snyderman (1959) were purposeful in the use of these words as descriptors. Motivators are defined as "the factors that lead to positive job attitudes do so because they satisfy the individual's need for self-actualization in his work" (Herzberg et al., 1959, p. 114). 
Hygiene is used to refer to factors which are connected to the context of doing the job. The rationale behind this is linked to hygiene in the medical field (Herzberg et al., 1959; Herzberg, 1966). "Hygiene operates to remove health hazards from the environment of man. It is not a curative; it is, rather, a preventative" (Herzberg et al., 1959, p.113). Hygiene factors, when removed as concerns, allow an individual to not be dissatisfied with the work conditions (Herzberg et al., 1959; Herzberg, 1966). “...when there are deleterious factors in the context of the job, they serve to bring about poor job attitudes. Improvement in these factors of hygiene will serve to remove the impediments to positive job attitudes" (Herzberg et al., 1959, p. 113).

Much of the work done by teachers, no matter where they work, is similar when one considers they instruct students with the goal of growth and achievement. According to Herzberg et al. (1959), individuals need to like their work for them to continue the work. This factor, along with recognition and achievement, is long-lasting when it comes to job satisfaction. This may be why teachers in rural areas talk about what they like about their teaching jobs (Burton \& Johnson, 2010). Conversely, job dissatisfaction, in regard to items tied to the working conditions, leadership, and salary, are included in the number of items stated as challenges for rural teachers.

Herzberg et al. (1959) determined "the factors...that made people happy with their jobs turned out to be different from the factors that made people unhappy with their jobs" (p. 111). Unhappy feelings about the job were connected to the working conditions, whereas happy feelings are connected to the work itself. For example, teachers may love what they do, but may not be happy in their current position, school, or community. An employee who is not unhappy would be considered neutral as it would not make them 
either satisfied or dissatisfied. Interestingly, when the hygiene factors fall to an unacceptable level, "job dissatisfaction ensues" (p. 113).

According to the researchers, motivators are "factors that lead to positive job attitudes...because they satisfy the individual's need for self-actualization in his work." (Herzberg et al., 1959, p. 114). The work individuals perform in their job or career is a large part of their lives.

Man tends to actualize himself in every area of his life, and his job is one of the most important areas. The conditions that surround the doing of the job cannot give him this basic satisfaction; they do not have this potentiality. It is only from the performance of a task that the individual can get the rewards that will reinforce his aspirations (Herzberg et al., 1959, p. 114).

Herzberg (1966) expanded the analysis of his theory and suggested "the hygiene or maintenance events led to job dissatisfaction because of a need to avoid unpleasantness; the motivator events led to job satisfaction because of a need for growth of self-actualization" (p. 75) resulting in the two factor theory. "A 'hygienic' environment prevents discontent with a job, but such an environment cannot lead the individual beyond a minimal adjustment consisting of the absence of dissatisfaction. A positive 'happiness' seems to require some attainment of psychological growth" (Herzberg, 1966, p. 78) leading this researcher to consider the opposite to be true for teachers in rural schools.

There are critics of Herzberg's motivation-hygiene theory who argue the idea of the motivators being linked only to job satisfaction and the hygiene factors being linked only to job dissatisfaction is not supported in empirical research (Gruneberg, 1976). 
Albeit, Herzberg's two factor theory has still been used as a lens for research in different disciplines. Maidani (1991) conducted a quantitative study to determine what differences in aspects of job satisfaction were evident between public and private sector employees. Interestingly, public sector employees were higher on the side of extrinsic or hygiene issues than private sector employees, while both private and public sector employees value intrinsic or motivators. As teachers in rural school districts work in the public sector unless employed by a private school, Herzberg's two factor theory is an appropriate lens for research regarding teacher retention. This dissertation in practice investigated the question of why teachers who have taught in rural school districts remain in the teaching profession yet leave a rural district for a larger district. It used the basic principles behind the motivation-hygiene theory to frame the study and pursue answers to the research questions.

\section{Design of the Study}

\section{Setting}

The setting for this study included rural school districts in Missouri. The state of Missouri is divided into 9 Regional Professional Development Regions that are similarly populated (“Central Regional Professional Development Center," n.d.). Within the entire state of Missouri, there are 332 school districts that meet the definition of small, rural districts among the 558 school districts within the state. There is a primary focus on the Central Regional Professional Development Center (CRPDC) region of Missouri, which includes 77 school districts, of which 56 meet the researcher's definition of small rural school district, and nine meet the researcher's definition of larger school district. 
However, participants were not excluded if they have taught in a small, rural district outside of this region but still in the state of Missouri.

Small rural school districts are defined as a public school district with total kindergarten through twelfth grade (K-12) student enrollment of 700 or fewer students. Larger school districts will be defined as public school districts with total kindergarten through twelfth grade (K-12) student enrollment of at least 2,000 students in the same school year. Enrollment data was based on publicly available data on the Missouri Department of Elementary and Secondary Education (DESE) website for fiscal year 2018 school year (DESE, 2019b).

\section{Participants}

Seventeen participants were selected for interviews using a snowball approach as a purposeful sampling method (Hatch, 2002; Merriam \& Tisdell, 2016). This means that participants were asked to suggest others they think may be interested and meet the criteria for the study (Hatch, 2002; Merriam \& Tisdell, 2016). The actual number of participants was determined based on the researcher's determination that data saturation had been reached (Merriam \& Tisdell, 2016; Seidman, 2013). Primary participants were contacted based on recommendations from employees of the CRPDC, principals in the CRPDC region, and community members living in the region, as these individuals are often aware of which teachers had moved from rural to larger districts. Participants were then asked to recommend other teachers they thought would fit the criteria for this study. Preliminary questioning via phone, email, or in person was conducted to ensure participants met the study's criteria prior to scheduling an in-depth interview (Seidman, 2013). Prospective participants with whom the researcher had worked at a rural school 
were eligible to participate in the pilot of the study but were not eligible as participants for this study.

Participants, between the 2008-2009 school year and 2018-2019 school year, must have taught a minimum of one full school year in a small, rural school district within the state of Missouri, preferably in the Central Regional Professional Development Center (CRPDC) region. They must have then migrated to a larger school district anywhere in the United States as defined by this study. Teachers who have migrated back to a small, rural school district were also eligible to participate in this study, as were teachers who began teaching in a larger district, migrated to a small, rural district, and then migrated back to a larger district. Participants who moved into administration or moved into administration and then back to teaching were not excluded from the study. Additionally, no exclusions were made for multiple migrations as there is a potential for a variety of teaching experiences with the connecting factor being teaching in a small, rural district and then migrating to a larger district.

Participant backgrounds, education, and career paths are presented in the following tables. This study included six male teachers and 11 female teachers. During their teaching careers, five participants taught only elementary students. Nine participants taught only secondary students comprised of any combination of junior high, middle school, or high school. The final participants have taught at both the elementary and secondary levels.

Presented in Table 1 are the participants' backgrounds, including the size high school they attended based on the parameters for this study. As family was brought up by 
the participants during the interview, their current marital status, as well as if they have children, is also presented.

Table 1

Participants' Background

\begin{tabular}{llll}
\hline Pseudonym & Size High School Attended & Marital Status & Children \\
\hline Albie & Small & Married & Yes \\
Annabelle & Large & Married & No \\
Brandi & Small & Married & Yes \\
Cassie & Large & Married & Yes \\
Cody & Mid-Sized & Married & Yes \\
Daniel & Small & Married & Yes \\
Greg & Small & Married & Yes \\
Hannah & Large & Married & Yes \\
Kelsey & Small & Married & Yes \\
Ken & Small & Married & Yes \\
Leann & Small \& Large & Married & Yes \\
Mac & Large & Married & Yes \\
Mia & Large & Single & No \\
Molly & Large & Married & Yes \\
Sabrina & Large & Married & Yes \\
Vicki & Large & Single & No \\
Whitney & Large & Divorced & Unknown \\
\hline Note: Nal & & &
\end{tabular}

Note: $\mathrm{N}=17$.

Given in Table 2 is a synopsis of the education level of the participants. All participants had a bachelor's degree and all but one either hold a master's degree or are working on a master's degree. Three hold educational specialist degrees, one holds a doctorate, and one is working on their doctorate. 
Table 2

Participants' Education

\begin{tabular}{|c|c|c|c|c|}
\hline Pseudonym & Bachelor's & Master's & Ed Specialist & Doctorate \\
\hline Albie & $\begin{array}{l}\text { B.S.E Sec Ed: } \\
\text { History }\end{array}$ & M.S.E. Athletic Admin & $\mathrm{N} / \mathrm{A}$ & $\mathrm{N} / \mathrm{A}$ \\
\hline Annabelle & B.S.E. Elem Ed & M.S.E. Literacy Ed ${ }^{a}$ & $\mathrm{~N} / \mathrm{A}$ & $\mathrm{N} / \mathrm{A}$ \\
\hline Brandi & $\begin{array}{l}\text { B.S. Actuarial } \\
\text { Science }\end{array}$ & $\begin{array}{l}\text { Master of Arts in } \\
\text { Teaching }\end{array}$ & $\mathrm{N} / \mathrm{A}$ & $\mathrm{N} / \mathrm{A}$ \\
\hline Cassie & B.S.E. Elem Ed & $\begin{array}{l}\text { M.S.E. Curriculum \& } \\
\text { Instruction M.A. ESL }\end{array}$ & $\begin{array}{l}\text { Ed.S. Ed } \\
\text { Leadership }\end{array}$ & $\mathrm{N} / \mathrm{A}$ \\
\hline Cody & $\begin{array}{l}\text { B.S.E Sec Ed: } \\
\text { Math }\end{array}$ & $\mathrm{N} / \mathrm{A}$ & $\mathrm{N} / \mathrm{A}$ & $\mathrm{N} / \mathrm{A}$ \\
\hline Daniel & $\begin{array}{l}\text { B.S.E. Middle } \\
\text { School Ed: } \\
\text { Social Studies }\end{array}$ & $\begin{array}{l}\text { M.A. History \& M.S.E. } \\
\text { Sec Admin }\end{array}$ & N/A & N/A \\
\hline Greg & $\begin{array}{l}\text { B.S.E. Physical } \\
\text { Ed }\end{array}$ & M.S.E. Sec Admin & $\mathrm{N} / \mathrm{A}$ & N/A \\
\hline Hannah & $\begin{array}{l}\text { B.S.E. } \\
\text { Elem/Early } \\
\text { Childhood Ed }\end{array}$ & $\begin{array}{l}\text { M.S.E. Curriculum \& } \\
\text { Instruction }\end{array}$ & $\mathrm{N} / \mathrm{A}$ & $\mathrm{N} / \mathrm{A}$ \\
\hline Kelsey & $\begin{array}{l}\text { B.S.E Sec Ed: } \\
\text { Math }\end{array}$ & $\begin{array}{l}\text { M.S.E. Curriculum \& } \\
\text { Instruction }\end{array}$ & $\begin{array}{l}\text { Ed.S. } \\
\text { Curriculum } \\
\& \\
\text { Instruction }\end{array}$ & $\mathrm{N} / \mathrm{A}$ \\
\hline Ken & $\begin{array}{l}\text { B.S.E. Middle } \\
\text { School Ed: } \\
\text { Science }\end{array}$ & M.S.E. Sec Ed: Science ${ }^{a}$ & $\mathrm{~N} / \mathrm{A}$ & $\mathrm{N} / \mathrm{A}$ \\
\hline Leann & $\begin{array}{l}\text { B.S. Business } \\
\text { Admin }\end{array}$ & $\begin{array}{l}\text { Master of Arts in } \\
\text { Teaching }\end{array}$ & $\mathrm{N} / \mathrm{A}$ & $\mathrm{N} / \mathrm{A}$ \\
\hline Mac & B.M. Music Ed & Master of Music & $\mathrm{N} / \mathrm{A}$ & $\mathrm{N} / \mathrm{A}$ \\
\hline Mia & B.S.E. Elem Ed & M.S.E. Elem Admin & $N / A$ & $\begin{array}{l}\text { EdD Ed } \\
\text { Leadership \& } \\
\text { Policy Ed }{ }^{a}\end{array}$ \\
\hline Molly & $\begin{array}{l}\text { B.S.B.A. } \\
\text { Marketing }\end{array}$ & $\begin{array}{l}\text { Master of Arts in } \\
\text { Teaching }\end{array}$ & $\begin{array}{l}\text { Ed.S. Ed } \\
\text { Leadership }\end{array}$ & $\mathrm{N} / \mathrm{A}$ \\
\hline Sabrina & $\begin{array}{l}\text { B.S.E Sec Ed: } \\
\text { Social Studies }\end{array}$ & M.S.E. Sec Admin & N/A & $\begin{array}{l}\text { EdD Ed } \\
\text { Leadership \& } \\
\text { Policy Analysis }\end{array}$ \\
\hline Vicki & B.S.E. Elem Ed & $\begin{array}{l}\text { M.S.E. Admin and } \\
\text { Leadership }^{a}\end{array}$ & $\mathrm{~N} / \mathrm{A}$ & N/A \\
\hline Whitney & B.S.E. Elem Ed & M.S.E. Ed Admin & $\mathrm{N} / \mathrm{A}$ & N/A \\
\hline
\end{tabular}

Note: ${ }^{\text {a }}$ In progress. 
Presented in Table 3 are the career paths of the participants. The certification areas of the participants are included as well as whether they were a coach, sponsor, or had no extra duties. The total number of years each participant worked in each size district in the state of Missouri, as well as the number of years participants worked in school districts outside of Missouri. Additionally, the number of years participants worked as an administrator is presented. However, administrative service is not disaggregated by district size. 
Table 3

Participants' Career Path

\begin{tabular}{|c|c|c|c|c|c|c|c|}
\hline \multirow[b]{2}{*}{ Pseudonym } & \multirow[b]{2}{*}{$\begin{array}{l}\text { Certification } \\
\text { Areas }\end{array}$} & \multirow[b]{2}{*}{$\begin{array}{l}\text { Extra } \\
\text { Duty }\end{array}$} & \multicolumn{5}{|c|}{ Years } \\
\hline & & & $\begin{array}{l}\text { Small } \\
\text { MO }\end{array}$ & $\begin{array}{l}\text { Medium } \\
\text { MO }\end{array}$ & $\begin{array}{l}\text { Large } \\
\text { MO }\end{array}$ & Admin & $\begin{array}{l}\text { non- } \\
\text { MO }\end{array}$ \\
\hline Albie & $\begin{array}{l}\text { 7-12 Social } \\
\text { Studies }\end{array}$ & Coach & 9 & 6 & 5 & 0 & 0 \\
\hline Annabelle & Elem Ed & Coach & 4 & 0 & 3 & 0 & 0 \\
\hline Brandi & 5-12 Math & Coach & 7 & 1 & 1 & 0 & 0 \\
\hline Cassie & $\begin{array}{l}\text { Elem Ed/Elem } \\
\text { Admin }\end{array}$ & No & 7 & 0 & 5 & 0 & 0 \\
\hline Cody & 5-12 Math & Coach & 9 & 4 & 3 & 0 & 0 \\
\hline Daniel & $\begin{array}{l}\text { 6-12 Social } \\
\text { Studies/ Sec } \\
\text { Admin }\end{array}$ & Coach & 6 & 0 & 2 & 1 & 0 \\
\hline Greg & $\begin{array}{l}\text { K-12 PE/K-12 } \\
\text { Special Ed/Sec } \\
\text { Admin/ Special } \\
\text { Ed Admin }\end{array}$ & Coach & 8 & 0 & 4 & 2 & 0 \\
\hline Hannah & PK-3 & No & 3 & 1.5 & 4 & 0 & 0 \\
\hline Kelsey & 9-12 Math & No & 5 & 0 & 13 & 0 & 2 \\
\hline Ken & $\begin{array}{l}\text { 5-9 Science/HS } \\
\text { Chem/HS } \\
\text { Biology }\end{array}$ & Sponsor & 2 & 0 & 7 & 0 & 0 \\
\hline Leann & 7-12 Business & Coach & 1 & 0 & 1 & 0 & 0 \\
\hline Mac & $\begin{array}{l}\text { K-12 Music/ } \\
\text { Instrumental } \\
\text { Music }\end{array}$ & $\begin{array}{l}\text { Marching } \\
\text { Band }\end{array}$ & 2 & 4 & 7 & 0 & 0 \\
\hline Mia & $\begin{array}{l}\text { Elem Ed/Elem } \\
\text { Admin }\end{array}$ & No & 3 & 0 & 8 & 0 & 0 \\
\hline Molly & 7-12 Business & Sponsor & 3 & 0 & 9 & 0 & 0 \\
\hline Sabrina & $\begin{array}{l}\text { 6-12 Social } \\
\text { Studies/ Sec } \\
\text { Admin }\end{array}$ & Coach & 3 & 0 & 8 & 2 & 0 \\
\hline Vicki & Elem Ed & Coach & 1 & 0 & 1 & 0 & 0 \\
\hline Whitney & Elem Ed & Coach & 7 & 0 & 9 & 0 & 0 \\
\hline
\end{tabular}




\section{Data Collection}

The primary method for data collection was interviews using an IRB approved interview protocol similar to Krueger and Casey's (2015) questioning route. The interview guide was semi-structured, providing the researcher with guiding questions to allow for flexibility and follow up questioning (Hatch, 2002; Merriam \& Tisdell, 2016). No incentives were provided by the researcher to participants for their interviews. All interviews were recorded and transcribed to aid in data analysis.

To ensure the interview questions solicited answers to the research questions, the researcher conducted a pilot study including three interviews with participants who did not meet the criteria for this study. Data collected from this pilot was not included in the study but aided the researcher to refine the interview protocol. Specifically, questions were edited to ensure answers from the interview questions would provide data to answer the research questions. Additionally, interview question 10 was added to ensure enough data to answer research question number five. The final interview protocol was submitted to IRB for review after the pilot was completed.

The actual interviews for this study ranged from approximately thirty minutes to one hour and forty-five minutes in length. They took place at a mutually agreed upon location or were conducted by phone. Observational data were also collected by the researcher during the interview to add to the data pool. These observations did not follow a structured observation protocol but were unstructured and allowed the researcher to record impressions and subtle factors which helped enrich understanding of the data leading to answers to the research questions (Merriam \& Tisdell, 2016). These observations of phone interviews consisted of the researcher's auditory field notes. They 
included things such as voice inflection, tone, speech rate, and the researcher's perception of emotion of the participants. However, when conducting face to face interviews, observations also included notes about the participants' body language. Data collection through interviews and observations during interviews continued to the point of saturation (Creswell, 2014; Hatch, 2002; Merriam \& Tisdell, 2016). This is the idea that no new information or insights will come from continued interviews (Creswell, 2014; Merriam \& Tisdell, 2016). The true test of when data collection through interviews and observations will stop was when the researcher concluded the research questions had been answered (Hatch, 2002).

Privacy of the participants was protected as much as possible (Creswell, 2014). Data collected were de-identified and all transcripts were coded. Identifiable data, including the participant's name, school districts, as well as the code key, were stored separately from the transcripts and observation notes.

Artifacts, when available, such as the school website, news articles, and other publicly available information, were also gathered regarding both the small, rural districts and the larger school districts at which the participants worked (Merriam \& Tisdell, 2016). These data were collected both prior to and after the interviews to add a layer of context and clarification to the participants' stories.

\section{Data Analysis}

Data analysis began soon after data collection started and continued simultaneous to data collection (Merriam \& Tisdell, 2016; Seidman, 2013). The researcher's thoughts, reflections, and observations regarding the interviews were recorded soon after each interview was concluded and the process of analyzing what was shared by participants 
began. Seidman (2013) discussed the difficulty in separating the analysis from the data collection. It was inconceivable that the researcher not begin the mental process of looking for themes as soon as data were available.

As more interviews were completed, and more data were collected, the researcher utilized a process of coding to find themes and patterns in the data (Hatch, 2002). The researcher used open coding to make initial notes and designate potential segments of interest (Merriam \& Tisdell, 2016). These were notated using words, ideas, or themes and were not limited to a specific set of codes. Even though this open coding process was not limited to specific codes, the researcher kept a list of codes used during this process to aid in the next stage of axial coding. During the axial coding process, the researcher narrowed down the code set and combined the codes from the open coding process into categories all while searching for the patterns and themes emerging from the data (Merriam \& Tisdell, 2016). While looking for these patterns, the lens of the study, hygiene-motivation theory, was used to create categories in which to present the findings (Merriam \& Tisdell, 2016). This cycle supported the researcher's plan to revisit the available data multiple times. The coding process continued as more transcripts were available to identify common themes in the data and, during this time, the codes were refined (Merriam \& Tisdell, 2016). Key phrases, terms, and ideas were used to determine both the codes as well as any patterns that emerged from the data.

As the data analysis occurred simultaneously to data collection, the researcher was able to determine when saturation was reached and when enough data were available to satisfactorily answer the research questions. At this point, the process of data analysis continued with the researcher analyzing the data, searching for both examples of the 
emerging themes as well as non-examples or contradictions (Hatch, 2002). It was important for the themes to be supported by the data. Merriam and Tisdell (2016) used the example of constructing a forest (axial coding) from the trees (open coding) and then ensuring the trees belong in the forest.

Findings from this study have been organized not by themes, but as answers to the research questions and are presented using thick, rich description (Creswell, 2014; Merriam \& Tisdell, 2016). Additionally, the researcher has been transparent regarding her role in rural schools and used both self-reflection and critical conversations with advisors to ensure her biases have not influenced the findings, conclusions, or implications of the study (Creswell, 2014; Merriam \& Tisdell, 2016).

\section{Limitations, Assumptions, and Design Controls}

\section{Limitations}

Limitations of this study included the fact participants were limited to have taught in small, public, rural schools in Missouri, preferably one region of Missouri.

Additionally, as this is a qualitative study, the findings are not generalizable and cannot be interpreted as the perspective of all teachers in the state of Missouri or the United States who have previously taught in a rural district before moving to teach in a larger district (Creswell, 2014; Merriam \& Tisdell, 2016). Instead, the data collected are the perceptions of a small group of teachers in Missouri whose perspectives add to the discussion of teacher retention in rural school districts. This study is also limited by the fact all participants had previously chosen to leave teaching positions in small, rural school districts. There was no participation of teachers who had chosen to stay in a small, 
rural school district, and there was no participation of teachers who taught in schools other than public school districts.

Due to the study design including the collection of both interview and observational data, limitations for this study also include the bias of the researcher. The researcher is open about currently working as an administrator in a small, rural school in the CRPDC region while her children attend school in a larger school district. The researcher is aware of this bias and has been careful to reduce any impact this had on the data collection and analysis process.

In regard to the data collected, the interviews recorded the perspectives of individuals rather than objective data. Without getting multiple perspectives such as the teacher, administrator, and peers regarding the same teacher migrating from one school district to another, there may be missing pieces to the story (Creswell, 2014). Further, artifacts gathered and reviewed, such as websites, only revealed what was available to the public rather than internal information that may be revealed during interviews from the teacher's perspective.

\section{Assumptions}

Assumptions for this study included the researcher trusting participants gave honest answers from their perspective. In regard to artifacts, the researcher assumed publicly available documents and information were accurate and were not altered for this study. Finally, the researcher identified herself to participants as an administrator who currently works in a rural school fitting the parameters of this study while her own children attend a school fitting the parameters for a larger school. 


\section{Design Controls}

Design control, such as fact checking and triangulation, were put in place to ensure the data collected were both valid and reliable. Participants were contacted for respondent validation to ensure there is no misinterpretation of their responses. Their feedback was reviewed, and adjustments were made to ensure an accurate representation of their perceptions is presented in the answers to the research questions. To ensure the research questions could be fully answered, the researcher continued to locate and interview participants to the point of saturation or when the interviews no longer provided new information (Creswell, 2014; Hatch, 2002; Merriam \& Tisdell, 2016). Not only did this provide the answers to the research questions, but continuing to interview participants until saturation was reached ensured the trustworthiness of the study (Merriam \& Tisdell, 2016). Contradictions in the data were not avoided but helped ensure the data truly answered the research questions (Hatch, 2002; Merriam \& Tisdell, 2016). The researcher also engaged in maximum variation as described by Merriam and Tisdell (2016) to ensure participants in the study were of a diverse group as much as possible while still meeting the eligibility criteria.

\section{Definitions of Key Terms}

For the purposes of this study, the following words and terms were used with the following definitions.

Small rural school district will be defined as a public school district with total kindergarten through twelfth grade (K-12) student enrollment of fewer than 700 students. Enrollment data for the 2018 fiscal year will be utilized from publicly available data published on the Missouri Department of Elementary and Secondary Education's (DESE) website. 
Larger school district will be defined as a public school district with total kindergarten through twelfth grade (K-12) student enrollment of at least 2,000 students in fiscal year 2018. Enrollment data for the 2018 fiscal year will be utilized from publicly available data published on the Missouri Department of Elementary and Secondary Education's (DESE) website.

Teacher will be defined as a full-time classroom teacher or a certified teacher in the classroom at least part of the day and fulfilling other duties within the school part of the day.

$R P D C$ is the acronym for Regional Professional Development Center. There are currently 9 RPDCs in Missouri, and the one specifically referenced by this study is the Central RPDC.

CSIP is the acronym for Comprehensive School Improvement Plan and is a five-year plan laying out strategies for improvement for a school. 


\section{Research Questions Answered}

\section{Research Question One: Why Do Teachers Leave Rural School Districts to Teach in Larger School Districts?}

Teachers participating in this study reported several reasons for their choice to migrate to a larger district. For some, the move was made primarily for financial reasons, while others discussed the workload as a precipitating factor. Many participants talked about their family and doing what was in the best interest for their interpersonal relationships. Administration, as well as perceived support, were also topics connected to their decision to migrate to a larger district. Career advancement and opportunities prompted some individuals. For some participants, they knew the move was inevitable due to some other singular and personal specific reason. It should be noted, however, that most participants did not cite just one reason. In many of their situations, the decision was complex and multifaceted.

Money and Finances. Teachers reported leaving rural school districts to teach in larger school districts for an increase in pay. The vast majority of participants had something to say about the difference in salaries as a factor in their migration. It was evident that not only was there an increase in pay, but there were also fewer responsibilities or hours required in the larger district. Even with the often increased cost of living moving to a larger town or city, the pay increase left participants better off financially. Participants also noted that the pay increase for education and experience was not as worthwhile in smaller districts. 
Cassie was able to point directly to money regarding her decision to migrate to a larger district. She discussed how she and her best friend had followed similar paths in their careers. When her friend migrated to the larger district, Cassie reported, she was talking about what a pay raise she had gotten, how easy it is [to work there]. Her curriculum's already made for her, whereas I was having to create my curriculum in a smaller school, and we would have to work at ball games for free. And she's like, "If you came to the larger district, you get paid to watch at ball games or crowd control, accepting money, concession stand, whatever." It was the money that was the biggest positive thing for me. I guess that was really the whole reason that I came [to the larger district].

Whitney spoke about her situation very directly.

I was looking for pay. It was money, just an increase in pay. It was actually going to be less travel time and more money...just absolutely to pay the bills." She divorced soon before making the decision to move to a larger district, "and at the time, I was just thinking about money, and thinking that I needed the money, and I needed that [position].

Albie was also very clear when it came to compensation and not only the difference in his pay between starting his career in a small, rural district to teaching in a larger district 19 years later. However, he clarified the difference in pay just moving an hour down the road to a larger district from one year to the next.

I can still remember how much I made my first year in 2001. My salary was $\$ 24,000$ a year. I got paid $\$ 900$ [each] to be Head Softball Assistant [Coach], Basketball [Coach], and Head Track [Coach]. So, my first year with that $\$ 2,700$ 
coaching, I made just over \$26,000 a year. Now, 18-19 years later, with a master's and everything, I'm making just a tick under $\$ 70,000$ a year. When I left the small district, I got a $\$ 20,000$ pay raise, and I'm working way less, working way closer to home. I've got way fewer responsibilities 'cause my preps are fewer, and I'm not having to coach year round like I was at other places to try to supplement that income. So, I got all this extra time, all this extra stuff with my family, and I got a lot more money. That's just the state it is now I guess with the big school versus the small schools...I never would have dreamed, starting out or whatever, at any point in my career that I would make this much teaching. Financially, it's unreal.

Albie is not the only participant that discussed the financial impact of moving to a larger school district. Daniel also discussed the financial struggles teaching in a small, rural district at the beginning of his career. "My first teaching contract was twentysomething thousand a year. So that ended up becoming, after retirement, like $\$ 600$ a month, which is hard to live off. That was a first-year contract." Daniel coached three sports that year and went on to describe the process for stipend pay.

How they did it is that you got it in June. You got those in a lump sum. So eventually, I was like, 'Look, I can’t... This is a struggle for me. They made a rule you got that stipend after the season. They wouldn't build it in, which was tough because it would have been nice to have that every month in my paycheck. Instead, it was a lump sum, and it got taxed like crazy, and I got retirement out like crazy. So it just, it didn't really add up. 
Cody also coached quite a bit in addition to his time in the classroom. As he spoke about the difference in compensation compared to the duties, he said at the larger district,

I was a freshman girls' basketball coach for the three years I was there, that's what I did. And that was the only extra duty I had. The only other thing is, I had to supervise prom every year for half of prom, like an hour and a half, and that was it. So extra duty-wise, there wasn't a lot, which was kind of nice, and I definitely made more...freshman girls' basketball, I think, paid more than my varsity head coaching in the small district. Teaching was a lot more [money], yes. Needless to say, the place that we lived in, the rent was a lot more than what our mortgage was on the house [in the small district]. Plus, I didn't sell the house until we [moved again], so I was paying rent in the city and a mortgage in the rural district... and I definitely made more.

Daniel and Greg both moved from teaching in a small district to administrative positions. When choosing to leave administration and go back to the classroom, both had to consider the financial implications for their families. Greg spent two years as a rural school administrator prior to deciding to go back to the classroom. He said, "Financially, I had to find something close to what I was making and I knew the only way that would happen was going to a bigger district." Daniel spent one year as an administrator before determining that was not the best fit for his family. He took a position in a larger school district and was given the responsibilities of department chair. In comparison to his compensation package in the rural district, he said, "My extra duties as Department Chair 
and stuff, that's all built-in, and I started probably almost $\$ 15,000$ higher. Okay, I contend I also have years in, but still."

Annabelle and her husband made the decision they needed to earn more which precipitated Annabelle moving to a larger district. She reported,

I think I made $\$ 11,000$ more when I went to the larger district. I think I left the smaller district making like 30 grand and then I went to $\$ 41,000$. But, paycheck wise it was not much more. It was maybe $\$ 400$ or $\$ 500$ more a paycheck each month. The taxes are definitely higher, so I have more taken out on taxes. Retirement always kills me because it's 14 point something percent, but that's the same.

Annabelle continued to talk about her expenses and how they increased once she and her husband moved out on their own closer to where they worked. She shared, I own my house now and my bills are so much higher. When I lived in the small district, I rented a three bedroom, two bathroom house with a two car garage for $\$ 600$ a month. And I was like, oh my gosh! My apartment was like \$375 [before renting the house] and so that was super easy. My husband made $\$ 18,000$ a year at that time. And my brother [who lived with Annabelle and her husband], my mom just paid me for his portion. But I was like, this is so nice! Now my mortgage is $\$ 1,200$ and our car payments are $\$ 1,100$ together. So, if I had stayed in the small district, I wouldn't have been able to afford my new car. So I get that I get paid more, my car payments are like $\$ 700$ a month. And I'm like, I can do that because I make more! But now I'm still living paycheck to paycheck because expenses are more. I think I can do more things, and so I just equalized it. 
Kelsey added to the idea that with an increase in pay, there was an increase in expenses. Her situation was a bit different in that she made a move from a larger school district and took a $\$ 14,000$ pay cut to move closer to family so grandparents could help care for her children while she and her husband worked. They made the choice to move back to the larger school district several years later and made these comments about the financial implications of that move. "When I moved back, I can't say this for sure. I'm trying to remember. I want to say it was close to $\$ 20,000$ when we moved back." When asked about how it felt first to take the pay cut, she said,

well, first of all, we were probably paying about $\$ 7,000$ in childcare. So, when we took that out of it [for her parents to care for the kids], you're not looking at as huge of a pay cut. We were about to add a second child to it. It's not as much for the second one, but we would have been taking another amount out of that. There was that, yes, but because my husband was working up here, I moved in with my mom and dad for probably seven months until we got a place. So it didn't hit as hard. We gradually moved into it. I think the hit didn't take as hard.

She then discussed the move back to the larger district after five years.

I'll be honest, when we moved up here, it was a larger house payment. Did we see an increase? Yes. Did it make things, I guess, more comfortable? Yes. Was it as big as you'd necessarily expect? I don't know, because they divide it up and take taxes out. It doesn't feel as big as you think it's going to. I know it's huge. I don't want to act like it wasn't, but when you start dividing it up, and then taking taxes out, and then honestly when we start looking at insurance, that's a whole other ballgame because, in the small district, my kids could be on my insurance. If you 
had children, children were one thing, and family was a different thing. So the children could be with me together. In the larger district, if you put two children [on insurance], it suddenly goes to family, and it's over $\$ 1,000$ a month. When you start looking at that, that $\$ 20,000$ starts decreasing. Like I said, yes, it has definitely made things more comfortable. I'm not going to act like it doesn't. To a brand new teacher who's having their insurance paid wherever they go, it seems like a huge difference. When you're talking about [a teacher] with a family, there's a lot of other aspects into it, and insurance is a big one.

Leann also was concerned with finances. In her case, knowing that we were having a baby coming, obviously expenses were going to grow. With the time that I was dedicating to school every day, not just teaching, but volleyball, and then FBLA and Yearbook, I didn't know if I could do this as a mom with my husband driving an hour. I'm here by myself all the time. I mean, He leaves at 6:30 [in the morning] and doesn't get home til 6:00 [at night]. So, that's me here by myself all day long. This may not be realistic. Initially I thought about just not teaching, staying home for the year, maybe substitute teaching here and there just because I didn't know what else to do. And then in December, we heard that my husband's district] was going to have a position for Business open. Leann and her husband chose to put all their eggs in one basket and hoped she would get the position for financial reasons. Sabrina made an overall reference to knowing how much different districts in the region pay teachers. She said, "It's an $\$ 8,000$ to $\$ 10,000$ difference just to go to [a larger district down the road]. That's a lot of 
money!" Ken added to the storyline of teachers migrating due to financial considerations when he said, "if I had made enough money, I could've tried [to stay]."

It was not just base pay that came up during the interviews. Long term compensation was also on the mind of the participants. Annabelle and Hannah commented that getting their advanced degrees in the smaller district would not have led to a significant enough jump in salary to justify the cost of the degree program. Annabelle commented her administrator in the small district let her know very bluntly that in the small district there would not be much of a pay raise for earning an advanced degree. Hannah said, “I didn't realize how much more money I'd be making, just in general, once I got my master's. It went up significantly."

Workload. Workload is another reason teachers migrate from small, rural districts to larger districts. Workload was discussed by the participants not only as a reason they chose to leave their small district, but was also discussed at length when participants were asked about the similarities and differences between the two types of districts. In regard to the statements made about workload, when teachers used it as a reason they left a small, rural district, they were clear that the workload was too much in a rural district. Not all participants felt this way, and this will be discussed later in regard to the answers to research questions three and four.

Teachers were very open about the number of preps they had in the small districts. Leann said, "I had 12 preps over the year. Every hour I taught something different." Daniel discussed his hiring process for his first-year teaching. In addition to teaching 7-12 social studies with something different each class period, he said, 
I coached varsity softball for four or five years. I coached junior high basketball for three years. I coached varsity boys' basketball for two years. I was an assistant for the boys and the girls' varsity basketball teams before I took over as head coach for one year for the girls and two years for the boys. Okay, so a lot of coaching. And when I was hired, my principal said, "Hey, so I want you to come here." "But I want you to be the junior high boys' basketball coach and the assistant basketball coach for boys in high school, and you have a choice between assistant baseball or softball. That's when I said, "I'll do softball.” And then that year, they also needed an assistant girls' basketball coach, so that's when I jumped over there. So I did four sports that first year.

Daniel shrugged as he finished that part of his story with, "Yeah, but I was single and didn't know any better." When asked if he would ever want to do that again, his answer was an emphatic "NO! I thought I'd miss coaching more than I do, but I don't. I don't coach anything now."

Mac was a K-12 music teacher in his small, rural district. Concerning the workload he had, he said,

I was the only music teacher for the entire school district. So, I did high school band and middle school band and high school choir and middle school choir and all the elementary music classes. It was just too much. I was not built for elementary music.

Mac talked about having to shift his mindset from high school students to early elementary classes during the passing period. When asked when he knew this was not a good fit for him, he said, 
Probably around January, February [my first year], I decided that the duties that I had there were not my strengths, and so I started looking for places where I would only be responsible for teaching band. Like I said, that was why I got into teaching, was because I enjoyed playing on my instrument. Band was what I grew up in, and that was what I wanted to do, at least at that point.

Overall, participants reported that in secondary settings, the workload is much lighter with fewer course preps, more resources available, and collaboration as a part of a team sharing the load reduces the feeling of isolation. Ken said, "it was a no-brainer. It was a quality of life thing, and so I just had to go." He said his workload was lighter at the larger school. "I got more money, it was closer to home, and I went from six preps to two, and on one of them I was just expected to do what the other lady did." He continued by stating, "I needed to be away from the workload that I had in the small district. I loved the people, but the job was rough."

In addition to the number of course preps, teachers discussed the workload involved when resources such as curriculum were either unavailable or out of date. Molly said, "When I started, I was given no curriculum besides my course title." Leann made similar remarks in more detail.

They had rewritten the curriculum in 2007 there. The teacher that I replaced had been there for 30 years. She started and ended her career there. When she left, she left everything because she was retiring, but her stuff was very outdated. They told me that in the interview, "You're going to have to rebuild your program because she's really kind of let it go because she knew she was going to retire." So, I had to rebuild and update everything. We did not have textbooks, and so 
how I decided to do it was to make PowerPoints and teach by PowerPoint and lecture, and discussion."

Daniel's situation was similar.

When I got there, they didn't really have curriculum there for me. The curriculum binders they have were from the early 2000's and I started doing this in 2012, so I made up a lot as I went because I had to. There weren't a lot of those resources. The PowerPoint notes, the readings, the worksheets; I typed all of those up all the time. So I had to spend a lot of time at school getting those done. And then the grading aspect of it is something that they don't really tell you about as much.

Contrast the above statements to what it was like once they left to go to larger districts. In Sabrina's case,

I suddenly now only have one prep. I had four classes a day with one period as a whole 90 minutes of plan period, oh my gosh, every single day. You had a plan period, which is just amazing. Our teachers have no idea how lucky they are that they have that right, unless they've been in a small school and then they would understand, but it was fabulous.

Participants also reported coaching might be an opportunity, but is not expected in the larger districts. Extra duty is a choice in these situations and not a condition of employment. In the smaller districts, extra duty was not limited to coaching. Hannah, an elementary teacher, said,

We did have to do gate duty for games and stuff. That's something that I don't have to do in the larger district. That was just a couple of nights. The biggest 
inconvenience for me was that I just had to stay there. I lived too far away to go home and come back.

Coaching, however, is one of the extra duties about which participants talked. Albie is very open that most of his moves from school to school were coaching related. His experiences will be discussed through the lens of opportunities. However, not every teacher viewed the amount of coaching required as an opportunity. Sabrina coached Volleyball in her small district but realized this was not what she wanted to do as she started a family.

I was pregnant during VB season, and I knew that being a mother was going to really be a priority for me, so I knew coaching was not going to happen anymore. There was just no way I was going to be able to do that. So I knew I would step away from that. I really hated the idea of having a baby and leaving it and driving 30 minutes away [to work] and all of that. So when a middle school job came open in [the larger district where we lived], I thought, I've never taught MS. But honestly, at that point, I also thought I really don't know that I want to teach middle school, but I do know that I don't want to have to coach anymore. At that point, honestly, in a small school, I think that was going to be the expectation that we really need you to coach, right? And I didn't want to have to do that with the baby. To be honest with you, I didn't get to the point where it came down to it, where I had to say I'm not going to coach, but I want to still teach here, and I don't know what they would have said. But I knew the expectation was that I would be coaching. So then when the position came open [in the larger district], I just applied. 
Leann's situation was similar, but she did not have the same positive relationship with her administration.

So when I found out last September that I was pregnant, and in October, I talked to [my administrator] about the fact that I would still technically be on maternity leave when school started next year and how I really was uncomfortable with coaching. At that point in time, the head coach was retiring, and I was supposed to be stepping into her shoes. That's what I had been training to do for two years. I said, "I just don't think that I can do that. I'm going to have a newborn at home and it's going to be hard enough for me to go back to work as is, let alone being a Head Coach gone six days a week." He basically told me, "I'll give you this year off, I'll try to get the Head Coach to stay for a year, but you're going to have to help her and do some things. You don't necessarily have to go to the games and stuff, but you're going to be required to help in terms of paperwork and things like that. But then after this year, you are going to coach again and your rehire is going to be dependent on you coaching again. I expect you to coach. That's why we hired you to begin with." And that really was a moment where I was like, so you hired me to be a teacher so that I would coach? That's not really... I mean, I coach because I like doing it, but I like teaching. I'm not here to be a coach; I'm here to teach.

When she applied to the larger district, she relayed, I knew that it would just be teaching. The extra duties are not required. It's not like, "Oh we're going to hire you to teach, but also you do this, this, this and this in order for us to hire you." So we knew that the extra duties would disappear and 
then I'd have a lot more support there, for assistance and less prep work, which means less time at school. So I can be home more.

In the elementary setting, the workload is primarily reported two ways. Some say it is easier in the larger districts. Others say it is about the same level of difficulty with prep time being less time consuming and grading taking more time, meaning their workload is just flipped from what they had in the small district. Elementary teachers did not report leaving due to the workload.

Family. As participants spoke about their reasons for migrating from small districts to larger districts, their reasons related to family were very much interconnected with money and workload. Family tied closely back to those other two reasons. When teachers spend less time at work, and their workload is lighter, they can spend more time at home with their families. When they earn more money, have fewer responsibilities and extra duties, they have more money they can spend on family activities and, in turn, more time with their families. Participants are reporting that they cannot meet the work/life balance as well while working in the small districts.

Two participants, Molly and Whitney, got divorced while teaching in the small districts. This impacted their decision to move to a larger district. Whitney was looking at her choices from a monetary perspective. However, Molly stated her divorce was why she moved.

Had that not happened, I was fine teaching there. It was just the small town politics and all that. But there was nothing I didn't like in the small district, and you don't know what's different until you do the other side. 
Leann's choice of a larger district had to do with the fact that in addition to money and workload, her husband worked in that larger district. They discussed moving, but in the end chose to drive together so they can spend time on the drive talking about their day, stopping for dinner as a family, and using that time in the car as family time.

Children were also a significant reason for some of the female participants. Just like Sabrina did not want to leave a baby in childcare and drive 30 minutes to work, Hannah had similar thoughts. She shared,

My biggest reason was my husband and I were about to start a family. We wanted to have kids. Thinking about childcare and how long my kids would be at childcare if I were commuting compared to being five minutes away from school was my biggest [reason for leaving the small district]. It was really starting our family and being close to home with the kids. If they got sick, I can go. You know, I'm closer. That was my main reason. I was really happy there [in the small district], but then, it was just like, if I work in the larger district [where she lived], it'll be less gas money. I'll be closer for the kids. It was just a lot of different factors, I mean, the biggest one being close to childcare, because I had to be at work at, I think 7:30 is when I started, so I would leave home before 7:00. If I had to take my children to daycare, that would be 6:30. I'd have to be getting them up at 6:00. It was like, it was more of a time with the kids thing.

The male participants were also family-oriented as they voiced why they decided to migrate to a larger district. Mac made a choice to move closer to where his girlfriend, and now wife, was living and working. That decision ended up pulling him out of the classroom and into an aide position for two years, followed by him leaving teaching for 
two years to work in a job that allowed him to earn more money. Eventually, he was able to move back into a teaching position, but this time in special education rather than music. Greg's choices had to do with the fact that he had left a teaching position in a small district to pursue an administration job in the small district from which he had graduated. He stated,

That was not what I expected it to be. [I] ran into the situation that the kids that were in school were kids of people that I went to school with, and when I had to say no, they were remembering me [from high school]. They would come to me with things like I was their buddy from high school. And when I had to say no [again], then I was the bad guy. So, it got to the point; I would rather get out of administration than lose acquaintances or friends.

Greg chose to move his family than have problems in the community. Cody's decision revolved around the fact they did not yet have children. When things were not going well for him and his wife in the small district, he said,

So, we didn't have a kid at the time; it's easy. [He and his wife said], "Let's talk about leaving." All right, no problem. So, I start looking around first for jobs. So I applied for all three [jobs that were posted].

Albie also had family on his mind when making career decisions. He had made a career out of moving to coach basketball.

I retired from basketball coaching because my family was starting to turn a little older. One day when we had a late, late, late basketball game at a tournament at a larger district, so I went home and put [my daughter] to bed and said, Honey, I gotta go, I got a basketball game tonight. She was four at the time, and she said, 
"You're always leaving me to go to basketball." I said, nope, not anymore, I'm done ... And that was the motivating factor for me to get out of basketball. I retired from that. It's like, okay, what's next?

Administration and Support. Participants discussed the perceived support from administration as well as other teachers as reasons they made the decision to migrate to a larger district. Poor support sometimes included administration, school boards, coworkers, and community. There were several who spoke highly of the support they had and told the story of how hard it would be to leave a district as they had a positive experience in this area.

As stated above under family, Leann did not have a positive experience with her administrators in the small district. She felt as if she did not get feedback regarding her teaching and that she was there to be a coach first rather than a teacher. This was not in line with what she wanted to do.

Daniel had the opposite experience with his first administrator in his small district. Daniel had such a favorable experience that the problems for him started when the first principal left and a new one came in. He shared,

And so then I started [thinking about leaving] about the time my first principal left. I don't want to say things were bad. They just... It wasn't the same. And so when the first principal left, I kind of started getting the itch to... Maybe I should leave too... And so I jumped on the first administration job that was available. I spent a year there and then moved to the larger district, teaching. I decided I wanted to go back into teaching.

Because his first principal left late in the season, he said, 
So I, I think that they struggled to find some people that could be like the first principal and carry the baton. And so I waited a year after the first principal left, and kind of played it out, and it wasn't as together. We had all these programs in place that had been set up with hand-picked teachers to lead and stuff like that. The new principal that came in just had to maintain it to get started. He didn't maintain it, he didn't really want to keep that going. So for me seeing that, seeing how good the small school was and then seeing where it was going and that's kind of what made me move.

Because of the model Daniel had in his first principal, he said the following about his search for a new position:

I mostly just applied to admin [jobs]. I think that was because I still like the kids a lot, and so if I was going to teach, my plan was to teach these kids [in my small district] because I had good, close relationships with them. But administration, seeing how my first principal ran it, that's what I wanted to do because I knew that I felt like I had the same kind of passion he did. I think he's just a really good decisionmaker, even just a snap decision. It seems to always be the right one. I knew I could have the same passion he did, and so that's why I looked at admin [jobs].

Cody was another teacher who made his choice to leave because of district leadership. He referred to good old country boys in a positive manner when he shared, So the biggest thing was the board. It was a bunch of the good old country boys that were on the board when we got there for the first four or five years. Then their kids graduated, so they got off the board, and then the new ones that got on 
were just different. It seemed like a lot of them had an agenda, and it wasn't quite as comfortable around there as it was before in the small district. I know that happens at every district, ... where board members are getting on with agendas, not necessarily to help the school in general, just something specific that they want to get done. So that started happening, and it didn't make me and my wife very comfortable at times. Well, things started going downhill with the board, like I talked about before, so we started to talk about leaving. We weren't really happy in the small district with what was going on with the school. School board-wise, administration-wise, we weren't happy, really. She wasn't really happy with her principal; I wasn't happy with mine.

Vicki's situation is somewhat tied to administrative support. However, her reasons for leaving have to do primarily with a toxic relationship with her grade level teammate who should have been a support rather than someone who made Vicki's life difficult. Vicki explained it as follows,

I had no intention of switching jobs after the first year. That was not something I ever wanted to do. I wanted to get my feet wet and grow as a teacher there. The partner teacher that I had...was a very, very toxic person. When you're spending your first year with a very toxic person that you can't collaborate with, you can't reason with ... I mean there was nothing I could do. It was just the everyday "I don't want to come to work because of her." We were supposed to plan together, and after observing how she treated her students and what she was doing with her students, I didn't want my kids anywhere near that, so I was just like, "Okay, we don't really have a curriculum anyways, so I'm just going to do our day and go our 
path, and let her do her thing," but we didn't agree. She went to the principal right away. I never got in trouble with that. I mean, the principal and I had a great relationship where I was like, "Look, these are the facts. This is what we're doing in my classroom. We're not ready for this," or, "We don't have time for this. It's not best for my students, so we're not going to follow along with what she's doing right now." He was very supportive of that, but when it came down to it, I went into his office....and said, "Something has to change. I cannot do a second year with this. This is not how I want to be a teacher. I don't want to leave, but for my own sanity, I need to unless we can do something to change things around." Just the way that this person was, no one else wanted to work with her either, so he offered me the kindergarten position that had opened up, but I'm not certified, and I didn't want to be certified in kindergarten. At that point, it was kind of like, "Okay, then if we can't do anything ..." and he said, "Well, we can't promise anything until March. I mean, you can stay or not." He offered to give me a recommendation letter. He offered to do whatever he could to prepare me for it, so he understood where I was coming from. The fact that there weren't any other positions, and nobody else wanted to move with her. It just came down to, "Okay, well, then I need to step away."

Overall, when asked what advice participants would give principals to help them retain teachers, participants talked about administration supporting teachers, listening to them, and building relationships. Sabrina summed it up by saying,

So as far as retaining teachers, it's all about relationships. You've got to give them the best support you can. You've got to support your teachers. Those relationships 
with them are super important. Because you've got to find a reason to make them want to stay.

Opportunity. For several of the participants, opportunities arose that made them leave the district. Mia made the statement,

So I knew that I was working with really good administrators. I was finishing up my master's degree in administration. And I knew that I was working with really good administrators, but I also knew that they weren't the only administrators that I could learn from. And I thought that if eventually administration is the field that I want to go into, that I should really go and gather some different experiences, work with different people. I feel like sometimes the best learning is being in it with them.

Greg's situation was similar. He reported he was recruited by the superintendent from his home town district. Greg said,

So, he knew I had my admin [certificate], and at the end of my first year as coordinator, he called and said that his principal was leaving. And I kicked around applying, and I didn't apply. And then the second year, the very next year, he called again and said that principal was leaving. So, he called the second time and I thought, Okay. Then I need to... I'm going to try it. That's how that all came about. It wasn't that I was disgruntled with anything here. It wasn't anything here. It was just an opportunity to go back to my alma mater.

Kelsey's situation was more thought out than Greg's as she had been thinking and planning for some time. She pursued her education and realized there was no room for advancement in the type of job she wanted in the small district. She explained, 
I started looking because when I got my ed specialist, I started thinking about what else I wanted to do with it. My ed specialist was in curriculum, so I would never be able to be a principal or a superintendent. I hadn't gone those routes. If I got out of teaching, what did I want to do? I probably wanted to get into being... they call them learning coaches now. They were instructional coaches at one point. Getting into a position like that or a curriculum role within a district [would be difficult]. I just knew the small district didn't have something like that. So I started looking. Then a position opened up at a larger district. They were opening up a new project-based learning environment for the larger district. So I ended up interviewing there and accepting a job

When asked if she targeted that program, she said,

No. I was looking around. I was really looking for an instructional coach position. I applied for some and never even got a phone call back, and so I started widening the search. I know with an instructional coach position many times that comes from within just because they know your teaching styles and those kinds of things. So I started looking more for math teaching positions then. I know I went to one interview, and I basically told them like, "I want this to be a stepping stone to what I can do and stuff." I'll be honest. I didn't get a phone call back about that one.

Even though some participants left their small districts for other opportunities in education, not all pursued opportunities within the field. Brandi chose to leave education for a while and shared her experience by saying, 
I actually left teaching for a year. I was doing a direct sales business and was making a lot more money doing that than I was teaching. So I took a break from teaching and then I really hadn't intended necessarily to go back to teaching, but well almost a year out into it, I got a call from the principal at a mid-size district who said they had a halftime math position they wanted me to interview for. So I went and interviewed for that. And then, of course, the half time position turned into a full-time position. So I taught there for a year. That was probably the most stressful experience I've ever had. And so then I was looking to get out, and so I actually took a position with a non-profit organization for two years [before taking a teaching position in a larger district].

Inevitable Migration. In a few situations, no matter how positive the experience was in the small district, the participants said it was inevitable that they would have made the switch to the larger district. Sabrina stated, "It was probably inevitable. I wish I could have spent more years there because I loved it. It was so much fun, but it was probably inevitable really based on my family being in the larger district." Cody was another teacher who said, "Honestly, I would've stayed there if the job had not come open, but I was always wanting to come back to my alma mater eventually." He continued I was not looking for a job and then somebody told me, or I saw it on the internet, I don't remember which one, that there was a job in [my home town] that had come open. I told my wife. I was like, "I'm not looking to leave, but..." She was like, "You always wanted to go back home, so might as well apply." I was like, "Okay." So that was the only place I applied that year. 


\section{Summary}

The reasons teachers leave small, rural districts to teach in larger districts are varied and personal. Depending on their circumstances, the combination of reasons they give have to do with money, workload, and their families. Administration, leadership, and peer support affected their decisions in one of two ways. When it was not positive, it made the participants look for other positions. When the administrative support was positive, other reasons for leaving were given, and participants comment on the positive nature of the support which will be discussed in the answers to the other research questions. Advancement and opportunities were also given as reasons for leaving the small districts and, at times, teachers realized the opportunity, such as an administrative position, was not a good fit. This had them looking for a teaching position that would pay similar to their administration level, resulting in them working in a larger district. Finally, for some individuals, their goal was to work in a particular district. If that is the case, the migration to the larger district will be inevitable no matter how much they like the small district.

\section{Research Question Two: How Do Teachers View Their Experience Teaching in a Small, Rural School District?}

Participants reported positive, negative, and mixed feelings when talking about their experience teaching in a small, rural school district. They reported challenges such as small town politics, resources, and the workload. Community, administrative, and peer support were seen as positives by some teachers and as negatives by others. The same is true of the relationships built with co-workers, parents, and students. Interesting is the fact that even when teachers had a negative experience teaching in a small, rural district, they joined the participants who had a favorable experience in recommending teachers 
take jobs in small schools even if they are unsure it would be a good fit. Some participants even went as far as to say all teachers should have the experience of teaching in a small school.

Challenges. Participants reported challenges in regards to working in a small, rural school district. Some of these challenges were precipitating factors to their decision to leave the district and, when this was the case, participants told their stories in one of three ways. Some participants stopped answering the questions or changed the subject. They made statements letting the researcher know that it was not a topic they wanted to discuss and the interview either came to an end or moved on to a different question. The second way participants handled talking about challenges was to clarify with the researcher about what would get out to the world. They wanted to make sure the answers they gave would not be able to be tied back to them or to the school districts in which they had worked. The final way participants talked about the challenges they had in small, rural districts was to just speak very frankly and directly as to what they perceived happened. In these situations, more than one participant made the statement that they did not care if I shared their name, their districts' names, or spread the word about what had happened even though they were repeatedly reminded that the researcher would deidentify the data so it would not be traced back to any particular individual.

Small Town Politics. Small town politics were a challenge for a few of the participants. Leann talked about the amount of drama in the small district within the community. She mentioned having students show up at her house when they had fights with their parents and how that was a challenge for her to navigate within the community. 
Albie's challenge had to do with power and control within the community and school district. He said,

That's one of the biggest challenges, and also its cliché, but you get the small town Mom and Dad politics. A lot of people growing up in those communities that never leave and feel like they have a little bit more say than they actually do and exert some of that power and control. [In the larger district], there's not that small town politics stuff that I've seen in a lot of the other places.

Cassie sums up this section when she talks about how it felt to work in a small district and live in another district. She said, "I just would get in my car and peace out, and I wouldn't see the kids again until the next day." She didn't have to worry if she went out for a drink in the evening, or deal with parent teacher conferences at the local swimming pool in her swimsuit, as described by Hannah.

Resources. Resources were a challenge in the small districts. The resources were often talked about regarding funding and had to do with professional development, technology, textbooks, and opportunities for the adults as well as the students. When teachers talked about this challenge, they did not necessarily categorize it, but they grouped resources as one big challenge. Daniel commented that his principal had students' best interests in mind, but he was just limited and funding and what he could actually get. Because I know that when I got there, they'd had a teacher pay freeze for a few years...So just the difference in resources at the small district is a struggle. I spent three years advocating for new government textbooks. 
Daniel compared this to his experience of asking for computers for his classroom in the larger district and getting a cart with enough computers for each student in a matter of weeks.

Kelsey also talked about the resources available in the small district. She shared that in the small districts,

you don't always have the newest resources and stuff like that. When I first got there, I was using an overhead. I ended up writing a grant and got a SMART Board and stuff like that. So there were things like those when I had come from a district where those things were just given to us, where I had to work a little bit harder for [them].

Kelsey moved to a district where she is working in an environment that is changing how education is delivered. She said,

I think looking back now I can say when I had I implemented standards-based grading, my ultimate goal was doing something like I'm doing now. Again, it goes back to I didn't have the resources to really make it happen. I don't necessarily know it was physical resources, but I didn't have the knowledge.

Workload. Participants discussed feeling overwhelmed with the workload in their small districts. While the workload was reported as heavy, not all participants sounded or even appeared upset about it. Their voices portrayed a remembrance of the stressful, overwhelmed feeling. Often, they would then move into talking about the support they received from their peers or administration. That being said, there were participants who definitely carry a very negative recollection of their workload experience in the small district. 
Overwhelmed was a word that came to mind to describe the feelings of the participants. Mac talked about his experience saying,

I was the only music teacher for the entire school district. So I did high school band and middle school band and high school choir and middle school choir and ALL the elementary music classes. It was just too much. I was not built for elementary music.

He made the choice four months after starting in the small district that it would be time to find a different position. Ken called his first year teaching in a small district a "monster." This was even after working in the district as a paraprofessional the previous two years. He said,

My first year in content was a monster because I was all of the junior high science department and half of the high school. As a first-year teacher, I had six preps and everything. I had six, seven, eight science, chemistry, physical science. And then a, whatever you want to call it, an intervention time kind of thing. The first part of the year, first quarter-ish, I was at school until six, seven o'clock most nights just trying to get everything set up, get copies made, trying to plan this, that and the other. By Christmas, I had had it kind of down to where I could get most of my stuff done on my prep, and within an hour or so after school without it being crazy. I'd still take home stuff to grade, this, that and the other, but I got better at it.

Ken's experience revealed the overwhelming feelings at the beginning of the year that turned into a manageable load by the end of the year. Kelsey's experience was similar 
even though she came first from a larger school before moving to the small district and then back to the larger school. She said it was

tough because I had gone from teaching two things to teaching five [courses] for seven [periods]. Trying to balance all of those pieces, I was working a lot of hours. I also thought about the balance piece [because] when I was at the larger school, I was grading 90 tests every time I was giving a test. At the small district, my class sizes were so small that those things balanced out.

Albie, Cassie, and Cody all talked about the workload in terms of being scared, intimidated, or not knowing what they were doing. Albie said, especially after my first couple of years when I was first year kid fresh out of college. I'm teaching every social studies class 7-12, coaching three sports, not having any idea what the hell I'm doing, and having all that stuff thrown in my lap is probably not the easiest transition but worked out pretty well.

Cassie said,

I was very intimidated. I'm not really sure why. I've got a very outgoing personality, and I'm comfortable with pretty much any situation that I am put in. But knowing I was going to be in charge of other people, children, for the first time instead of like with student teaching how you're just kind of, "Oh yes, this is my class, but it's not." You know it's still someone else's class. But I wanted to have everything perfect. I knew my students were just going to be the best students ever. The parents were going to love me. And I just had really high expectations for myself, but I was afraid and intimidated at the same time. I had just kind of masked those fears and pretended that I was the world's greatest 
teacher. I had three days of training prior to school starting. And that was pretty much just like little meetings here and there. And it was nothing that was super informative for me that made me feel better. If anything, it almost made me feel kind of overwhelmed. They were talking a lot about data, and I had never done anything with data. So I thought, "Oh my gosh, this is something that I have never even implemented in my classroom. How on earth am I going to do that?" So it almost put more stress on me than good. But I was in my classroom for, I'm going to say a good month before school had started, just getting my classroom together and trying to get like stations set up and [doing] all the little things that I thought would make me the greatest teacher ever.

Cody put it bluntly when he said, I was absolutely scared to death. I had really no clue what I was doing that first year. I mean, I'm sure you remember the same thing. So I'm going in, I have like six preps I think, my first year. I don't share any classes with anybody at the small district because it's so small, so I'm the only teacher teaching these subjects, so I had no one really to talk to. The high school math teacher at that school then, we never talked to each other for whatever reason. I was just kind of by myself. My mentor was the English teacher, and she helped me out some. She tried to talk to me about classroom management and things like that, but really going into that day one, all I had was some stuff from college, remembering about ice breakers and things like that, so I used those. But otherwise, I really had no clue. I knew how to make seating charts and things like that, to make sure I knew where all my 
kids were and try to learn their names, but otherwise I really was just scared to death and blind.

When asked how long it took him to get into the groove, he said,

I don't know if I ever did that first year. It took me a while. I don't know, towards the end of my first year I started feeling a little more comfortable. The second year I was a little more prepared at the beginning of the year with how to start off the year better so that I didn't have as many classroom management problems. So my second year went a lot smoother than my first year because of that. Probably a couple months into my second year is when I really, really started to feel comfortable.

When a teacher did not necessarily know the content, their workload included teaching themselves the content in order to stay ahead of the students. Ken shared,

I found out the first half of August that I was also going to be teaching chemistry. I didn't have my certificate yet. So I had a middle school degree, which is zero chemistry, and six weeks' notice that it was going to be offered, and I was going to be teaching it. So it was a bit of a crisis. Most nights, the middle school science it was cake. It's water cycle, that kind of stuff. Physical science, I had down pretty well just from being a bit of a science nerd myself. But chemistry, by and large, took most of the effort, just because I'd have to teach myself the stuff the night before and then try to pretend like I know what I'm talking about the next day with it. 
Sabrina also discussed the workload in number of preps. Leann, Daniel, and Greg added to the conversation when talking about the need to rewrite curriculum in addition to their classroom and extra duties.

Positive Experience. Even with the challenges described above, when reflecting on their experiences in a small, rural school, participants talked about how much they liked the overall experience. Sabrina felt like her move was inevitable, yet she said the following about leaving to make the move to the larger district, It was terrible. I cried a lot. I loved my job there and the people I worked with. I loved my students. I loved my athletes. If you were to ask me my favorite years teaching, it would be those three years. They were my favorite. They were absolutely my favorite years but, sustainability-wise, it was not going to work out for my family. Looking back, I wish I could have spent more years there because it was so much fun.

Relationships. Much of what the participants had to say about relationships in the small districts was positive. Teachers reported they felt connected to each other, to their students, and to the community and parents. Whitney, Ken, and Annabelle all used a statement similar to, "it felt like home" when talking about the relationships they had in the small district. Whitney wanted to work in the small district, and there was not an opening after having student taught in the small district. After teaching elsewhere for a year, in response to how it felt landing a job her second year in the small district, she said, "It felt like I was coming home. It was a breath of fresh air." Cassie said something similar concerning leaving the small district. 
That was one of the saddest times. The small district was, and it still is home. I talk to everybody there still. And the principal there is the godmother of my daughter. That was home. I still see the students all the time because I live so close to there. But it was not a fun situation leaving. I was afraid that I had made the wrong decision for a long time. But because I missed that homey feeling and I just missed my people.

The close knit nature of the staff was something Cody looks back on fondly. He said, When I first started, the staff was super close and, a lot of the staff were older when I first started there. Obviously, I was super young. There were six or seven of us that started together. Funny enough, it was me, my wife was one of them... years, she started the same year I did. But we were the young ones, but a lot of them on the staff were older, and they accepted us really easily and helped us out a lot, encouraged us, and were super positive with us. They would invite us to stuff after school and hang out. If a group of teachers got together on a Friday night, they would invite us over also. Even the older teachers, and they had a group of friends, but they brought us. So how tight the staff was really, really great.

Ken put it just a little differently, If you're okay with not having the same level of relationship with your coworkers, then go to the bigger district. A place like, a district the size of something like my small district, they do feel like family and a lot of the people 
that you're working with are related to a lot of the other people that you're working with in the literal sense.

Daniel specifically talked about the type of relationships he had in the small district with students. He said,

I've been able to develop some deep connections at both the rural district and the big district, but the rural... I just felt like I knew those kids. I knew those kids' families, like I knew everybody at such a more personal level. That means a lot, being invited to weddings, afterwards and stuff like that, getting kids today that I haven't talked to for three years, that will tell me, "Hey I got accepted into this college" and stuff like that.

Mia also keeps in touch with students and families from the small district she left. She said,

I was sad to leave the community, and luckily for Facebook, I still am able to keep kind of in touch with them like, "What are these kids up to?" Because I was friends with their parents after I had left.

Molly said that it was not just her relationship with the students, but it was the relationships students had with each other. She talked about how she did not really appreciate how deep their relationships were with each other until after she left the district.

Of all the participants, Annabelle talked in great detail about her experience in her small district, particularly about the relationships she built. She talked about moving to a new town by herself for the first time right out of college and shared, 
Everyone was super welcoming. School hadn't started yet, and I went to the grocery store. I was just walking down the aisle minding my own business and this lady came up to me and she's like, "Are you the new second grade teacher?" I was like, "Yes, who are you?" She's like, "Bye." I was like, "okay." I guess it was announced in the newspaper or something. I was like that's creepy but cool that everyone knows what's going on. They knew that someone new was starting and I guess I was the only unfamiliar face, so they just figured it out. I [realized] people pay attention. My grandma cut it out, she's like, "Your name is the paper." When school started, she reflected, The small district definitely was faster [to build relationships when compared to the larger district] cause when I got to the small district, everyone came and introduced themselves to me. Everyone was welcoming. Everyone told me, if you have questions, I'm in this room or come see me and they would check in on me every day. My administrator would check in on me every day just to make sure I was okay.

When it was time to move on to the larger district, she said, my last day I packed up my car and I was driving and I was like... I seriously cried all the way home, and I was like, "I really didn't want to leave." And every time... see I'm getting like, and I'm not an emotional person, I'm really not.

Seeing her get emotional talking about her emotional connection and the relationship she was leaving was very moving.

Support. Support is something all teachers talked about and when it was good, it seemed to be really good. Three levels of support were noted from the participants' 
responses and included peer support, administrative support, and community support which also includes parent support.

Peer. Teachers benefited from colleague to colleague support through mentoring programs, informal support between each other, and more formal collaborative support spanning across content areas. Annabelle talked about the mentoring program in her small school district. She said,

I was buddied up with my partner teacher, so that was easy. I taught second grade, the other second grade teacher was my mentor and so we, I think we had to write down monthly maybe what we had discussed and when we met, which was every single day. So I was like, this is dumb. Like I get it. Some people sit there and don't ask for help. But, if I don't know something, I'm going to go find somebody who knows. I like to do things right but, my partner teacher was awesome. Then when I moved to fourth grade my second year, it was still a mentor program but it was a little more relaxed.

Mia's mentoring program in her small district also provided positive peer support. She shared,

I was the only new elementary teacher, and they hadn't hired anybody new in five or six years. So most of the staff at the school were veteran teachers. They've been in the classroom for a long time. Most of them lived in the community and they weren't going anywhere. And I kind of feel like because of that, because I was the new person, they were so very welcoming. I think part of that is just small town culture a little bit. But also, they had time to invest in me and really grow me as a teacher because, number one, I was the only one in the elementary school who 
was new, and so they just had time to give to me. My principal spent a lot of time with me. My mentors, the other first grade teachers, spent a lot of time with me, helping me think through the setup of my classroom and it was awesome.

Looking back at it, every new teacher deserves that.

She also reflected, the teacher team was very supportive, and we collaborated often. One of them was my mentor for the first two years, so that was great. Even the reading specialists were always great at coming in and meeting with us and talking about specific kids. And administrators were awesome, too. I mean, my principal was in my room probably every day, just kind of... Sometimes it would be evaluative or just giving feedback, but it's also observing and interacting with the kids. She would leave little sticky notes on your desk, like, "Hey, you did a great job of this," or, "Next time, think about doing it this way." But it always seemed very supportive, never... You weren't fearful of the feedback at all.

Ken, Daniel, Whitney, and Kelsey all talked about being able to go to anyone for support. Daniel said, "we supported each other; we help each other, we talked." Kelsey said the peer support was "amazing, absolutely amazing. I always felt if I ever needed anything I knew where to go. I had great co-teachers." Ken went a little deeper with his comments. He said,

Any and every question I had, I could get answered. It was just, the people were all great. I knew if I didn't know who to ask, whoever I did ask would point me in the right direction. But it was one of those types of things where you never know what you don't know until you've got to do it, and then you realize, "Oh, wait a 
second." I never felt like I didn't have a go-to, you know what I mean? But there's just a lot of those little, I don't know what the term is, but not institutional type things, but there's just a lot of processes in place that everybody knows that nobody talks about. So when the new guy comes in, you're not necessarily [thinking of those things] since you haven't thought about it in forever, you don't really know what they need to know.

Kelsey clarified her recollection of peer support when she shared,

Throughout my time at the small district, I realized it doesn't necessarily have to be somebody in math that listens to those [instructional] ideas. I was talking to an English teacher and she would say, "Well, yeah, I think that idea would work." Not necessarily [about] the content, but the activity. So you could still run things by [other teachers], but it took me a while to figure out, to be able to talk school with a lot of people, I guess.

Administration. Administrative support, when it was good, came out very strongly from the participants as they talked about their experiences in the small, rural districts. Participants did not seem to hold back as to how they felt about the support they received from administrators, and some participants emoted this not only through their words, but their vocal inflection and body language.

Mia was one who was very impressed with her administrator in the small district. [My] administrators were awesome, too. I mean, my principal was in my room probably every day, just kind of [checking in]. Sometimes it would be evaluative or just giving feedback, but it's also observing and interacting with the kids. She would leave little sticky notes on your desk, like, "Hey, you did a great job of 
this," or, "Next time, think about doing it this way." But it always seemed very supportive, never... You weren't fearful of the feedback at all.

It wasn't just the elementary principal that was supportive and visible in her small district. She went on,

There's just one elementary principal, and then our superintendent. And our superintendent was in our building all the time, too. He would come and eat lunch with the kids; he'd come and eat lunch in the teacher's lounge and talk to us. So he knew you by name; he'd come into your classroom and say hi. So it was just very supportive. And his office was not in our school. So he definitely made an effort to leave the district office down the road and come over and see you, and talk to you, and see how things were going.

Annabelle shared that her principal went out of his way to make sure the teachers understood the common language and acronyms used in their district. She talked about an acronym definition guide he had created and shared with them during their orientation days to make sure they could participate in the conversation. Whitney said that along with the peer support, she always felt supported by her administrators. She said, "I always felt the leaders were visible in our classrooms and just very much a part of our students' learning." Ken talked about his administrator's support in regard to him being in a new content area. He stated:

No, I had a great principal when I was there. She was very supportive and tried to find me all kinds of good PD, especially that year I was an uncertified Sped [teacher]. If she'd come across something that she thought I'd benefit from, she'd sign me up for it, and I never had any big concerns. 
Kelsey also had positive memories of the administrative support she received.

I loved it. He was very relaxed about things, but also there to listen. I guess his philosophy was I know what's going on in the school. Because I'd ask him, "What do you think about this or whatever?" He was like, "If you're doing something that you shouldn't be or if you're not getting results," he goes, "I'm going to know about this. I hear about what's going on. I know how things are going and stuff." So he was relaxed in that sense, but supportive. When I went in and I said, "Hey, I want to start doing standards-based grading," he's, like, "Okay. Talk me through this. How are you going to explain it to a parent? How are you going to do those pieces?" Then he was like, "I'm all for it." He goes, "I just want to make sure you know your answers when you go into it," and stuff like that. So [he was] very supportive in what I wanted to try when he felt like it was also good for education... but he also always asked me the questions to make me think about why I was doing something.

Cassie voiced her principal was very supportive even with change in upper leadership in the district. She shared:

[Administrators] were amazing. We had a change while I was there, three different superintendents. So they were going through some trial and error with different superintendents. But my principal had remained the same whole time and she was just fantastic. Very supportive and it was all about student growth, the whole building was just very stuck on student growth, and how do we get our students to grow. And they were very big on professional development. No matter who you are within the district, you're always striving to learn and to do better. So 
that was nice to have a team that was willing to push you; send you wherever you need to go in order to get your next level of education. They were very supportive with that.

Community. Community, including parent support, was something almost all participants agreed on as a positive recollection from their time teaching in small, rural districts. This ranged from specific conversations about a student's individual behaviors, to classroom support, to full community support of the school district. Below is a sampling of what participants had to say.

Albie and Sabrina both described the full community support of the school district. While their statements are similar, it is important to see that this type of support is not just limited to one community and one school district. Albie's experience:

Some of the smaller places that I've been, like on a Friday night, you knew where everybody was gonna be... They're gonna be at the football game-everybody in town. When I was at one small district, we were really good at football, basketball; earned a state title in both of those while down there. If you wanted to rob the town, go somewhere on a Friday night because everybody's gonna be at the football game.

Sabrina's experience:

On Friday nights, everybody was there. I mean, people who didn't have kids showed up to the games. They would do homecoming; we would do a parade through the town. The expectation was when they [the town] did Saturday stuff, my VB team had to be there volunteering and being a part of whatever little festival, fundraising, whatever, so it was a very tight knit. 
Mia shared:

I loved it there. I mean, the community was great. Everything revolved around the school, so home football games, and everything. The community was super supportive. The high school athletic teams and choirs and bands would always come over and do things with the elementary school kids. It was a very close-knit community.

Albie justified why the connection between the community and school was so strong:

I think those smaller communities to smaller schools, you have that tighter knit bond because you spend so much time. I grew up with the same kids that I graduated with. We were in school from kindergarten and in some cases, preschool all the way up through graduation.

Vicki, who did not have the best experience in the small district, still felt as if the community support was there: "that was probably the best community I've ever been a part of/worked in. That great hometown feel; everyone knew each other, and you knew all of the kids by the end of the year and they all knew you."

Parents were very supportive of teachers in the small districts as described by the participants. Cassie shared:

the best thing about working in a small district, in my opinion, was like the support of the parents because it was such a small school. They always wanted to be involved. Like, "what can I do to make things better?" I remember my first year I wanted to have a fall party. For the fall party, I reached out to the parents, because we couldn't call it a Halloween party. We ended up having a fall feast. 
Parents cooked turkey and brought turkey in. It's just every student in the small school district is acknowledged. Everybody knows everybody and there's really no times ... It was hard for students to fall through the cracks because you knew every child. You knew every parent.

Whitney communicated parent support was not only there when she called parents about something that happened with their student:

The families were so involved in the small district. They were very interested in what was going on in the classrooms and they very much wanted to support their child's education. It was very clear. And it wasn't as much of me reaching out. Of course, I would reach out to them, but they would also make initial contact just checking in. That was something I didn't realize at the time was just significant and not as common at other places.

Cody shared this support was critical for him to even stay in education, not just stay in the small district a little longer:

There were certain parent groups that were super supportive, and we would see them around a lot. They were always willing to give an encouraging word, even when things were going bad in our personal lives, or things in the classroom maybe weren't $100 \%$, and they knew it. There was always a group of parents that were there to give you an encouraging word...The board at that time was really, really super nice to the new teachers, to the young people, and it helped me stay in education. Because there was a time, really early in education, I was thinking after a couple of years, "There's no way I can do this. There's no way I'm going to 
survive," but some of that encouragement there at the small district helped me stay with it.

At the elementary level, Hannah shared the community was out in full force supporting them as well. She said:

Those families were amazing. They were very supportive of all their children's education. If you had any concerns, they addressed them right away. The families were really good there. The staff was great there. I had really great principals and administration the whole time I was there. They had good family nights and would really try to get people there. They'd serve pizza and have different games, and lots of people came in. It really was a great district to work for.

Negative Experience. Even though the majority of the participants' stories revolved around positive experiences, not all shared that sentiment. The negative experiences shared by participants were often described as why they made the choice to leave the rural district. Six of the participants shared negative experiences with the researcher.

Mac's story includes him being overwhelmed by the teaching load of a k-12 music teacher. He knew early on his first year that this was not the best fit for him. When asked about his experience in hindsight, specifically about the worst part of working in a small, rural district, he said:

Yeah, pretty much any day. The way the schedule was set up that year, the "high school band," it was actually grades seven through 12 , met at the beginning of the day, first hour. And then at least two days a week I would have that class, and then that class would leave, and they were immediately followed by a 
kindergarten class. After a 50 minute band rehearsal, I don't know, there's just a lot that goes on in those, and there's just a lot for your brain to handle. The next thing I know, I've got these 20 kindergartners sitting there, and I'm like, "I have no idea what to do with these kids." Shifting your brain from seniors to kindergartners in the blink of an eye, just any day where I had to do that was like, "I can't do this. This is not something my brain is going to be able to handle.

He went on to say:

So, at the time I didn't really know [what I needed]. I just knew that I did not feel at home, I guess, or I didn't feel that it was the right fit for me. I had some nice coworkers. But, as far as the teaching, I pretty much felt lost that whole year.

Albie had something to say about the administrative turnover in small districts he taught in:

The biggest problem that I saw in the smaller schools with the administration is turnover. There's so many of them... I had young administrators who were looking for experience and [would then] move up. I had a bunch of them that were administrators that had been around the game for a long time, and this was their way out; this was their last step out the door. I've had nine different head principals in 19 years and, of those nine, [for] four or five of them it was their last job before they retired. So I'd be there with them for a couple of years, and then they'd retired. Then we get somebody else. So the turnover in the smaller places is, I think, a little bit more prevalent.

Leann's negative experiences revolved around her administrator. She felt as if high expectations had not been set, administrators did not give her feedback or support, and 
had struggles when talking about her maternity leave and her desire to step away from coaching:

I felt like there wasn't an expectation level to do our best. And for me as a person, if I'm going to do something I'm going to do it the best I possibly can and put everything into it. And I felt from day one the administration didn't have that expectation of the teachers, because they didn't want to put in the time. And so the teachers don't put in the time. One of the things that really stood out to me during the summer was when I was there and a teacher came in and we had met briefly when I was shadowing, and she was like, "Wow, I mean you're up here this summer working, why?" And I just thought that was really bizarre. Like, What do you mean? Why? We should be up here working, especially as a new teacher, getting stuff prepped. And then I had another teacher come in, I was reorganizing the room and decorating and doing things to make the room more comfortable. And she was like, "You're putting a lot of money into your room." And even my principal made a comment about the amount of money that I was spending because the school doesn't pay for it, obviously. And why would I put so much money into it? And I'm like, "Well, I'm going to spend every day here, so I want to enjoy my time. And I feel like if it's a comfortable environment, the kids will enjoy it more. Why would I not put the time?" The expectation was just much different than I anticipated it to be.

In regard to administrative support, she shared:

So in my first year, obviously I had no experience teaching; I was observed one time. By State law through, if you're not certified, it requires eight. And I was 
observed once. Actually, in March, he came to me and said, "Do you have a day this week that you're doing discussion with your kids... so I can come observe because the board meeting is this week and I need to recommend you for rehire, but I need to have an observation to do that." He was never in my classroom ever. And even with my observation, [he] gave almost no feedback on what I needed to be doing. I scored really high, which I think I genuinely deserve those scores. Obviously I think I'm a good teacher, but I think that there could've been some feedback provided on why you scored this or what you could've done to score next higher, and none of that was ever really provided.

She also did not appreciate the way her administrators handled her concerns with students, particularly bullying:

I didn't have issues with classroom management in terms of needing kids sent to the office for any kind of reprimands. But I did have lots of reports on bullying that I would turn in and nothing was ever done for those students being bullied in order to assist the students. I specifically had one student who was consistently bullied by a classmate. I consistently wrote reports and turned that student's reports in, and that student was never punished for his bullying, even though it was consistent, which is in line with bullying. And he even admitted several times like, "I don't like her, so I don't really care." He was never punished. There was never anything done about it. Just very lazy. The expectation level was very low on what he expected of us. And so that transferred to how he did his job as well. She also had strong feelings about the school board's leadership in this matter: 
So my principal was a 7-12 principal. And yeah, it's just consistent. It's just how he is. And the Board doesn't have an expectation for him to be any better, from my understanding. There've been a lot of complaints from teachers and parents about the lack of anything really. And nothing's been done... the kids on our side say, "We know the principal doesn't like us." You know that he doesn't talk to them. He doesn't interact with them.

Leann's reaction to her negative experiences with leadership continued when she was told her contract would not be renewed if she did not agree to coach even though she would be on maternity leave the following season. Her principal offered she could assist the head coach while on maternity leave and then take on the head coach the following year. This was not an offer Leann was willing to accept.

Cody's experience with administration had to do with not only his challenges with the school board that prompted his decision to move districts, but also with a principal that did not directly cause him discomfort, but affected teachers to the point of them going home in tears: "He was more to side with parents and students before he helped out the teachers as much."

Vicki's experience with the toxic relationship between her and the other teacher on her grade level team was the reason she chose to leave the small district. Even though she felt supported by administration in no longer collaborating with this individual, the experience did not get better. She appeared to be very hurt by what transpired in the small district and this was evident from her sighs and her body language as she talked about it: 
I mean honestly, that one specific person is what ... and when you work in a small school, you can't get away from it. They're always there. You can't just shut your door and do your own thing because they're always there.

Recommend Other Teachers Should Have This Experience. No matter what type of experience participants reported, all of them stated it would be worth it for teachers to take a job in a small district. Some said it was the best experience of their lives, others said the experience will prepare teachers for anything, but almost all of them said new teachers should give it a try, even if for just a short time.

Great Experience. Annabelle is not the only teacher that looks favorably on her time in a small district. In fact, when it was time for her to look for a position in a larger district, she interviewed with a high paying, larger district. She was taken aback by the comments of the interviewer:

What turned me off is the lady interviewing me was asking where I had been. I was like, "Oh yeah, I was in a small district." I don't remember what brought it up, but she asked something about curriculum and I [described it to her]... She said, "Oh, so you're ready to be back in civilization." I was like what does that mean? That was just so rude and off-putting... She completely turned me off to their district.

Brandi also really liked her experience in the small district. She shared:

it feels a lot like community when you're in a small district with the staff, with the students, even with the parents. Although, I will say again, my view could be skewed because I lived there and my kids went to school there.

Mac let us know that even though he did not like his first small district that, 
I feel very fortunate. As you said, I've had a very varied career. But I wouldn't trade that for anything. I think I have learned great things each place I've been, whether it's a positive or a negative thing. I've learned what I'm good at and what my strengths are, and I've learned what I'm not good at and what I should not be doing. And so, I think that's the main thing, is I've tried to take a little bit away from each of my experiences and apply it to where I am now and what I'm doing right now. I've certainly, definitely used the things that I've learned in each job on a daily basis right now.

Prepare Teachers for Anything. Mac brought up a great point when talking about small districts and his experiences:

I think everybody, everybody should work in a small school district at some point in their career. I don't know, it's almost like if you have not experienced the small school environment, you don't really have any understanding of education, if that makes sense. If you've taught in these big institutions for your whole career, and have only worked for a gigantic band program that does all these things, you have no understanding of what it's like to really have your boots on the ground and really get to know kids, and really get to make an individual difference in some of those kids that you can't reach in a larger environment.

Annabelle shared her training in the small district was critical to her success as a teacher today:

My years in the small district were seriously... Everything I learned there is what I've based my teaching on. And so that's kind of, it kind of sucks because then I left and took that training elsewhere. And then the big districts training is not 
anywhere close to what I got in the small district. Because it was just so like it was like more intimate. It was more catered to my needs rather than like here's how we want all of you to do this. But yeah, I would definitely start in a rural district and if you can, I would stay in a rural district because it becomes like your own, it's your family, it's like you're helping make decisions. You have a bigger voice.

Try it. Overall, the theme from the participants is that teachers should try a position in a small, rural district. From Daniel suggesting not to let the pay scare new teachers because, "you figure it out" to ten participants talking about the specific support teachers get in small districts. Ken did talk about the workload and said,

Once you do learn to cope with that level of crap that comes from being at a small district and having six preps your first year... You get to the point where even that is kind of a fond memory. So you'll look back at the small district and say "Okay, so I was at school until seven most nights trying to figure out what I was doing." I had no idea how to teach chemistry, and I was tasked with teaching chemistry and that kind of stuff. But once you get through that, or you at least learn to deal with that, the rest of it was so much fun because you saw everybody all the time, because there were only nine adults.

Brandi looks back and said, "I will just say that I'm glad I've done both."

\section{Summary.}

When analyzing the participant responses, the experiences of teachers in small, rural school districts are mixed. While some focused on the challenges, others told stories of the positive relationships and support of those in the community and the school. For a 
handful of the participants, the experience was not a good one. Even so, almost all participants would still recommend new teachers take jobs in small districts, even for a short while. According to the participant stories, an anticipated short term in a small district could turn into many years and finding a home.

\section{Research Question Three: What do teachers perceive to be the differences between rural school districts and larger school districts?}

Aside from the obvious size of the school district, participants talked at length as to what they perceive to be the differences between the small rural school districts and the larger school districts in which they worked. The differences were not limited to compensation and resources but encompassed many aspects of both the work environment and the work itself. The data revealed differences that include hiring practices and orientation to the district, demographics of the district, and student discipline, including classroom concerns as well as perceived administrative action regarding discipline. The data also include perceived differences in professional development, instructional practices, and teacher workload. Further perceived differences include administration, community, parent, and peer support; relationships with both students and peers; and the opportunities available in the different size districts.

Hiring Practices and Orientation. Participants discussed the differences between small and larger districts regarding moving through both the hiring process and orientation/induction in the school district. Beginning with the application and job hunt process, participants noted differences between districts based on size. Greg talked about knowing someone as being how he landed a job in a small school district rather than directly applying for the position. He said: 
To be honest with you, I was sitting at a 5th and 6th grade basketball game, and the principal came up and sat down beside me and said, "Hey, our special ed teacher is retiring at the end of this year. If you're interested in it, you need to fill out an application." Since I had subbed here and there previously, I had that connection.

Greg went on to talk about how he had not gone to school to be a special education teacher but had been a physical education major. He still had six weeks of student teaching when he signed a contract to be a special education teacher the following school year, and would have the experience of being a first year teacher while learning how to be a special education teacher and work toward that certification.

Other participants discussed the differences in the interview process. The consensus of the participants seemed to be the larger districts had a longer timeline between interviews and decisions when compared to the smaller districts. Annabelle addressed this when she said:

Big districts take forever to contact you to even give you an idea of where they are in the process and if you contact them they really don't respond to you. I was like well I need a job, [so I applied to the small district] [The small district principal] ended up calling me [quickly] and offered me a job.

The actual interviews varied between the districts with participants describing large panel interviews as well as interviews with only one or two district personnel in both types of districts, revealing that it is not the size of the district that determined the type or format for interviews. 
It should be noted that multiple participants reported that during the interview process with larger districts, they were told experience at a smaller district was recommended when they did not secure a position in a larger district. Cassie summed it up when she described her first job hunt process out of college:

I applied in the larger district and in a small district just because I just wanted to have the experience of having interviews before I got interviewed [in the larger district]. So I interviewed in the small district and got offered that position. I interviewed in the larger district and did not get it. The administrator had told me, and I had even worked there that summer before I had began teaching. I had had a whole summer school course there and knew the principal; she loves me. Well, when I interviewed with her, she said, "We just want you to get a few years under your belt like in a smaller district before you come to a larger district." So that was super heartbreaking for me, and I thought all I wanted to do was work in the town that I lived in forever and I didn't get that. So I was really scared and sad to go to the small district, but it ended up being a blessing because I was part of the administration team before I left there. I was welcomed the moment that I came in. My mentor teacher was, it was her last year before retirement, so she knew everything and just welcomed me with open arms. And it ended up being a fantastic experience. But I didn't go there because I thought, "Oh hey, I'm going to apply in [this small district] and work there forever." I just did it just to be able to have that experience of the interview. And then low and behold, it ended up being home for seven years. 
Cassie stayed in the small district for several years before making the move to a larger district, but Vicki only stayed in the small district for one year before making the move. She said the larger district told her, "They wanted me to grow a year before I tried to come back... they tend to want the experience." She expanded by sharing her thoughts on the differences between the district sizes in regard to hiring:

I think smaller districts tend to be a little more willing to try out new teachers and mold them how they want them to be as a teacher. I think bigger districts kind of already have this vision and they're looking for that specific person.

After talking about the hiring process, the teachers went on to discuss the orientation and induction experiences they had and the differences between the district sizes. The most apparent difference discussed had to do with the number of new hires and the number of people in the back to school meetings. Mia has experience with three different districts that were small, medium, and large. In the small district she was the only new hire, there were about 20 in the medium district, and in the larger district there were 100 new teachers. She described the orientation and induction in the larger district as not “as personal or as tailored to me, just because they can't, because they have to reach every single person in that room and the specific job that they're doing." Ken said, "It was very weird to be a face in the crowd as opposed to one of the three new guys, you know what I mean?" He continued to say, "the big thing was dealing with the scale of it."

The actual new teacher meetings were also discussed by the participants. No participant said they liked the new teacher meetings in the larger districts. Ken summed up the consensus of the participants by saying, "it was a lot of information and very little of it useful." Whitney felt as if the schedule "was very rigid" and that the training did not 
"go very deep...we going into this training for a little bit and then we'd just be doing rotations for five or six days going through [the basics], and we'd leave very confused." Greg said his new teacher days were double what they were in the small district and it felt as if it was completely different as they did not stay in their own building in the larger district, but went to different buildings during those meetings. It should be noted that the statements from the participants regarding the new teacher days may be impacted by the fact they are not first year teachers, but new to the district teachers.

Kelsey's situation was one where she had moved from a larger district to a small district, and then years later she went back to the same larger district. Even though she had previously taught in the larger district, she said,

I had to go back through the new teacher orientation stuff. I had three days where they took you back through all the stuff that they do for new teachers. They have the instructional teachers coming and talking to you. They talk about their mission and their vision, and the lawyer comes in one day. We went through those. Honestly, much of it hadn't changed except for some of the technology pieces since I had been there previously.

Annabelle was very vocal about her disdain for the induction process in the larger district. She shared about being required to go to a yearlong program. She made a point of working on getting out of this requirement as she felt like it would not be beneficial to her as a veteran teacher, but she talked about what the other first year teachers had said and shared:

I asked the other teachers who went. How's it going? Is it helping? They're like, no, we sat there the entire time and cut out manipulatives... Oh today we made 
anchor charts. We decorated anchor charts. They were so mad, and they were fresh out of college. One girl was just all the time, flustered like she didn't know what was happening. I asked, are you getting anything from it? She's like, no, it's just adding to my anxiety. Oh no. So I heard it was pretty pointless.

Annabelle went on to describe how this was different from the small district. She said, "everything we did in the small district had a purpose and everything we did was going to be used. That made it meaningful.

As far as the information presented and how they felt after the meetings, the participants were mixed. While most said they were not overwhelmed, Cassie and Cody shared some aspects were overwhelming. For Ben, it was the size of the district, and for Cassie it was that the expectations were different. She shared,

It was almost like teaching for the first time all over again. I was afraid and intimidated and didn't want to do anything wrong. Just starting all over, it was the same grade, which was nice, but they had many different things than we had in the small district.

In both district sizes, the participants talked about having mentors. In the larger districts, it was typically a veteran teacher in the same grade and content area, but this is not true in the small districts. Kelsey shared her thoughts about mentors in the small district:

I don't think they called it a mentor because it wasn't my first year teaching, but they had somebody that we sat down, and worked through different pieces and stuff, and talked about logistics and everything. One of the pieces that was hard for me the first probably year, year and a half in the small district was that I had 
come from a place where I had 14 people that were teaching math with me. They weren't all teaching the same thing, but I always had somebody that was teaching it along with me that I could give this idea out and stuff, and they would talk me through it. Then I was going to the small district where I had a junior high math teacher and me. We were the department, and we weren't even really teaching the same thing ever. That was tough even though they put the supports in and stuff. That was just tough going from a very large department to not really having a department and being able to throw things out there. I will say that throughout my time in the small district though, I realized it doesn't necessarily have to be somebody in math that listens to those ideas. I was talking to an English teacher and she would say, "Well, yeah, I think that idea would work." Not necessarily the content, but the activity. So you could still run things by another teacher, but it took me a while to figure out, to be able to talk school with a lot of different people.

Overall, the participants noted there were definitely differences in the number of new hires depending on the size of the district. They also were consistent with the idea that the orientation and induction practices were more tailored and personal in the small districts as opposed to the larger districts. It was also shared that some larger districts would let applicants know they preferred candidates with experience in smaller schools prior to hiring in the larger district.

Demographics. Participants discussed the demographics of the school districts as being very different depending on district size. The consensus of the participants was that there was much more diversity in the larger districts as opposed to the small districts. 
Hannah shared her perspective on the broader diversity in the larger district as there was a larger population pool. However, Molly talked about only having one student of color during her time in the small district as opposed to having 31 languages in addition to English spoken in the larger district. When it came to working in the larger district, Daniel said:

We have a high EL population there; we have a high SPED population. We had a meeting the other day, and I said, "our SPED department covers $13 \%$ of our student population, and they have 16-17 teachers, and then our EL students cover $8 \%$ or $10 \%$ of our population, and there's one teacher for that." And so those kids, they needed somebody. We have nine languages spoken in our high school, nine or ten languages in the high school and 50 in the district. I love that. I love seeing those kids whose parents immigrated here. I realized quickly, that just 'cause it's a bigger school, those kids still need good teachers. And they latched on to me, and I latched on to them. Very quickly, that first year was everybody says you remember your first year of teaching kids. I will remember my first year here because they were fantastic! I have kids who didn't speak English and so many different languages. I had kids who were transgender. I had kids who were openly gay. I had kids, just kids from all over the place and loved it, loved it, absolutely loved it! They got me excited every day.

He then went on to discuss the challenges of this diversity: And this was tough, so I guess this was another struggle. I had in my AP world [history] class, five kids that I know were smarter than me. They had 33-34s on the ACT type of smarter than me. I gotta make sure these kids are challenged. 
That was something that stresses me out. Then, how to handle those low EL kids. Like level one EL kids. How do I teach them? They're sitting in my class, how do I still connect with them, how do I still teach them? I told the EL teacher I had a zero background, and she was gonna have to help me. So a lot of those things were just new and stressful. I felt like I've been doing this for eight years and I have a good grasp on teaching, but those types of new experiences you get with a big school with a high need population; that was stressful and hard at the beginning.

Cody shared that while he had experience working with students living in poverty, it was different in the city. He said, "the bad neighborhoods in the city are different than in the small town and country." Additionally, some of the very large districts provided training on cultural competency as a part of their beginning of the year PD sessions for teachers. This was something Annabelle was surprised about, but her building is $90 \%$ minority, so she understands why it is needed.

Discipline. When it came to discipline issues in the different size districts, the participants agreed they had more incidents in the larger district than in the small district. Many of the participants talked about using strategies learned through specific programs such as Behavior Intervention Support Team (BIST), Positive Behavioral Interventions and Supports (PBIS), or Love and Logic. More stories were shared about corporal punishment being used in the small districts versus the larger districts, with a notable story being shared by Sabrina:

I only know of one time that it did happen in the small district, and it was with a kid who just struggled everywhere. But I know that I had talked to the parent. I 
had also given the principal updates on what's going on. I want to stay in truth, the straw that broke the camel's back was something that happened in my classroom, and I can't even remember the exact situation. That mom came up there, and actually, the principal, I remember I didn't witness it, but I talked to the principal about it later and he just said, "Well I gave her the option to do it or I would do it, and she said she wanted to."

Brandi shared:

In the small district, there were very few discipline issues. But I'm not sure. I think some of it is just that, again, a lot of the kids that I had, or they knew me from the time my kids were in kindergarten. Because when I left there, it was my older son's junior year. So any kid in the high school had seen me, or most of the kids, I guess. There obviously were new kids, but most of [the kids] had seen me or known who I was since they were in kindergarten. Even just the way they interacted with other teachers, I felt like there was just a level of respect there. They just didn't go some places. They just didn't act certain ways, other than there were a few of them. But maybe the percentage-wise that might've been the exact same as the larger district was, it's just it was a bigger school.

Annabelle currently works in a gifted program where she has kids bussed to her from multiple schools. She shared she can see a difference not because of the school size as much as the approach each individual school in her current district takes concerning behavior management:

So I see everybody [students from all schools], and it's really interesting. I can tell which buildings have strong behavior management and which ones don't. My 
school [building] just yells at kids and they are not very positive. And so when my poor little kids from the really consistent schools get there and they get screamed at for talking once in the cafeteria, they break down. They're like, "Oh my gosh, I didn't know." But then the kids from the more wild buildings, it's just like home to them. The lower the income of the school, the more negative the teachers seem to be in this district. It seems as if the more poverty stricken populations at those schools are kind of a rougher crowd. But then the teachers are also not as positive. It's very strange... In the small district, everyone did it the same way. So that was really rough coming over. It's a different group of kids. I get it, but they need some consistency for sure.

Based on the experiences, it is not clear if district size impacts discipline as it may be a similar percentage of students acting out, or the schools' behavior management approach may be the cause of success or challenges with student behaviors.

Resources. From the perspective of the participants, monetary resources seemed to be greater in the larger districts. This was very much reflected when they discussed compensation. The specifics of what they shared can be found in the answer to research question one and is a significant reason as to why these teachers chose to migrate to a larger school district.

Other differences pertaining to resources shared by the participants include the idea of physical supplies. In the larger district, as opposed to the small district, Annabelle said, "we have a whole room. It's just teacher supplies, and I'm like, what?"

Technology also appears to be more prevalent in the larger districts. When Sabrina made the move to the larger district, she said, "I had the palm pilot for the kids." 
She also talked about smart boards and other technology they had in the classrooms. Albie said that in the small district he had to check out laptop carts or reserve the computer labs. In the larger district, "I got a brand new set of 30 chrome books, brand new, just for me, and I get to use them every day. I've never had that before." Kelsey shared:

[In the small district], you don't always have the newest resources and stuff like that. When I first got there, I was using an overhead. I ended up writing a grant and got a SMART Board and stuff like that. So there were things like those pieces in the larger district that were just given to us where I had to work a little bit harder for in the small district.

Leann talked about the lack of textbooks in the small district. She said, "I asked for three books, and they bought them without an issue, but I found cheap ones." It should be noted that this meant they bought three books for her to teach from, but no books for the students. They learned through notes from PowerPoints created by Leann since they did not have other resources.

Professional Development. When it comes to opportunities for professional development (PD) and the type of professional development, there seemed to be a pattern based on district size. The small districts tended to have opportunities for teachers to attend PD that was specific to their needs and allowed teachers to attend PD out of the district. Hannah said:

In the small district, anytime we wanted to go to a conference or anything like that, they always were totally supportive of that. Making sure people were trained. If people felt like they needed to have some professional development, they 
always approved it. I don't know of anybody that was ever not approved for a conference.

Cassie shared something similar:

And they were very big on professional development. And no matter who you are within the district, you're always striving to learn and to do better. So that was nice to have a team that was willing to push you, send you wherever you need to go in order to get your next level of education. They were very supportive with that.

The participants also reported this seemed to be dependent on money being available in the district. Sabrina shared:

I did not go to a single professional development outside of my small district, not a single one. It was not something that was offered; the money wasn't there. It wasn't encouraged, not because our principal wasn't great, but I really think there was just a financial hardship there. And then when I came to the larger district, it was like, "Oh you wanna go to this conference. Do you wanna go to this to do that? It was just a completely different professional the situation to walk into. While they were able to attend PD sessions in the larger districts, most said it was often limited to in-district PD. Small groups or individual teachers would often go to outside PD and were expected to bring the content back to the school. If a teacher were to be approved to attend out of district PD, they had to plan and get approval well in advance. Ken shared that he had an opportunity to go to a two-week PD in Chicago. He said that while the actual PD was "dirt cheap, the problem was the hotel room." He went on to say that, "I don't have a doubt in my mind that the admin in the small district 
would've been supportive of me doing it, but they would not have been able to pay for me to do it." Hannah talked about conferences in the larger district and said, "We have to put in our conferences the year before, but in the small district, we could be more like, "I heard about this in a couple of months. Can I go?"

Albie felt the PD was more engaging in his larger district and wished there was more "PD that doesn't suck." He does not like PD that is sit and get and prefers PD that teaches the way that we expect teachers to teach. He also shared we do have more opportunities, I think, in the bigger places with PD funds that maybe aren't there in the smaller places. There's just more money to go around, but at the same time, you've got a lot more people that are wanting those funds to go do things.

Annabelle shared a difference between the district sizes in that there was quite a bit of optional PD offered in her larger district, and teachers would be paid to attend these sessions. She said in the small district, teachers would not necessarily get paid to spend extra time outside of the contract day to learn.

Brandi commented that PD in the larger district seemed to be in-district as they would bring someone in to get everyone trained at once rather than send teachers to conferences. She said she felt like the larger district had the resources to do this, whereas the small district she was in did not.

The in-district PD also seemed to be reported as more meaningful in the small district than in the larger district. Annabelle said that while she enjoyed PD in the small district for this reason, in the larger district she felt like, "why am I here? This is dumb. This is not beneficial to me. Why are you wasting my time?" Hannah shared, 
when I was in the small district, and it was for the elementary teachers, they had one of the representatives from Greg Tang come to the school and train all the teachers in different math, using all the different math manipulatives as him, actually, but one of his representatives that comes to Kansas City. Then, they would invite districts in the area to help with the cost. The other districts would send teachers, too. I always was impressed with both of the trainings that I went to there.

Whitney talked about there not being a lot of flexibility to PD in my current larger district. Like when I was in one district, there was a lot of PD, like choose your own type PD, like ed camp style, find your passion or find something that you personally need to work on. Here it's more district wide, like we were really focusing on equity. So we have a lot of equity PD.

Instructional Practices. Participants relayed a few differences when it comes to instructional practices in the small and larger districts. Whitney shared I have noticed, and I think it definitely varies building to building in the larger district because there's just so many of us. Sometimes it feels like we're our own separate entity. I mean, you kind of forget there's this giant district that we're a part of. But if I were to compare the instructional practices here in versus the small district, they seem... sometimes I get the feel here that they're kind of robotic. Sometimes I feel we're expected to follow certain programs that the district has adopted, just verbatim. That's concerning to me because it kind of takes our creativity and maybe a little bit of passion away from me as a teacher. 
Whereas, in a lot of the smaller districts, I don't really recall feeling that way. I mean, of course we had instructional programs and things that we were either required to use, or they were recommended, but I always recall more flexibility than what I see here.

Annabelle shared the same sentiment and commented that "it's almost like synchronized teaching" in the larger district. She said she "had the freedom to move things around or extend something if the kids weren't getting it" in the small district. Vicki went so far as to describe how her lessons not only have to be laid out to match every other teacher, but the structure of her day was timed, specifically the mini-lesson of reading and writing workshop. That being said, Vicki shared it is helpful to have a team and instructional coaches from which to get help as a second-year teacher.

Albie shard that in his larger district, there is quite a bit of project-based learning and collaboration between content areas to provide students and teachers to have opportunities he did not have in the small district just because there were fewer people with whom to work.

Overall, Mia seemed to sum up this whole section when she said that in her experience,

the small district was more traditional in their approach to teaching, where the larger districts were more innovative, and wanting to have more buy-in to technology and had resources to purchase technology. I would say definitely the practices were different, but good teaching is good teaching,

Workload. Workload is a topic that elicited quite a bit of response from the participants. There is a disparity between the workload in the different size districts 
according to the participants. Hannah was the only participant who thought her workload was more in the larger district than the small district. Based on the conversation with her, it could be due to the fact that her small district was not requiring data to be collected on her students other than observation, and she did not have a great deal of grading with her small class. Hannah moved from Kindergarten to second grade and shared how her workload is bigger: "A lot of it has to do with just more kids in our classes, having to grade papers and we do grading different." She talked about using a plus/minus system in the small district to note mastery versus the grading she is doing now. Hannah also discussed the workload involved in learning new curriculum programs in both math and reading.

There was a difference between the perspective of the secondary teachers and the elementary teachers, even though both groups felt very strongly about the difference in workload between the different size districts.

Secondary. Secondary teachers discussed the number of preps, as well as coaching, and outside duties. The consensus was clear that the workload was considerably greater in small districts. It was not uncommon for the participants to report having many more preps in the small district than in the larger district. Daniel said, "I remember I worked a lot. I was at school probably six or seven days a week throughout the year."

Mac, a music teacher, talked about his workload being too much in the small district and shared:

I was the only music teacher for the entire school district. So I did high school band and middle school band and high school choir and middle school choir and 
all the elementary music classes. It was just too much. I was not built for elementary music. Probably around January, February, I would say I decided that the duties that I had there were not to my strengths, and so I started looking for places where I would only be responsible for teaching band.

He went on to say, "I loved a lot of the aspects of the job, but it was just the time commitment, it was enough to say, 'No, I need to find something that leaves me a little bit more freedom of having my own life."”

Even though Ken felt the workload was insane in the small district, he recalls it fondly.

Once you do learn to cope with that level of crap that comes from being at a small district and having six preps your first year, you get to the point where even that is kind of a fond memory. So you'll look back at the small district and say, "Okay, so I was at school until seven most nights trying to figure out what I was doing." I had no idea how to teach chemistry, and I was tasked with teaching chemistry and that kind of stuff. But once you get through that, or you at least learn to deal with that, the rest of it was so much fun because you saw everybody all the time, because there were only nine adults. You know what I mean? And so yeah, I absolutely enjoyed it.

Albie also shared positive memories of the workload, even though it was a lot:

I like the variety of getting to do something different every hour. It was never the same thing. I never had two units of American history or Two World History classes. It was, okay, we're gonna have this class first hour, and third hour we are gonna have something different and there were different age levels and different 
age groups all day long. So, that was kinda nice, but the preparation was insane because some of these classes of teaching was also just semester-long classes. My first two years, I had like 11 preps each year. And that was tough at 21 years old and trying to figure out what I'm doing. 'Cause I still don't feel like colleges really prepare us the best for what it's actually like to be in a classroom on your own, full time. And it took a long time to get the old feet underneath me.

Leann not only discussed the amount of work that needed to be done in the small district, but she commented on the amount of time she spent at school the summer prior to her school year beginning. She came into a position that had few curricular resources that were up to date following a teacher who had been in the position for many years and had just retired. Leann talked about having to clean out the previous teacher's materials and to reorganize to make it her own. She spent a fair amount of her own money to make the room comfortable for her and her students to the point her principal commented on the amount of her own money she was spending on the room because he wanted her to know the school could not afford it. Leann is not alone in spending time in the small district rewriting and revamping up to twelve courses to be taught in one school year. Daniel said:

And when I got there, they didn't really have curriculum there for me. Or the curriculum binders they have were from the early 2000s and I started doing this in 2012, and so I made up a lot as I went because I had to... There wasn't a lot of those resources. So, the PowerPoint notes, the readings, the worksheets, I typed all of those up all the time. And so I had to spend a lot of time there at school getting those done. 
In the larger district, secondary teachers responded strongly that the workload was different. Most felt as if their workload was significantly reduced in comparison to the small district, but a small number felt that it was not necessarily less, but different. Kelsey shared how she had more planning and prep work in the small district with fewer number of students, but in the larger district she has more grading and less preparation and the grading all seems to come at once as all her classes may have a test within just a couple of days. That being said, the majority shared ideas similar to Cody:

I only had three classes a day because we have block scheduling. We had block scheduling in the small district also, but I was only teaching Geometry once, or Algebra once, and then seventh grade math. But in three hours a day, I would have two of one class and one of another in the larger district, so it really wasn't too bad when it came to teaching stuff like that. It was nice, prep wise, when you only have two because then you can make it better. You had more time to make it better and find fun stuff and more engaging stuff for the kids. Plus I had other teachers that were teaching the same thing that were like, "Hey, I have this activity that was fun, you want to use this?" And I'm like, "Heck yeah!" Or I would find something, and I'd be like, "Here you guys, I used this, what do you think? If you want to use it, great, if not, throw it away, I don't care." And it was nice having those other teachers to really help you.

In the larger districts, several secondary teachers talked about having 90-minute plan periods daily with only one or two preps. Sabrina said, "it allows you to really create great lessons for your kids. But then I also have that 90 minutes every day where I can 
plan and work with." Cody said that in the small district, with the number of preps he had,

really all I did was use the textbooks they gave me, and I just went from the beginning and got as far as I could until the end of the school year. That's pretty much all I did. I didn't find any great activities, nothing fun. It was pretty boring. In the larger district, I had 90 minutes a day to plan and to grade and make copies, and do whatever, and I could find some neat stuff and put some neat stuff together.

He went on to talk about the high school math department in his school in the larger district was the same number of the whole high school staff in the small district. His initial reaction to his teaching load in the larger district was, "Oh my gosh, this is crazy. I only have two preps, two preps, that's it? This is unbelievable. That's all I have to think about is two classes to teach? This is crazy!” Ken says he spends his time in the larger district differently. He did not take on any extra duties his first couple of years, but now has picked up a few things he wants to do. He said in the larger district he can leave on time, most of the time.

That was a huge thing, because now instead of feeling like I'm going to be here until seven planning, I got a kid that wants to come in after school for extra help. Well, you can't tell the kid no, but that means you're going to be here until late. Now I don't have that. Between Google classroom and fewer preps and my schedule not changing really at all, I've got a pretty good plan. And so any of my time instead of planning, I go into tweaking the plans, finding a better activity, or 
whatever. And then my time after school is, if I can get a kid to come in, by God, we're going to do some extra practice.

Ken also shared,

Hell, I sat in on physics class, just because I'm a bit of a nerd. I joke with the kids; I'm terrible at adulting, but a lot of days, I need a break more than I need to be productive with my 50 minutes off, and so I'll just go into another teacher's room and see what they're doing, do whatever they're doing and I did that for a whole year with that physics class. I even took the tests with them. We had, there was a couple of kids, and I had good relationships from a year prior and we'd be talking smack on each other about seeing who's going to have the higher test score and this, that and the other. And so that was, being able to do that kind of stuff was great fun as opposed to not constantly feeling like I'm drowning in planning and prepping.

Elementary. The elementary teachers talked more about balance as their workload is similar but balanced differently. Vicki shared this sentiment as an elementary teacher. "I have to prep more. I didn't have to grade as much, but now I have less prep and I have to grade more. It's balanced out pretty well.” Mia, an elementary teacher, said, “I don’t think your workload necessarily gets bigger just because you have more kids. I still have to plan small groups, and my small group might have six instead of four, but I am still prepping and planning the same amount." Whitney also shared that her workload was similar to an elementary teacher in the classroom in the different size districts.

Extra Duty. In regard to extra duty, participants shared they had more required duties in the small districts than in the larger districts. In the small districts, it was 
common for teachers to eat lunch in the lunchroom with students or to have some type of lunch duty. Annabelle talked about her experience in the larger district, and shared, "We never have to do lunch duty. They have people who do that for you so you can eat in the lounge, which is nice. And then recess, that's kind of the same." Sabrina shared:

There was a lot more planning involved. Not to mention you wore a lot of hats. So I was the FBA person, which is not a school sponsor thing, but I did that and, oh, my gosh, I was like... I have to think through my roles. I was Junior class sponsor. And gosh, all these things, so not to mention supervision and coaching which was an enormous chunk of my time. So yeah, it was definitely stressful. We ate in the cafeteria. That was the expectation. You had to eat in the cafeteria with the kids so you will help with supervision. All teachers did.

Daniel coached four sports in addition to his multiple preps his first year. He shared: I coached varsity softball for five years. I coached junior high basketball for three years, coached varsity boys basketball for two years. I was an assistant for the boys and the girls varsity basketball teams before I took over as head coach for one year for girls and two years for boys. Okay, so a lot of coaching. When I got hired, the principal said, "I want you to come here, but won't you be the junior high boys basketball and the assistant basketball coach for boys in high school. And you have a choice between assistant baseball or softball." And that's when I said, "I'll do softball." And then that year, they also needed an assistant girls coach, and so that's when I jumped over there. So I did four sports that first year. Yeah, but I was single and didn't have any better. 
In the larger district, Daniel no longer coaches. He shared, "I thought I'd miss coaching more than I do, but I don't. I don't coach anything now.” Leann also talked about her extensive extra duties. She shared:

I was Assistant Coach for Volleyball, High School. And then I also did FBLA [Future Business Leaders of America] my first year. And then my second year, I did those two and added yearbook. I also was responsible for doing the programs for sports games. So they essentially asked me to work that into one of my classes and make it a class assignment, which I did, but there's a lot of back work that has to go into to be able to give that information to students. And so that became another duty; every time we had a home game, I had to do programs for them. And then we did a school store. So I had to purchase food and stock and money. As Leann talked about the tasks that involved time outside of the school day, she continued to think of more responsibilities:

There were lots of other things, like new technologies. We did have a tech company, but they weren't housed within the building. So if it was something they thought I could answer, they would come get me and I would try first. Mia talked about her workload regarding the committees on which she has to serve. She said in the small district, because there's fewer people to do all the jobs, you have to be on more committees. There's fewer people but the same amount of tasks that need to be done. So I think the extra stuff on top of just lesson planning and grading is definitely more in smaller schools. 
Administration. Administration is an area that evoked many different responses. They did not seem tailored so much to the size of the district as much as they did the type of administrator. The larger districts had more administrators than the small districts, and teachers seemed to be able to get to know the administrators better in the small districts. It seemed as if in the small districts, the superintendent was more visible in the buildings than in the larger districts. Whitney's statement covers the consensus of the participants when she said,

in a smaller district, they just seemed to be more available and more visible and more time in the classrooms. And then, when transferring into the larger schools, they weren't available as much and most of the time that they were in the classroom it was for formal purposes.

The other overwhelming response about administration was the turnover for small district administrators seemed to be higher than the larger districts according to the participants. Albie's statement summarizes the responses:

The biggest, okay, I loved a lot of the principals that I have worked for; they have been awesome. But the biggest problem that I saw in the smaller schools with the administration is turnover. There's so many of them... I had young administrators who were looking for experience and then move up and I, I had a bunch of them that were administrators that had been around the game for a long time, and this was their way out. This was their last step out the door. I've had nine different head principals in 19 years and of those nine, three or, I think four or five of them, that was their last job before they retired, so I'd be there with them for a couple of years, and then they'd retired. Then we get somebody else. So the turnover in the 
smaller places is I think a little bit more prevalent. The principal that we have here in the larger district, he's been here for, I think this is like his 13th year in this building.

Support. In the small districts, the participants talked about not only was there a great deal of support for the school, but that they also had to be careful what they said as you might not know who is friends with whom, or who is related, even distantly, to whom. As shared in the answer to research question two, the support of the community is overwhelming in the small districts. The participants did not feel the same about the larger districts. Whitney shared, "it's very difficult to get support there versus the small district where it was so easy."

Parent. Similar to the community support, the answer to research question two also includes the participants' thoughts on parent support in the small districts. Participants said it is more difficult in the larger district to get parent help for parties in the elementary school. Hannah shared:

I do feel like there are some really great, supportive families in the larger district. In the small district, there were only some that weren't involved, but I don't think that you noticed it as much, because there were so many others that really took the lead. Their PTO [Parent Teacher Organization] was really strong. A lot of people went to the PTO meetings because they would have the parent night, the family nights with the pizza and everything, and then have the PTO meeting right then. Everybody was already there anyways, so a lot more people were involved. In the larger district, our PTO is great, but there's not really a ton of people, a ton of parents that come. [As far as parents go], it's really been hit and miss. It was a 
very small pool that signed up to help with any classroom parties or anything like that. If I ask for things in the classroom, it's usually a handful of maybe five to seven parents that are always the ones to donate things, but they're always more than willing to if I ever need anything.

Even so, she said most of her parents do attend parent-teacher conferences At the secondary level, it seems as if parent involvement with teachers is much less at the secondary level, especially in regard to parent teacher conferences. Albie's words are similar to what was heard throughout the participant interviews:

The thing that I missed the most is I felt way closer to the kids and the communities of the smaller places. Because in the larger district, I know my kids, and I've coached some of them for four years in softball. I still can't tell you what the names of their parents; I don't recognize them. It's a weird dynamic. Parentteacher conferences - I might get three or four parents come in for conferences, and of course what three or four you're getting? The ones of the kids who don't need to actually talk to you 'cause their kids are awesome. Why are they awesome? Because they have great parents. But when I was in the small districts, I had 15-20 people at night coming in for conferences.

Peer Support and Relationships. The biggest differences reported by participants included the fact there were more teachers on grade level and content area teams in the larger districts. Molly was the lone business teacher in her small district and shared in the larger district, "we have four business teachers!" Collaboration in the larger districts was noted as a strength. Mia talked about her "teacher team was very supportive and we collaborated often." Sabrina said, "in the small district you are totally a lone wolf...I was 
on my own island...I didn't have anybody to bounce ideas off and there was nobody there to check with me."

Participants also noted that in the larger districts they do not necessarily know all the teachers in their building, let alone the district. They said it took longer to develop the relationships in the larger districts than in the small districts. Annabelle said that in the larger district, her team introduced her to certain people, but in the small district, “everyone came up and introduced themselves to me. Everyone was welcoming and would check in on me every day."

There was really no difference noted based on district size as far as peer support is concerned. Participants noted a great deal of support, as well as a lack of support, in both district sizes. This seems to be more dependent on the individuals and personalities in each school rather than district size.

Student Relationships. Participants, especially at the secondary level, reported that they had stronger relationships with more kids in the small districts. Brandi shared: In the small district, I literally knew every kid. In fact, every kid in the high school, and the middle school, and half the elementary kids. [In the larger district] it was a little bit weird because I'm like, "I don't even know the kids' names in my own class." And that took a couple of weeks. So I felt bad about that.

Greg echoed this thought when he shared:

Something that bothered me a little bit was I didn't know [their names] when I'd say hi to the kids. I didn't know their names because coming from the small district, I knew everybody's name because there's only 125 students, kindergarten through 12th grade. There's 800 kids walking just the high school hallway in the 
larger district. I didn't know all their names, so that was hard for me at first. And when the bell rang, you've got 800 kids changing class. You've got to know how to walk with the flow.

However, it is not just the student/teacher relationships that are different, but the student/student relationships as well. Albie said:

I think in those smaller communities and smaller schools, you have that tighter knit bond because you spend so much time. I grew up with the same kids that I graduated with. We were in school from kindergarten and, in some cases, preschool all the way up through graduation. And in these bigger places you got kids that are constantly coming and going. I've got kids in these classes that don't know the other kids sitting two seats over from them. That's something that I miss; the close knit that the teachers had with the community or with the kids and vice versa, but also the kids with themselves.

Even though the majority of the elementary teachers felt as if they were able to connect to their students in both district sizes, Vicki was honest and pointed out that the depth of the relationship was different. She said, "I feel like you can't build those relationships as much as you could with those 16 [in the small district]."

Looking Back. Many of the participants talked about how much they had enjoyed their time in the small district and would not change having that experience. Vicki shared her time in the small district, "was more enjoyable." Annabelle talked about wanting to stay late to do things in the small district, but she leaves as soon as she can in the larger district because it was fun in the small district. Mac said: 
I've had a very varied career. But I wouldn't trade that for anything. I think I have learned great things each place I've been, whether it's a positive or a negative thing. I've learned what I'm good at and what my strengths are, and I've learned what I'm not good at and what I should not be doing.

Summary. It is clear there are significant differences between small and larger districts. The demographics of the communities are reflected in the schools with the larger districts being much more diverse. The resources available in the larger districts seem more plentiful, especially in the areas of purchased curriculum and technology. Professional development seemed to allow more freedom and specificity in the small districts when money was available. However, there seemed to be more in-district PD brought into the larger districts. Workload was an extensive area with differences. Yet, secondary teachers reported a larger disparity than the elementary teachers. Overall, most of the participants look back fondly on their time in the small districts when reflecting on the differences between the two, and several feel as if their time in the small district was more enjoyable.

\section{Research Question Four: What Do Teachers Perceive to be the Similarities Between Rural Districts and Larger School Districts?}

When asked about the similarities between the different size districts in which the research participants worked, they did not have as much to say as they did about the differences. The answers were not as consistent and seemed to be very specific to the participant. For example, Mia's opinion was:

To me, success of the school, the success of people, the success of teachers, the success of administrators doesn't matter as much the size of the school as it does 
the culture of the environment...I think it's just all of that community piece. I think the reason why I've liked the smaller schools in the big districts is because it's had a very unique community, either just being a unique neighborhood or a unique school in general that's different than the surrounding ones. And then being in a rural school, just the entire community is just always rallying around the school for events and support, and that sort of thing.

She had the experience that it was more about the school building itself rather than the district. Mia and Becky both had experiences working in smaller schools within larger districts due to the programming of that school. This allowed them to make the connection that it was not so much the district as it was the actual school.

When analyzing the data, teachers, in general, reflected on the similarities of the workload in some cases but seemed to focus in more on the professional development and instructional practice side of the work. They also discussed community, student, and adult relationships. The final two aspects discussed by participants were administration and resources.

General Workload. Regarding the workload overall, three elementary teachers talked about the idea that the workload was about the same. Mia shared:

I mean, I have 50 kids right now, and I'm not one to equate... I don't think your workload necessarily gets bigger just because you have more kids...I still have to plan small groups, and my small group might have six instead of four. But I'm still prepping and planning the same amount. 
Whitney concurred when she said, "I would say the workload was pretty similar." Vicki shared a bit more about her workload remaining balanced, but the amount of time spent on different tasks had changed:

I have to prep more. I didn't have to grade as much, but now I have less prep and I have to grade more. It's balanced out pretty well, but... The first semester [at the rural school], I put more hours in. I think that was really due to the fact that I was a new teacher. I wanted everything to be perfect and ready to go. This year though, [in the larger district], I will put in a few minutes here and there, but I'm not going to stay hours on end because that's just not good for me. It wouldn't be that I had to. It would be because I wanted to.

These are the only three participants that stated their workload was similar.

Professional Development. When asked about professional development (PD), more participants shared similarities between the different sized districts. Ken shared, "during the year, it was about the same. I've always tried to go to Interface [a conference]." He discussed that in both districts he had been able to attend the conference that would be most beneficial to him. Hannah also talked about being able to attend professional development conferences. She said both districts wanted to "make sure people were trained." The only difference with this was that in the larger district "we have to put in our conferences the year before, but in the small district, we could say, 'I heard about this in a couple months. Can I go?"”

Participants also discussed the typical PD teachers attend at the beginning of the school year as well as district provided PD throughout the year. Albie was very vocal about his disdain for PD. In fact, he said, "We have a ton of PD. Two of my, no offense 
to the administrators out there, two of my least favorite letters are PD. I think sometimes we over PD.” He then went on to talk about how in both sizes of schools: so much of the stuff that you go through is a lot of sit and get... and we do it here too, so much sitting and getting goes completely against the way we want our kids to be taught. Yet we're coming in and trying to teach our teachers the way that we don't wanna teach our kids. You know what I mean? We don't want... They said have your kids active, have them involved, have them doing something, have them being hands-on. But for professional development, a day you're gonna come in here and sit for three hours and we're gonna have somebody come talk to you, and now you're gonna take notes and we're gonna break for lunch...

Ben also said PD was similar in that every year he must watch the same training videos no matter the size of the district. He talked about how when he first started teaching in the small school, they sat in a room together and watched them on a VHS tape, but now they watch them on their own. He said:

I just let them run now, and when they're done, then I put complete and go on. I can pass the quiz. After 15 years of teaching, I'd better be able to pass a quiz about FERPA [Family Educational Rights and Privacy Act] and all that stuff. Overall, it seems as if there are some similarities between the small and larger districts as they both must provide the mandated trainings, both provide professional development opportunities through the year in-house, and both provide opportunities for teachers to attend conferences.

Instructional Practices. When it comes to instruction and how instruction is delivered to students, there were some similarities reported. Cassie talked about both 
sizes of districts using data to make instructional decisions. However, the way the data was reported was different. The way she planned was very similar because I have always been a planner. I plan far out and make sure I have things that are stretching the lessons in case students get done early. So, I didn't really have to change much with my planning [in the larger district].

Vicki also talked about instructional practices. She stated that both districts do reading and writing workshops, but in the larger district, time mattered more. She said she learned the workshop model during student teaching, implemented it at the small district, and when she got to the larger district, they wanted to tighten up her delivery and keep to the recommended times for the mini-lessons.

Mia was the final participant who discussed instructional practice similarities. She looked at it from the viewpoint that while the small district was more traditional and the larger district was more innovative, "good teaching is good teaching," and both districts worked toward this.

Relationships. Relationships are important in both types of districts. Participants discussed the similarities in support and positive relationships, but this was shaded by comments to the effect that it was not quite the same. For example, Hannah talked about the support of the PTO in both districts. In the small district, there were many people in attendance at meetings, as it was often combined with a family night. In the larger district, she said, "our PTO is great, but there's not really a ton of people...for the size of the district, there's not a ton of parents that are in the PTO. They are supportive of us whenever we need something." 
Kelsey is a teacher currently teaching in a small school in a larger district. She said that she feels as if there are more similarities between the small district and where I am now because of the mentoring piece and because we started off smaller. The first year I was at this school, I knew every kid in the building even if I didn't have them in class, and the same thing would have been for the small district. I knew all the kids. Even if I wasn't teaching you, I knew your name. At the small district, a kid could start math in eighth grade with me and still be taking me as a math teacher as a 12thgrader. Similarly here, as we grow it changes a little bit, but that first group that we had as we go through, I had them, and I had them [again]... so you get to know your kids better I think with those smaller environments. You know all the different ins and outs to the pieces. As we grow, that goes away.

This student teacher relationship was also commented on by Cassie. She said:

I feel like I attempted to do what was best for the students, like wanting to see that student growth. The districts are both very low in scoring, like math scoring and that kind of stuff. So there are lots of ways to encourage students and dig for data. She continued to say the other similarity for her is that the small district became home for her and the larger district she moved to was already her home as she lived in that community.

When it came to relationships with staff, again, Kelsey discussed how being in a small school in a larger district reminded her of working in the small district. She found it easy to get to know everyone. Annabelle mentioned that in both districts she had a 
mentor assigned to her, and Sabrina talked about being familiar with the larger district made it easy to build and maintain relationships when she moved there. She shared it was a district that I was familiar with; it still felt pretty comfortable. I ended up walking into a team of teachers [in the larger district], where I knew them already. My teammate, actually my first year teaching [in the larger district], the girl across the hallway from me was one of my best friends, so that was amazing. And then my true content area teammate was a former teacher of mine, which was really fun, so that was really enjoyable to come back and work with her.

Again, these are the only participants that talked about the similarities between the sizes of districts regarding relationships.

Administration. Administration was described as similar by some participants. Those who felt strongly that their administration worked in a similar manner, such as Sabrina, Daniel, Mac, and Kelsey shared that they had positive experiences in both sizes of districts. Mac did mention that in one of the larger districts, he did not have a positive experience with the administrator, but in the other larger districts, he did.

Sabrina has only worked for two administrators. She said:

Both of those men were super supportive. If I ever had an issue with the kids, they would take care of it and honestly that was pretty few and far between... I really can't even think of a time where I really needed admin intervention. They were always really good with helping me with parents. As a teacher, I just always felt like I had a lot of support, but really, both of them were fabulous, both of them evaluation-wise were very similar. They would be in my classroom and which is positive, but were by no means trying to micromanage me. One of my 
administrator's quotes is, "I hire good people, and I get out of their way." And I think that's important and I think that's something I try to do now as a leader. Kelsey's administrators were similar to Sabrina's. Kelsey shared:

I don't think it's everywhere in the larger district, but the principals that I've always worked for believe that they hire the people to do a job, and they don't micromanage, "You are the expert in your classroom. I want you to bring your knowledge in. No, I'm not going to let you do something that's not best for kids," but they really have trust in their teachers. So, I think that's everywhere that I've taught. I call it a relaxed atmosphere. They are pulled back, but any time I've talked to one of the principals about it, it has been a matter of, "We trust our teachers. I hired you to do a good job. If you're not, then I'll be in there talking to you about why you're not doing the job I hired you for, but I hired you for this job, and I trust you.

Resources. Only two participants felt as if there were similarities when it came to resources. Molly is a business teacher and discussed that in both the small and larger districts that she was able to apply for and receive an Enhancement Grant from DESE. She said the district paid for $25 \%$ of what was requested in the grant and the state paid for the remaining $75 \%$. This allowed her to have upgraded computers, furniture, and other technology on a regular basis.

Annabelle also talked about the resources, but in her case, she discussed the classroom budgets provided by the school district and the PTO. She shared: 
In the small district, the PTA gave us 100 bucks, and then the school gave me 200 bucks. In the larger district, we get 150 and my program now though, we have our own budget, which is $\$ 5,000$, and so, I don't have to buy my own stuff anymore. She continued to explain that if she did not work in the gifted program, she would have only had access to the supply closet in the district and her allotted classroom budget, but in the small district, there was not a supply closet.

Annabelle also continued with the idea that even though the paycheck she received in the larger district was more money than the small district, it does not feel like she was getting ahead. She stated:

I'm still living paycheck to paycheck because expenses are more. I think I can do more things, so I just equalized it. I don't know, it's hard to save even though I'm making a lot more. I'm like, well I bought more stuff because now I make more. That's just me being a poor financial person. So, I still live paycheck to paycheck, but that's my own fault because I buy a lot on Amazon.

Summary. When it comes to the similarities between the small and larger districts, participants did not have as much to share as they did with the differences. Some participants discussed similarities with the overall workload, professional development, and instructional practices. Relationships with the community, students, and adults were mentioned, as were administration and resources. When considering the number of participants in this study, saturation was not reached to draw inferences as to if these really are similar between small and larger districts. However, for the participants who shared their experiences, these similarities were accurate to the best of their recollection and were specific to them. 


\section{Research Question Five: How Do These Teachers View Their Decision to Leave a Rural School District For a Larger District?}

Most of the teachers interviewed for this study view their decision to leave the small, rural school district for a larger district favorably. Multiple teachers stated the move was inevitable and they would not have remained their whole career in a small, rural district and the majority of them voiced they had no regrets about their decision. However, they point out specific items they miss. There were statements made about their wishes and dreams, including aspects of the rural school they wish would be at the larger schools. Evidence of their views will be presented below, as will the statements of those participants who do regret their choice to leave the small district.

Inevitability. Multiple participants said the move to a larger district was inevitable. The idea that the move was inevitable has been discussed in the answer to research question one, why do teachers leave the small rural school district to teach in a larger school district. Sabrina, Leann, Cody, and Hannah all discussed they had a goal to work in the larger district for a variety of reasons. Cody talked about teachers wanting to work in their hometowns and needed other experience first when he said:

it happens at smaller schools. That's the only place some teachers can get their first experience, and then they go to bigger schools to try to make more money, or they get a job anywhere. Get experience for a couple years and then they try to go

back home. That's what a lot of them want to do is go back home eventually. Like I ended up. Of course, it took me 13 years to get back here. 
Cody talked about having friends he grew up with and went to college with whom he has always wanted to work and coach. He knew he wanted his kids to grow up with his friend's kid in the same district they did.

Positive Decision. Most of the participants viewed their decision to leave the small district positively. They often answered the direct question, "do you have regrets about your decision to move to a larger district?" with a simple, "no." Twelve of the participants then expanded their answers when prompted. When Kelsey answered that she had no regrets, it was evident through her vocal inflection that she loved where she was and what she was doing with her current job that the researcher commented on it. She spoke about how she misses the opportunity to teach her nephews, but, "I love what I'm doing now and would make the decision again." As she reflected more on her career path, she said,

I wouldn't have changed any of my decisions though. I think that everywhere I've taught has helped me be a little bit more of the teacher that I am now. To be honest, I don't know if I hadn't moved to the small district if I would have gotten my ed specialist. So, I think it just has helped me to get to where I am, but I love what I do. I often think about the fact that if I was still at the small district, if I had gone to my principal and said, "Can I try this project-based learning?" I think he would have absolutely said yes. I think I could have been just as happy doing it there. I didn't have the resources, though, and I think that that's what makes the differences, the resources.

When asked to expand his answer as to if he regretted the decision to move to the larger district, Mac said, 
No. I really don't. I feel that this is one of those hindsight is $20 / 20$, or whatever they say, that every part of my career has played its role in getting me to a place where I feel comfortable currently. I got my special ed certification that allowed me to get a job in the larger school district, which allowed me to slide into the position that I'm in now. My couple of years in the larger district [he didn't like] gave me familiarity with string instruments... And this is one of the strange things about my current larger district, the orchestra director is actually the assistant high school band director as well, so in addition to teaching orchestra most of the day, I spend first hour as the assistant marching band director. And so my time in one of the smaller districts and a larger district as a marching band director gave me great skills with that. Anyway, no, I don't have any regrets. I think it's been very tough at times, but I think it's been a good sequence of events.

Mia's response to this question was also worth noting. She shared:

I think it's been a good move. I think it opened my eyes to different cultures, different teaching practices, different teaching methods. I know that I would not have access to some of the resources that I have access to now, had I stayed in the small district. And also just networking and professional development opportunities, I feel like I have a lot more at [the larger districts than at the small district] just because it seems like they have more funding to provide professional opportunities that I wanted to attend or go to.

Albie was very expressive when it came to his answer as to whether or not he had regrets: I have no regrets. I love this place, I love the other places I was at, but one of the big things that helps me here is the freedom. Here as soon as softball season is 
over, I'm out the door, I'm picking up my kids from school and we're going to the Y, we're going to the park, we're gonna hang out. At the small school, whatever I'm coaching in the fall would get done, which was in football, then I got into basketball, by time basketball season gets done, I'm just so dead tired, worn out. [At the end of the school day, I pick my kids up and] it's like we're going home 'cause I need to nap. I love this place. I miss the people at the small school, I really do. I still talk to some of them on a regular basis on Facebook, text messages, emails, and stuff. I miss the people I worked with that, yeah, I have zero regrets about making that call. 'cause it was the best thing for my family. Molly's decision to move was due to her divorce. She also said she had no regrets. She shared, "Had that not happened, I was fine teaching there. It was just the small town politics and all that." Brandi had no regrets, but she said, "it took a little while." She said she thinks where she is now is "a really good fit. I am very happy with it here.” In Brandi's situation, she had left teaching and, when she wanted to come back, there was no position available at the small school. She shared,

I also am glad that the small district didn't have that position open because I think that this has helped me to grow and stretch a little bit as a teacher and not fall back on a crutch. Again, I know a lot of people that are there. So, it would've just been like right back into what I was used to. But with that would come all the same problems that we all complained about five years ago. So I do feel like this is a good fit, and I'm glad I'm here. 
Regrets. Only two participants shared they had regrets about leaving the small district. Whitney shared,

I do regret leaving, I really had a great experience in the small district at the middle school, and I regret leaving for more money. It seems to be my primary reason for leaving, more money. I do regret that in some ways because I know that I would be much happier there. And then in other ways I also know that I'm trying to set up my... it's all money. It's all going around money because I'm also trying to set up my retirement.

Daniel's regrets are a bit different. It is important to note he left the small district after not having a good experience with a new administrator after he had worked for what he viewed as an amazing principal. He shared he likely would have stayed had the new administrator worked similar to his former administrator. When asked about whether he had regrets about leaving the small district, he shared:

I dealt with that [regrets] for a little while, and she [his wife] would have to remind me. It wasn't those first couple of years as opposed that last year, and so I kinda struggled with it [regrets], but it wasn't really the same that last year... when I think back now, it was good with who was there, but who was there isn't there now. And so it wouldn't be the same. I guess I'm more comfortable with it now, leaving it like I did, but the small district was home. I could have seen myself being there for really the entire 32 years of education, whether it was as a principal or not, or teaching, I could have stayed there probably forever because I like the kids in the community so much. So I guess I still think about that sometimes. But, I've had to tell myself that I'm passionate about education. I'm 
just passionate about making changes in education that are needed, but not every place is ready for that. And that was a hard pill to swallow. I can come in here with a million ideas how I feel like things could be better, but they're still gonna be hard for people that do not want to change.

Daniel continues to think about his decision to leave the small rural school district even years after leaving. He talked at length about his wife supporting him and reminding him that his decision was for the best. Daniel tells himself that even though the kids in the small district needed him as well as other passionate teachers, that the kids in the larger districts in which he has worked also need passionate teachers, and he can make an impact there as well.

Looking Back. Participants were asked their thoughts about their decision to leave the small rural district. Framing the question with the idea that hindsight is 20/20, participants shared there are things they miss, but there are also things they do not miss. Kelsey shared that even though she now teaches in a larger district, she and her husband made the choice to move to a larger, but not overly large district in which to purchase their home. She stated, "We moved them to a smaller district [that still meets this study's definition of larger district] just because they were coming from a small rural district. We decided that moving them to a very large district would probably disrupt them even more than we already were."

Ken shared his move was a "quality of life thing. I wouldn't still be teaching. There's no way I would've kept that up. The people that are there and have made careers ... I just can't imagine how they do it. I don't have the juice.” He went on to say; 
Once you do learn to cope with that level of crap that comes from being at a small district and having six preps your first year, well, [you can do anything]. It's kind of like, I look back on my time at one job with great fondness just because all of those kids were awesome. Some of them were awful, but they were all fun in one way or another. And even the bad stories, the "bad stories" where I've got a kid trying to beat me up. I had a 12-year-old make a shank and try to stick me with it, that kind of stuff. You get to the point where even that is kind of a fond memory. So you'll look back at the small district and think, "Okay, so I was at school until seven most nights trying to figure out what I was doing." I had no idea how to teach chemistry and I was tasked with teaching chemistry and that kind of stuff. But once you get through that, or you at least learn to deal with that, the rest of it was so much fun because you saw everybody all the time, because there was only nine adults. You know what I mean? And so yeah, I absolutely enjoyed it.

That being said, Ken was very vocal that he would not consider going back to the small rural district unless the pay was much greater than it was when he was there.

When asked if they would consider leaving the larger district environment, many of the participants said they would not go back to the smaller school. Reasons included pay, workload, commute, and opportunities. Much of this has been discussed in the other research question answers. What is interesting is that Whitney stated the following when asked what advice she would give teachers considering making the move from small to larger districts:

My head probably would say don't go, don't go, just stay. I would be like, happiness is more important now. I think I would just maybe share with them my 
list of pros and cons. I would probably mention what I've noticed with the levels of support. Of course the money. I've done quite a bit of reflection, and really the money is one of the only pros that I have found. So, it's probably what I would share with them. Well, and I shouldn't say only, being here in a larger district, one of the other perks that I have noticed is of course they do have a lot more money to work with, and there are some pretty cool opportunities that they could provide students and staff with curricular type opportunities.

On the other hand, Ken, Albie, Hannah, and Whitney all said they would consider going back. In fact, all but Whitney said if the money were right, they would go back. Hannah said she would never have gone to the larger district had the pay been at least the same. Albie would like to go back as an administrator in a small school at some point, and Ken said he would teach again at a small school if the pay were similar to what he currently makes. Only Whitney talked about the fact that she really wants to go back to a small district even though she knows she will take a pay cut:

At this point, where I'm at right now, I am actually considering going back to a small rural district now that I have experienced big. I'm not sure what I'm going to do. I kind of want to try out another building or two, within the district that I'm at, just to kind of get a feel. Then if I still have the same feelings, I'm thinking about going back to the small rural community. I miss it. I'm willing to take a cut in pay to do that. I know I'll have to, there's no way out.

Finally, Albie and Sabrina both shared that location was key. Albie's words were, "if I could take that building with those kids, the staff, the teachers, the administration, 
and I picked it up and stuck it about five miles from my house, I never would have left." Sabrina stated something similar when she shared:

I think when I left, I remember telling my boss, "If you could just move the small school to the larger district, I would stay, and that was the truth, there was nothing that I dislike about that experience...[my reason for leaving was] coming back to my hometown, my family's here, [even though it was] the best experience teaching I've ever had.

Summary. For the most part, teachers think they made the right decision to leave the small rural school district and cited reasons such as pay, workload, administration support, and reasons that were inevitable. Only two participants had regrets about their decision, with only one participant actively considering making a move back to a rural school knowing it would mean a pay cut.

\section{Research Question Six: What Motivation and Hygiene Factors Do Teachers Reference When They Discuss Their Experience in a Rural School District?}

The lens through which this study was viewed was Herzberg's (1966) motivation/hygiene theory. Data revealed participants referenced both motivation factors as well as hygiene factors. As discussed in the theoretical framework section of this dissertation, the motivation factors "stand out as strong determiners of job satisfaction" (Herzberg, 1966, p. 72). These include "achievement, recognition, work itself, responsibility and advancement - the last three being of greater importance for lasting change of attitude" (Herzberg, 1966, p. 72-73). The hygiene factors, which are connected to the context of doing the job, include "company policy and administration, supervision, salary, interpersonal relations, and working conditions” (Herzberg, 1966, p. 72). 
Summarized in Table 4 are the motivation factors referenced by participants when they discussed their experience in a rural school district. All factors were referenced by participants except for the motivation factor of recognition. While some participants used the word recognition, they were talking about students being recognized for their achievements rather than referencing recognition of their work.

Table 4

Motivation and Hygiene Factors Referenced by Participants

\begin{tabular}{|c|c|c|}
\hline Factor & Type of Factor & Referenced by Participants \\
\hline Achievement & Motivation & Yes \\
\hline Recognition & Motivation & No \\
\hline Work Itself ${ }^{a}$ & Motivation & Yes \\
\hline Responsibility & Motivation & Yes \\
\hline Advancement & Motivation & Yes \\
\hline $\begin{array}{l}\text { Company Policy and } \\
\text { Administration }^{\mathrm{a}}\end{array}$ & Hygiene & Yes \\
\hline Supervision & Hygiene & Yes \\
\hline Salary ${ }^{\mathrm{a}}$ & Hygiene & Yes \\
\hline Interpersonal Relations & Hygiene & Yes \\
\hline Working Conditions ${ }^{\mathrm{a}}$ & Hygiene & Yes \\
\hline
\end{tabular}

${ }^{a}$ Most commonly referenced factors.

One of the most referenced motivation factors was the work itself. Teachers talked about the actual work of teaching. When asked about the similarities and differences between the two sizes of districts, participants talked about planning lessons, teaching students, grading, and extra duties. Teachers discussed committee work, professional development, and meeting with parents both in and out of the building. These references corroborate the researcher's assumption that much of the work of teaching is similar without regard to district size. Mia's statement that "good teaching is good teaching," sums this up. To take it one step further, participants spoke very favorably about the work of being a teacher. 
Participants also referenced the other motivation factors, but not as often. Achievement and advancement were referenced when participants talked about earning advanced degrees, moving on to administrative or curriculum jobs, and the idea that there were not always ways to move up their career ladder in the small districts. Both Greg and Daniel discussed leaving the small districts to pursue principal positions before deciding they wanted to go back to teaching. Kendra talked about her desire to become an instructional coach, and that was not an option in the small district. She also explained her ability to try new things in both the small and large districts, and this was one way responsibility was referenced. The participants took the responsibility of planning and creating high quality educational experiences for their students very seriously and referred to this very positively. Sabrina talked about working in the large district to enhance lessons and "create great lessons for your kids." In the small districts, Leann and Cody talked about taking time to ensure students had what they needed as far as instruction. Leann created most of her own teaching materials, and Cody worked hard to move his students through the provided texts. Overall, whether in the small or large districts, teachers referred positively to the motivation factors. This researcher concludes that from this, based on Herzberg's (1966) motivation-hygiene theory that the participants like their jobs and what they do.

Hygiene factors, or the working conditions, were also referenced frequently by participants with salary, working conditions, and administration and policy being the most mentioned. Salary was overwhelmingly cited as the reason teachers migrated from small rural districts to larger districts. "It was money, just an increase in pay," as Whitney said it very directly. Albie said the financial gain moving to a larger district just down the 
road was "unreal." Participants, at times, did not seem to like to admit what a powerful factor money was in their decision to leave their small districts. Ken's sentiment, "if I had made enough money, I could've tried [to stay]," was not explicitly stated by the other participants, but was inferred from their body language, tone of voice, and the context surrounding their statements.

Working conditions have been equated by the researcher with one dominant theme from the data, which is workload. Teachers, specifically at the secondary level, talked at length about the incredible amount of work and how the load was so much less in the larger district. Mac was overwhelmed with the workload involved with being a K12 music teacher. He wanted to teach, and he wanted to teach music, but what was expected of him was too much, and he knew by February of his first year it was time to move on. It was also not uncommon for teachers to talk about the number of preps they had in the small district as opposed to the larger districts. In the small districts, the highest number of preps referenced was 12 in one year, and this was by Leann. In the large districts, one prep was the lowest number referenced. It was more common for the teachers to have more than four preps during a semester than it was in the larger districts. In the larger districts, it was not uncommon for teachers to have only one or two preps during the semester. Additionally, a level of dissatisfaction was noted as the teachers talked about the extra duties in the small districts and how these were not necessarily optional, but expected. This expectation was not noted in the larger districts.

Company Policy and Administration was a factor that caused the teachers to be dissatisfied when it was bad. Teachers who reported either Board Policy, the school board, or their administrators were not a positive factor, cited it as a reason they left the 
rural districts. Cody talked about a change in the school board being a precipitating factor to his decision to move to a larger district. Teachers who felt that their administration was positive, discussed not wanting to leave, but felt they had to for other factors. Annabelle and Daniel both had amazing principals in their small districts and did not leave until those administrators left first. Sara also had a great experience with her administrator in the small district, but felt compelled to leave for other reasons. She wanted to work with other administrators and move closer to her friends in the city.

The final two factors, supervision and interpersonal relationships were mentioned by participants, but not as often. Supervision was often referenced at the same time as company policy and administration. However, more specifically, participants talked about how they were supervised and managed instead of the administrator as a person. Leann talked about her administrator not observing her but once in the small district and he did not give her feedback. Several participants talked about how often administrators were in their rooms and whether or not they were micromanaged. There was no pattern to participants being dissatisfied or not dissatisfied based on supervision when it came to district size. However, there was a pattern based on district size in how participants spoke about interpersonal relationships. In the small districts, participants mostly talked about the close-knit community and the support they had from their colleagues. While they had this in the large districts, it was not quite the same, and it took longer to build those relationships. There was only one participant that chose to leave the small district based on a toxic relationship, and that was Vicki. She wanted to stay, but did not feel she could cope any longer working with her partner teacher. For most of the participants, the interpersonal relationships were difficult to walk away from when they left. 
Based on Herzberg's (1966) work, we know that individuals can be both satisfied and dissatisfied at the same time. Maidani (1991) went so far as to say public sector employees stay in a job longer while dissatisfied because they like the work they do and will put up with dissatisfaction in the areas of the hygiene factors. Dissatisfaction in the area of hygiene factors is a significant reason why people leave jobs (Herzberg, 1966; Maidani, 1991). Through the analysis of this study's data, it is clear that teachers left their positions in small rural districts to teach in a larger district due to dissatisfaction with the hygiene factors surrounding their job. What is not clear is if they stayed longer as a whole as public sector employees as no participants were interviewed who worked in public schools.

\section{Discussion}

\section{Why Teachers Leave Small, Rural School Districts}

One of the goals of this study was to determine if what has been reported in the literature about rural school districts and larger school districts is the same when purposefully finding participants who have taught in a small school district and then migrated to a larger school district to continue their career. Looking through the lens of Herzberg's (1966) motivation-hygiene theory to take into consideration job satisfaction, and the idea that an individual may be both satisfied and dissatisfied with their job at the same time, it was found that teachers are satisfied with the motivation factors of their job in small school districts while citing hygiene factors as the primary reasons for making the decision to migrate to a larger school district. Teachers reference aspects of their job that fall into Herzberg's (1966) motivation factors as what they often liked about their job. Specifically, teachers referenced the work of teaching students in the classroom, 
building meaningful relationships, and making a difference in the lives of students as reasons they loved, not just liked, their time in a small school district. Conversely, teachers referenced aspects of their job that fall into Herzberg's (1966) hygiene factors as to why they chose to leave the small district and opted for a larger district. On this topic, they specifically referenced extrinsic aspects of their jobs such as monetary compensation, administration and policy, and working conditions including overall workload and extra duties.

Financial Compensation. Teachers leave small, rural districts primarily due to financial reasons. The amount of a raise teachers report varies from less than $\$ 1,000$ to over $\$ 15,000$, depending on the teacher's experience and the district to which they are moving. However, teachers report that when looking at long term financial considerations, the larger districts tend to have a larger increase in pay for additional college credit hours and degrees, as well as paying coaches and sponsors more.

Workload. Teachers also leave small school districts due to the overwhelming workload. While more elementary teachers will talk about the workload being similar or somewhat more in the small districts, the consensus of secondary teachers, as well as K12 music teachers, is that there is a disparity in workload based on the size of the district. The workload was noted to be significantly less in the larger districts. This, combined with having coworkers who teach not only the same grade level students, but also the same content, was cited as a benefit of working in a larger district. Teachers in small school districts, who teach at the secondary level or K-12, noted they do not need to work after contract hours often unless they choose to do so. Whereas, in the small school 
district, it was the norm to work several additional hours each day just to not fall too far behind.

Teachers have the same amount of time protected by the rules that govern school districts per week no matter how many preps they have each day. Teachers in small districts with up to six preps a day do not have enough time during their planning period to adequately prepare lessons, collaborate with other teachers, grade papers, contact parents, and attend student meetings. This conversely compares to their experiences in the larger districts where they often have time to collaborate with other teachers, share planning duties, look for new and exciting ways to engage their students, and still have time to complete grading, contact parents, and attend students meetings. Several of the teachers in this study also commented that they are able to take breaks during their plan time and do things that may not even be related to the courses they teach without the worry they will have to stay late to complete work they did not do.

Teachers in small districts do often have smaller class sizes, which can mean less grading. However, this does not balance out with the larger number of preps to contend with daily. Teachers report that even with a longer commute of more than an hour each way that their day is still shorter in the larger district than in the small district because they are able to get most, if not all, their work done during their contract hours.

Administration and Support. Administrator and peer support were reported as reasons teachers chose to leave a small district; however, this is not a universal reason. Teachers felt very strongly about the administrators for whom they worked, as well as their peers. The feelings were either overwhelmingly positive or overwhelmingly negative. When an administrator was described as incompetent, not supportive, or just 
bad, teachers tend to find a job in a larger district more quickly. Those teachers who had positive experiences with administrators, stayed longer and agonized a bit more over their decision to leave. These teachers cited other reasons as the ultimate reason for leaving and wanted to be clear it was not due to the leadership in the small district. Additionally, teachers also reported both positive and negative administrators in larger districts. Rather than choosing to leave in those situations, they reported they do not see their administrators as much in the larger districts, and they are able to rely more on their colleagues who teach the same grade and content they do.

While relationships with administration and good leadership are important, it does not seem to be specific to school districts based on their school size. However, a negative experience with administration in a small district can cause the district to lose a teacher faster than in the larger district, as teachers do not often have a wide variety of colleagues to choose from to get the support they need to grow as a professional.

Other Causes for Migration. Even if small school districts were to address all of the above, there are reasons teachers choose to leave that cannot be mitigated by the small district. Teachers leave the small rural district to move closer to home. It is not uncommon for a teacher to take the first job opportunity available to them once they graduate from college and then teach in the small district until they find a job in a district closer to their hometown. This is true not just for teachers who migrate to larger school districts, but teachers report leaving one small school district to teach in another small district closer to their hometown before finally getting the job in the larger school district. Family, friends, and the social life available in the cities are a draw for these teachers who have moved far enough from their social network that it is a journey to visit friends 
and family. While a small district cannot fix this, school leaders can work to incorporate these transplant teachers not just into the school, but into community life as well. Teachers who experienced this reported staying in the small district longer than those who reported feeling like an outsider. However, ultimately, they knew when they started teaching in a small district that it was inevitable they would move to a larger district.

Finally, teachers report a lack of opportunity for advancement in the small school districts and leave to pursue career opportunities such as instructional coaching, administration, and teacher leadership such as department chair, that are not available in the small district. Teachers who want to become a principal may have the opportunity to move into that role in the small district, but there is often only one administrator per building, and if the timing and fit are not right, they must move to another district for this type of positions. This is similar to roles such as instructional coaching and department chairs. Small districts often do not employ these positions, and teachers must move to a larger district for this type of role. There are roles for teacher leaders in small districts, and these are often as part of an advisory team or committee work, and are often not compensated.

\section{Teachers Reflections on Teaching in a Small, Rural School District}

For the most part, teachers look back on their experience teaching in a small, rural school district with fondness. There are aspects of working in the small town that are not replicated in the larger districts and are often missed by teachers after they have moved on to a larger district. Community support and engagement is greater in the small districts than in the larger districts. School events are community events and the community shows up whether or not they have a student in the school. The support of the community 
at sporting events, school concerts, and fundraisers is something unique to the small districts and teachers miss this in the larger districts. Teachers created positive relationships not only with their students, but they knew all the students in their building and often in the district if they had been their long enough.

When the support received was positive, teachers credited the nature of the small district, the closeness of the staff, and the goal of administration to do what is best for students. In the small districts, teachers learned to rely on other teachers who did not necessarily teach the same grade or content to discuss instructional strategies, lesson activities, and student growth. They noted they had people in the larger districts that did teach the same classes and it was easier to bounce ideas off one another, but they learned more about collaboration in the small districts due to necessity.

Teachers also remembered the negative experiences they had as well as the challenges they experienced in the small districts. While not cited as a reason for leaving the small districts, there is a disparity in instructional materials, technology, and general resources and materials in the small districts when compared to the larger districts. Teachers often had to create their own instructional material in the small district as opposed to having things like current textbooks, the teacher materials to accompany the text, and other instructional resources in the larger districts. Technology, such as interactive whiteboards, student computers in the classroom, subscriptions to instructional programs, and the training to go along with these are more prevalent in the larger districts.

Teachers also reflected on the intense workload and, when applicable, negative experiences with administration and school boards in the small district. A negative 
experience with administration can overshadow any of the positive experiences in the small district. Teachers who reported a great disdain for either the administrator, the school board, or the actions of these people tend to not look back as favorably on the rest of their experience in the small district. However, they still highlight the community and peer relationships built in the small district.

Teachers who have the experience teaching in a small school district recommend others take on this challenge. Even when they had a negative experience, they still suggest new teachers have this experience. Teaching in a small district allows teachers the ability to grow in their craft, learn more about themselves as both a person and a teacher, and balance a great many responsibilities with limited resources. Teachers say they are better teachers for their experience in the small school and they left prepared for anything.

\section{Similarities and Differences}

Teachers who have taught in both small and large districts reported there are many similarities and differences based on school size. It does not seem to be dependent on district size for teachers to care about their students, to want their students to learn and be successful, for teachers to have strong relationships among their colleagues, and for teachers to feel supported.

On the other hand, there are definite differences between small and larger districts. According to teachers, the larger districts have more instructional resources and expect all teachers who teach the same grade and content to be at the same place at the same time, especially at the elementary level. Multiple teachers reported that at times it feels very scripted and robotic how they are expected to deliver content to students. This 
is not the same in the small districts where teachers report being able to be flexible with pacing as needed to do what is best for their students, and they are encouraged to be creative with both the materials chosen for class activities and instruction.

Professional development is another area that seems to be dependent both on district size and financial resources of the district. Larger school districts tend to bring in a speaker or send a small group of teachers to conferences expecting them to present to the rest of the team. Small districts tend to provide more individualized professional development opportunities based on the financial resources available. Teachers have more opportunities to attend content specific conferences of their choosing in the small districts, unless the money allocated for the year has been used. Teachers also report demographics of the district are dependent on district size. They also feel as if there are fewer discipline issues in the small district, although they are unsure if it is a similar percentage in the larger district or not.

\section{Recommendations}

Now that we have the data from this study, it is important it be shared, and school leaders in small, rural school districts use it for the purposes of improvement.

\section{Recruitment, Hiring, Orientation, and Induction}

Small, rural school leaders may want to consider adjusting their practices in the area of recruitment, hiring, orientation, and induction. This begins long before there is an opening in the building by building relationships with teacher education programs in the region. Building this relationship and encouraging teacher education programs to allow rural school leaders to participate on panels discussing the positive nature of working in a small district, as well seeking out preservice teachers to complete observation hours and 
student teaching in the small district, will allow more preservice teachers to get their feet wet in the small district and hopefully see the many benefits of working in this environment.

Small school district leaders should also consider reviewing their interview protocol to ensure they are asking the right questions to determine if a candidate is a good fit not only for their district and team, but for small schools in general. Gaining information about an applicant's background and experience without asking those questions that are both inappropriate and illegal in interviews can be an art. However, the information may make the difference between hiring a candidate who seems to be a good fit and needs little coaching over one who may also be a good fit, needs a bit more coaching, but in the long run will stay longer in the district. This is worth strong consideration as student achievement can suffer with teacher turnover (AEE, 2008).

Orientation and induction are also areas that are worth reviewing. Teachers who are connected to mentors, their teaching team, administration, and the community are more likely to register this hygiene factor as positive rather than negative. Teachers who feel like they are successful and connected are more likely to stay in a small district, or at least strongly question if it is time to migrate to a larger district. By supporting teachers, it is conceivable a small district could hold on to a teacher for a bit longer than if they were not supported.

\section{Administration}

It is not enough for small, rural districts to hire and work to retain high quality teachers, but it is essential they work to hire and retain high quality school and district leaders. The findings are clear in that when teachers felt they worked for a good 
administrator they stayed longer, or at least considered staying. When the administrator was not perceived as good, teachers tried to leave as quickly as they could.

Administrators in small, rural districts should have an understanding of what it means to teach in this environment. They should pursue professional development to help them support their teachers and students in this environment in addition to the many professional development opportunities they need to manage all aspects of their position.

\section{Financial Compensation}

Unfortunately, it does seem to come down to money. Small school districts should strongly consider working to move their salary schedule to be closer in line to those districts to which they often lose teachers. While it may not be possible to pay the same as larger districts, school districts should consider the potential cost to the district in the areas of finances, time, and student achievement of not working to adjust the salary schedule. At the very least, districts should look at the salary schedules of neighboring small districts and their conference schools when making decisions for upcoming years. When doing this, districts should not just consider the base pay and the amount of increase per step, but whether or not the district is encouraging teachers to further their education by paying a reasonable increase for earning graduate credits and completing advanced degrees. Teachers consider these long term salary prospects when looking at whether or not it is financially reasonable for them to stay in a small district, especially if they are pursuing a degree they feel strongly will help them be a better teacher for their students 


\section{Workload}

The workload disparity between different size districts is unlikely to go away. However, small districts, particularly at the secondary level, should take stock of the amount of work they expect of their teachers and consider what can be let go. If there are tasks assigned to teachers because it has always been done that way rather because they are truly important and impact student achievement and wellbeing, it may be time to have conversations as to whether it is time to let this go. Likewise, when adding a new initiative, program, or practice, small districts should consider what they can first take off a teacher's plate before adding something new. Small district leaders could work with their teachers to brainstorm ways to help teachers manage the workload in small districts. Creative scheduling to maximize teachers' plan and worktime might become a pivotal practice in small districts to retain teachers.

\section{Support}

School leaders should ensure teachers and administrators in small schools have the support needed to not only meet expectations, but to grow as educators and leaders. By ensuring this support, teachers may not report feeling isolated when it comes to being the only, or one of a few, teachers of a grade or content area. Teachers should know where to go to get help, find resources, and feel like it is safe and ok to do so. Principals in small school districts should make it known that decisions are made in the best interest of students and staff. They should review their procedures and day to day habits to determine if staff and students feel as if they are able to approach the principal to ask for help as needed. When the building principal is known to support staff and students, is transparent that decisions are made in the best interest of students, and is available, 
teachers may want to stay in the district even if the pay is higher in the larger district down the road.

Small school districts would benefit from working with community groups to connect teachers to the community in addition to the school district. Communities should reach out to teachers to bring them into the various social and civic groups and ensure teachers feel the support of the community as a whole rather than only the school district, whether or not the teacher chooses to live in the district.

\section{Advocate}

Additionally, small district leaders, teachers, and community members should advocate with legislators regarding the financial support needed by small, rural school districts to prepare students to be ready to enter college or the workforce. Legislators may not realize the financial implications to small districts, the disparity in pay, the difference in workload, and access to resources. It may not be enough only to address legislators that serve the small, rural district, but it is likely necessary to reach out to other legislators, particularly those on the committees making decisions about education at the state and federal level.

\section{Significance of the Study}

By understanding the reasons teachers report they are leaving rural districts, school leaders may be able to adjust recruitment and retention practices in rural schools. Findings in current literature include the idea that salary and benefits are often lower in rural districts, in addition to student motivation and achievement being a significant challenge (Gagnon \& Mattingly, 2015; Hardre \& Hennessey, 2010; Monk, 2007; Ulferts, 2016). Monk (2007) and Ulferts (2016) also cited challenges with high quality, specific 
professional development opportunities, and access to curriculum and course materials. Additionally, Burton and Johnson (2010) contended when teachers are underprepared and are placed in rural classrooms with challenges such as low achievement and poverty, teachers can not only grow frustrated with teaching, but also with their students. "In turn, [they] become frustrated with their jobs" (Burton \& Johnson, 2010, p. 377).

Unfortunately, teacher education programs, in general, do not adequately prepare students for teaching in rural school districts (Barley, 2009; Burton \& Johnson, 2010). Teachers are not specifically prepared to understand and manage the challenges of professional, geographic, and even social isolation found in rural schools (Baker-Doyle, 2010; Barley, 2009; Beesley et al., 2010; Monk, 2007). Notably, this isolation is a common challenge for teachers in rural schools when compared to the environment of teachers in larger schools (Barley, 2009; Burton et al., 2013; Fishman, 2009). BakerDoyle (2010) found a teacher's social networks, both inside the school as well as in the community, play a role in their choice to remain in their position. Findings from this study may assist school leaders make changes to help beginning teachers in rural districts successfully manage the challenges related to isolation and make connections within the school and the community.

In addition to isolation, research supports the idea of the workload in rural schools being difficult to manage (Barley, 2009; Monk, 2007; Ulferts, 2016). Teachers find having more than four preps daily is not uncommon. They may teach multiple grades and multiple subjects. Additionally, they may need to be certified in additional content areas or may teach subjects for which they do not hold certification (Barley, 2009; Monk 2007). Added to this workload are extra duties, including lunch, committee work, and 
other meetings (Barley, 2009; Monk 2007). While this has been presented in the literature, findings from the study should help determine teachers' perceptions of workload within the rural and larger school districts. These findings may provide cause for rural school leaders to reassess teachers' duties and the compensation provided when compared to the larger schools to which they lose teachers.

Not only will rural school leaders across the region be able to use this information, the researcher's institution will be able to use the data and findings to make adjustments to hiring practices, including interview protocols. Additionally, improvements could be made to mentoring programs and possibly duty assignments to address issues that may have allowed a teacher to choose to stay in the district. In regard to compensation, the researcher's institution will have data to support salary schedule change proposals to the school board. By adjusting practices based on the data and findings in this study, a rural school could be better able to meet a Comprehensive School Improvement Plan (CSIP) goal such as "recruit, attract, develop, and retain highly qualified staff” (Kingsville R-1, 2017).

Finally, this study adds to the literature on teacher retention as well as begin to fill the existing gap in the literature regarding rural schools. Specifically, it addresses the unanswered question of why teachers leave rural districts to teach in larger districts and allows insight as to what may help keep these teachers in a rural district for the duration of their career.

\section{Recommendations for Further Research}

While this study adds to the current body of literature regarding small, rural schools. The findings point to a need for further research in the following areas. 
1. As this is a qualitative study reflecting the experiences of a small number of teachers in Missouri, quantitative research should be conducted to explore the many findings of this study with a larger number of participants. Quantifying the results in addition to telling the stories of teachers will give a broader perspective to the answers to the research questions.

2. Research should be conducted to determine the financial compensation threshold needed to attract, recruit, and retain teachers, staff, and administrations in small rural districts. Compensation packages as a whole should be examined in addition to salary schedules.

3. More research should be conducted in the area of workload disparity not only between small and larger districts, but also of secondary teachers as compared to elementary teachers.

4. Several study participants mentioned that administrators in larger schools have encouraged them to gain experience in a small school to "get their feet wet" prior to teaching in a larger school. This practice should be explored through interviews with educators and administrators in both small and larger school districts.

5. Look into partnerships with rural schools and university teacher education programs to allow pre-service teachers to see the benefits of a rural school and what it really looks like from the inside throughout their time in college.

\section{Summary}

In summary, this qualitative study adds to the body of research regarding rural schools and teacher retention. The study explains why teachers migrate from small, rural schools to larger school districts. Ideally, this information may allow leaders in rural 
school districts to adjust their recruitment, hiring, and induction practices to better retain teachers.

Looking through the lens of Herzberg's (1966) motivation-hygiene theory, the researcher interviewed teachers who have migrated from a small, rural school to a larger district. Participants were limited to teachers who have taught in a small rural school in Missouri, preferably the Central Regional Professional Development Center's (CRPDC) area within the state of Missouri, for at least one school year and then migrated to a larger school district anywhere in the United States. Ideally, participants taught in the larger school district for a full school year; however, those with less experience were not excluded. Data were analyzed through a coding process and answers to the research questions were presented, along with recommendations for practice and areas for further research. 


\section{SECTION TWO}

PRACTITIONER SETTING FOR THE STUDY 


\section{Introduction to Practitioner Setting for the Study}

Information clarifying the history, as well as the organizational and leadership structures of this study's setting will be presented in this section. The researcher will discuss the history of education in the CRPDC (Central Regional Professional Development Center) region by first discussing education in the United States and the state of Missouri. From that point, an analysis of the organization and leadership will be presented. The section will conclude with implications for research in the setting.

\section{History of the Organization}

\section{History of Education in the United States}

To understand education in the setting for this study, a general examination of the history of education should first be conducted (Sass, n.d.). July 4, 1776 is celebrated as the birthday of the United States of America. Since nearly that time, public schools, including rural public schools, have been a part of the picture of our nation. The Land Ordinance of 1785 provided for public schools in the western territories by requiring land set aside for their maintenance (Indiana Historical Bureau, n.d.). Two years later, the Northwest Ordinance required land in each township be set aside to support public education (Varsity Tutors, n.d.). Fifty years later, Horace Mann began his role as the Secretary of the Massachusetts State Board of Education and is now a prominent name in education history for his work toward better preparation for teachers, better funding for public schools, and his passion that universal, free, public education should be a priority for the United States (A\&E Television Networks, n.d.). Fifteen years later, in 1852, Massachusetts became the first state to pass a compulsory attendance law (Grocke, n.d.). It took over sixty years for all states to pass such laws. 
The year 1867 marked the creation of the Department of Education at the federal level (U.S. Department of Education, 2017). Although education is not mentioned in the Constitution and is considered a states' right issue, the federal Department of Education was created to help states ensure their school systems are effective (U.S. Department of Education, 2017). Over the next 50 years, the United States saw a precedent set for tax levies to support public education, the beginnings of land-grant colleges, a push for standardized curriculums, funding for school transportation, and an overall call to reform education in the United States (BlackPast, 2014). The stock market crash of 1929 marked the beginning of the Great Depression, and during this time, public education saw cuts to funding, school closures, pay cuts for teachers, and teacher layoffs (Smiley, n.d.).

Fast forward nearly thirty years, and the United States witnessed the landmark Supreme Court decision in Brown V. Board of Education of Topeka in 1954. The Supreme Court decision did not agree that separate schools are equal, and the first steps toward the desegregation of public schools were made (The National Center for Public Policy Research, n.d.). It should be noted that even in 2019, there are school districts across the country that were not yet satisfactorily desegregated, and the challenge toward equality in public education continued (Northam, 2019).

From this point in history to the present day, it seems as if every few years a new law is passed that affects public education. In 1983, The National Commission on Excellence in Education published their report, A Nation at Risk (United States National Commission on Excellence in Education, 1983). This report began with the pointed statement, "Our nation is at risk," (United States National Commission on Excellence in Education, 1983, I2) and further went on to explain why the commission called for 
significant reforms in the U.S. education system as well as teacher preparation. While some states passed legislation for standardized testing, curriculum, and standards following this report, federal legislation was not signed into law until 1994 as the Improving America's Schools Act. This was followed by the approval of the No Child Left Behind Act (NCLB) in 2002 which not only required high-stakes testing, but also held schools accountable for the results and stated the penalties for schools not making progress toward the NCLB goals (U.S. Department of Education, n.d.). Schools struggled to meet the requirements outlined in NCLB, and, in 2012, waivers were granted to 33 of the 50 states. During the time of NCLB, the Common Core Standards Initiative was introduced in 2009 (National Governors Association Center for Best Practices \& The Council of Chief State School Officers, n.d.). While it was expected that most states would adopt these standards, Indiana was the first state to move away from the Common Core standards in 2014, and more states followed (Nick, 2014). Then, in 2015, President Obama called for standardized testing in public schools to be limited to no more than two percent of class time (Doering, 2015). In December of 2015, the Every Student Succeeds Act (ESSA) was signed into law replacing NCLB and returned the judgment of school quality more so to the states.

Betsy Devos was named Secretary of Education in 2016 and confirmed in 2017 (Diamond \& Acosta, 2016). In both 2018 and 2019, several teacher strikes took place across the nation as teachers protested working conditions, funding, pay, and benefits (Wamsley, 2018; Yan, 2019). 


\section{History of Education in Missouri}

While significant events were happening that affected education nationwide in the early $19^{\text {th }}$ century, Missouri was moving out of the category of territory and became a state in 1820 (Phillips, 1911). Within the Missouri Constitution, the state's early legislators provided for public education. "Schools shall be forever encouraged in the new State... One or more schools shall be established in each Congressional Township as soon as necessary, and the children of the poor shall be taught free" (Phillips, 1911, p. 6). In the early years of statehood, from 1820-1853, Missouri school districts were governed by townships, and $25 \%$ of state revenue and dividends were spent on education. Funding was distributed proportionately based on the number of students served by the school (Phillips, 1911). During this time, much of Missouri was still a frontier. Families considered survival a higher priority than education. Those students who went to school and who had a teacher often "studied whatever the teacher could teach, or whatever they had books to study" (McGuire \& Phillips, 1929, p. 270). In 1855, there was a push for a more consistent elementary curriculum and textbooks from the state; however, schools and districts did not fulfill the state's wishes (Phillips, 1911).

With the Civil War, education in Missouri faced many challenges. This was the first major funding cut to education in the state, and all funds to schools were eliminated. In 1867, under state superintendent Parker, a new push, including taxes for school purposes, teacher qualifications, curricular requirements, and leadership, came with the Parker Laws (Phillips, 1911). In 1899, school libraries were recognized, as well as a state course of study for rural schools formalized (Phillips, 1911). Continuing with this forward progress, it was also recognized that any student graduating from any elementary 
school, including rural schools in the state, would be permitted to attend any high school in the state of Missouri without entrance exams, as was previously required (Phillips, 1911). This determination recognized the education received in all Missouri schools, whether in a city or rural area, should be sufficient to prepare a student for the more rigorous educational pursuits in Missouri high schools.

As more schools were needed, so were qualified teachers. As early as 1843 , under State Superintendent Minor, there was a push for schools to prepare teachers for the classroom. In 1855, he "urged Normal [schools] be established without so many limitations and nearer to the people" (Phillips, 1911, p. 76). That same year, it was asked that one boy per county be sent to the University to be trained as a teacher at no cost to the student. The student would then be committed to go back to their county and teach for two years (Phillips, 1911). It was recognized that teaching was a stepping stone used by young men as they saved money to get further training for a different career or to save until they could open their own business. It was not until the late 1860s that the conversation included training women to be teachers (Phillips, 1911). In 1868, under State Superintendent Parker, legislation was laid out to approve six Normal districts as well as the logistics of leadership and administration of these state funded schools (Phillips, 1911). The University of Central Missouri (UCM), which hosts the offices of the Central Regional Professional Development Center (CRPDC), began as one of the state Normal Schools (College celebrates 100-year anniversary and commitment to preparing educators, 2019).

Education in the early years of Missouri history had many problems. At the time Phillips (1911) wrote his book about the history of education in Missouri, he noted there 
were over 2,000 school districts in the state of Missouri. Many districts were extremely small, more vocational training was needed, and the high school curriculum needed improvement (Phillips, 1911). Additionally, Phillips (1911) stated, “probably more than half of the elementary teachers of the state have had very little pedagogical training and are not high school graduates" (p. 293-294). Fortunately for students of the era, new laws at the time noted after the year 1918, all teachers in the state of Missouri must have at least a high school diploma or the equivalent in training (Phillips, 1911). Even so, this did not address Phillips' pedagogical concerns.

Schools continued to make progress, and more was put on the shoulders of those working in schools as time went on. A report from the Sedalia public school superintendent to the Missouri school board in 1930 reported the school nurse was vital to the school district and insinuated this was often the only healthcare students received as they noted the incident rates and improvement/cure rates of many health concerns affecting students (The Sedalia Public Schools, 1930). The need for personal finance education and saving for retirement were noted, as were the addition of school clerks, special education teachers, and the additional burden of reporting data to the school board and the state (The Sedalia Public Schools, 1930). During this time, teachers were typically females who taught an average of three years until they married. Those who pursued teaching as a longer career often took classes at the Normal schools during the summers to improve themselves within their profession (Phillips, 1911).

School consolidation and reorganization was a topic needing attention as the number of Missouri school districts continued to grow. In 1835, a study with the purpose to show how Missouri had outgrown the small district system was presented (Lawrence, 
1937). In this study, Lawrence (1937) stated there were 8,931 school districts in Missouri with an average geographical district size of eight square miles. Of these 8.931 school districts, 7,983 were rural schools, and only 769 of these school districts met state standards. In the state, only 948 districts operated a high school, with 387 of these being consolidated districts that shared a high school. Throughout this report, Lawrence used the word "inequities" often when referring to the quality of both education and facilities for students of Missouri. He noted a need for schools in rural areas, as transportation to and from school in rural areas was a concern. After this report was published, elementary districts shrunk by nearly 1,000. By 1948, the legislature passed a school district reorganization law (Townsend, 1976). By 1952, the number of school districts in Missouri shrank to 4,537, and by 1958, Missouri only had 2,629 school districts. Missouri continued to work to reduce the number of school districts and, in 1969, required all districts with only three directors (board members) to be consolidated. By 1976, Missouri reduced the number to 563 school districts serving 1,036,711 students with 56,407 certificated personnel.

Fast forward to the current structure of schools in Missouri, where there are 558 local education agencies (LEA) serving 883,703 students. Of these LEAs, the state of Missouri operates three programs serving students who are blind, deaf, or have significant disabilities (DESE, 2018). Charter school LEAs included in the total number 36. There is also one virtual instruction program (DESE, 2018). Missouri public school students are served by 85,563 certificated personnel, and of those certificated personnel, 69,082 are classroom teachers (DESE, 2018). Additionally, when looking at the size of school districts in Missouri, nearly $60 \%$ of the school districts, 332 to be specific, are 
small districts with total kindergarten through $12^{\text {th }}$ grade enrollment numbering less than 700 students. An additional 57 school districts have a K-12 enrollment between 700 1,000 students, 67 school districts have an enrollment of 1,001-2,000 school districts, and 102 school districts serve an enrollment of greater than 2,000 students (DESE, 2019b).

\section{Organizational Analysis}

The organizational structure of Missouri schools can be analyzed using Bolman and Deal's (2013) four frames. Looking through the lenses of the structural, human resource, political, and symbolic frames allows one to understand the organization from a variety of viewpoints.

\section{Structural Frame}

Bolman and Deal (2013) defined the structural frame as the actual structure or organization chart of the organization. In their writing, they asked the reader to consider the architecture of the organization. Missouri is a local control state, and each local school board of education governs its own school district (Mo. Rev. Stat. § 171.011, 1963). Missouri schools are also required to operate under the Department of Elementary and Secondary Education (DESE) (Mo.gov, n.d.). Additionally, schools wishing to receive any federal funding must also adhere to the federal requirements attached to this funding (U. S. Department of Education, n.d.; U.S. Department of Education, 2010).

Structurally speaking, the Missouri State Board of Education is an eight-member board. The governor appoints the members, and the Senate confirms the members (DESE, 2019a). According to the DESE website, the school board must be comprised of a balance of individuals from different political parties as well as locations around the 
state. Some of the responsibilities of the board include appointing the commissioner of education; accrediting local districts, establishing requirements for certification of teachers and administrators; establishing requirements for academic performance, standards, and assessment; ensuring federal programs and monies are appropriately managed; and operating state schools for students with disabilities, as well as programs for adult citizens with disabilities (DESE, 2019a). The board does not oversee higher education in Missouri.

Local school districts are then governed by their local school board. School districts in Missouri typically operate under a seven director board (Mo. Rev. Stat. § 160.011, 2018). School board members are elected by the public and are the body responsible for the education of students residing in the district (DESE, 2019a). School districts will then have a leadership structure outlined by the school board that includes their superintendent, principal, and teachers.

\section{Human Resources Frame}

Bolman and Deal's (2013) human resources frame looks at an organization through the lens of its human capital. When looking at the assumptions of the human resources frame, Bolman and Deal (2013) highlighted

- Organizations exist to serve human needs rather than the converse.

- People and organizations need each other. Organizations need ideas, energy, and talent; people need careers, salaries, and opportunities.

- When the fit between individual and system is poor, one or both suffer. Individuals are exploited or exploit the organization - or both become victims. 
- A good fit benefits both. Individuals find meaningful and satisfying work, and organizations get the talent and energy they need to succeed. (p. 117)

When looking at education in Missouri, or at schools and teachers in general, the human resources frame seems to be a good fit. Schools are designed to serve students, and teachers work within that structure. Teachers need schools, and schools need teachers. When the fit between a school or school district and a teacher or administrator is poor, one or the other suffers. It would not be unrealistic to believe they both may suffer. When the fit is right, both the school and the organization can thrive.

This frame links to this study's motivation/hygiene theoretical framework by Herzberg (1966) in that a teacher could be both satisfied with the work they do and dissatisfied with the environment. When the teacher and the school or district are a good fit, both thrive, and the teacher is satisfied in both the work environment and fulfilled in the work they do. As stated earlier, Missouri is a local control state and each school district, whether big or small, has its own culture. A good fit for a teacher in one district does not mean a good fit will be found in another district of similar size. Similarly, there is no guarantee a good fit will be found just by changing the size district in which a teacher works.

\section{Political Frame}

Bolman and Deal's (2013) political frame looks at organizations through the lens of power. This frame considers how resources are allocated, who has the power to make decisions, how conflict between individuals and groups is handled, and who has influence on all the above. 
School districts in Missouri receive federal, state, county, and local funds (National Center for Education Statistics, 2019). School leaders need to be aware of what legislation may affect school funding, as well as the requirements to receive the funding (Missouri School Funding Inadequate, 2019). In the state of Missouri, teachers' organizations, such as the Missouri State Teachers Association (MSTA) and the Missouri National Education Association (MNEA), employ individuals to keep an eye on legislation during the legislative session (Missouri State Teachers Association, 2019; Missouri NEA, 2019). These organizations also encourage their members to have an active voice and contact their legislators regarding both education friendly and not so education friendly legislation.

As the local school board is responsible for the education of their students, they are the body that hires and fires in the school district (Missouri State School Board Association, 2019). The day-to-day operations are handled by school leaders such as the superintendent and principals, and they submit recommendations to the board. However, the ultimate decision as to whether or not an individual is hired, rehired (including tenure), or fired falls on a vote by the school board members (Missouri State School Board Association, 2019). Based on Bolman and Deal's (2013) description, the difference between overbounded systems where power is tightly controlled, and underbounded systems, where control is loosely controlled, an individual school district may fall anywhere on the spectrum depending on its school board and its school leaders. A change in membership on the school board may also change this dynamic, and neighboring districts may be very different. 


\section{Symbolic Frame}

Bolman and Deal's (2013) symbolic frame looks at the organization through the lens of the culture and traditions of an organization. These may be defined traditions, written expectations, unwritten traditions, or expected behaviors. Schools are filled with symbolism. Many small and larger schools host pep rallies, spirit weeks, and encourage the wearing of school colors and symbols at school related events. When the school is a large part of the community, the symbols of the school spill out and may become the symbols of the community.

Schools also hold several ceremonies that are significant in our culture. Students' first day of kindergarten, or even the first day of any grade, is a significant moment that is often photographed and remembered. Moving from elementary school to middle or high school may culminate in a ceremony to mark that graduation or celebration, and high school graduation is typically a momentous occasion for the student, their family, and the teachers who have worked with the students over their school years. These ceremonies serve to "socialize, stabilize, reassure, and convey messages to external constituencies," such as the community and future employers (Bolman \& Deal, 2013, p. 260).

When rural schools experience high turnover when it comes to teachers, the culture becomes one where it is expected that teachers never stay. Students, their families, and the community expect a teacher will leave after only a couple of years. When the traditions and stability are taught to newcomers from those who have only been in the school a short time or from the students and families, this is how we have always done it may be referencing a long-standing practice or something that is relatively new to the school or district. 


\section{Leadership Analysis}

Just as each school district is different, each district is led by individuals who have a variety of leadership styles. Rural school leaders must balance the day-to-day management tasks of running a school with the leadership skills necessary for strategic planning and long term growth. Rural school leaders must also understand the power structures in their district and work within those structures to move their followers to a common goal (Northouse, 2016).

Rural school leaders wear many hats and are often tasked with being a generalist rather than a specialist. (Versland, 2013). Different situations arise that require different approaches to leadership, and often a situational approach to leadership is necessary (Levi, 2014; Millward, 2015; Northouse, 2016). In situational leadership, leaders use a combination of directive and supportive approaches (Northouse, 2016). Just as teachers are tasked to differentiate instruction to meet the needs of each student, situational leadership allows leaders to take into consideration the needs of their followers and "match their [leadership] style to the competence and commitment of the followers" (Northouse, 2016, p. 94). Using this approach requires the leader to understand both the nature of the situation, tasks, and goals needing to be accomplished, as well as the skills and abilities of those involved. Some individuals may require a directive approach to accomplish their work, others may need a coaching or supporting leader, and others may need the leader to delegate tasks and allow the individual to do what they do best (Northouse, 2016). This style of leadership requires the leader to "demonstrate a high degree of flexibility" (Northouse, 2016, p. 98) and connects to the idea that rural school leaders wear many hats and must address the variety of situations that arise. 
Turnover in relationship to school leaders is also a challenge that should be explored when examining leadership in rural schools. Pendola and Fuller (2018) contended it can take five to seven years for a principal to be effective and to facilitate meaningful growth and change. Rural school administrators tend to stay in their position approximately five years (Pendola \& Fuller, 2018). For a leader to facilitate change and growth that is sustainable, especially when considering the high turnover amongst rural school leaders, transformational leadership should be examined (Northouse, 2016). Yang (2014) contended that "transformational leadership is a crucial quality of principals" (p. 280). Transformational leadership is not solely the responsibility of the school leader but, instead, relies on the interaction between both the leader and followers where shared leadership is facilitated (Northouse, 2016). Developing a shared vision that will inspire all involved is needed to work toward success as a transformational leader (Yang, 2014).

Knowing there is a high turnover rate in schools both in regards to teachers and administrators requires those who stay to continue with the work and learning of the organization. School leaders should strive to create a culture of organizational learning rather than facilitating only individual learning and growth (Gill, 2010). By doing so, when changes inevitably happen, the organization will be able to adapt and adjust as needed.

To help create this organizational learning culture, rural school leaders should work toward moving away from committees working as functioning workgroups and should instead work toward having functioning teams in their schools (Gill, 2010; Levi, 2014). The work in schools is complex with change being inevitable with new staff, students, and requirements on the horizon. Levi (2014) discussed the importance of teams 
when a service is being provided, when quality is important, and when change happens quickly. All of the above happen in the school setting.

Baker-Doyle (2010) addressed the idea of teachers' social networks having a significant effect on teacher retention. Isolation has been reported as a concern of teachers in rural districts (Beesley et al., 2010). School leaders should acknowledge this as a need and work to facilitate both tasks and social needs and behaviors within workgroups (Levi, 2014). This team approach is needed in schools where the members are interdependent as they work collectively toward their common goal.

Working in teams allows for shared or distributed leadership (Northouse, 2016). The school leader using a shared leadership approach will need to determine how leadership decisions will be made and shared. They will need to determine if the teams will make recommendations with the leader making the final decision, or if they will allow the team to make the decisions the school leader will then help implement (Northouse, 2016; Rogers \& Blenko 2006/2013).

Due to the variety of types of work assigned to a rural school leader, a variety of leadership approaches are appropriate. Each school leader will need to evaluate which leadership styles are appropriate based on their unique situation.

\section{Implications for Research in the Practitioner Setting}

As stated in Section One, an understanding of some of the reasons teachers report they are leaving rural districts may allow school leaders to adjust recruitment and retention practices in rural schools. Findings in current literature include the idea that salary and benefits are often lower in rural districts, in addition to student motivation and achievement being a significant challenge (Gagnon \& Mattingly, 2015; Hardre \& 
Hennessey, 2010; Monk, 2007; Ulferts, 2016). Monk (2007) and Ulferts (2016) also cited challenges with high quality, specific professional development opportunities, and access to curriculum and course materials. Burton and Johnson (2010) contended when teachers are underprepared and are placed in rural classrooms with challenges such as low achievement and poverty, teachers can not only grow frustrated with teaching, but also with their students. "In turn, [they] become frustrated with their jobs" (Burton \& Johnson, 2010, p. 377).

Unfortunately, studies report teacher education programs, in general, do not adequately prepare students for teaching in rural school districts (Barley, 2009; Burton \& Johnson, 2010). Teachers are not specifically prepared to understand and manage the challenges of professional, geographic, and even social isolation found in rural schools (Baker-Doyle, 2010; Barley, 2009; Beesley et al., 2010; Monk, 2007). Notably, this isolation is a common challenge for teachers in rural schools when compared to the environment of teachers in larger schools (Barley, 2009; Burton et al., 2013; Fishman, 2009). Baker-Doyle (2010) found a teacher's social networks, both inside the school as well as in the community, play a role in their choice to remain in their position. Findings from this study may help teacher educators understand the need to prepare pre-service teachers to manage these challenges. The findings may also help school leaders make changes in induction programs to assist beginning teachers in rural districts successfully manage the challenges related to isolation and make connections within the school and the community.

In addition to isolation, research supports the idea of the workload in rural schools being difficult to manage (Barley, 2009; Monk, 2007; Ulferts, 2016). Teachers will find 
having more than four different class preparations daily is not uncommon, and they may teach multiple grades or multiple subjects. They may need to be certified in additional content areas or may teach subjects for which they do not hold certification (Barley, 2009; Monk 2007). Added to this workload are extra duties including lunch, committee work, and other meetings (Barley, 2009; Monk 2007). Data from this study allow rural school leaders to reassess teachers' duties and the compensation provided when compared to the larger schools to which they lose teachers.

Not only will rural school leaders across the region be able to use this information, the researcher's school district will be able to use the findings to make adjustments to hiring practices, including interview protocols. Additionally, improvements could be made to mentoring programs and possibly duty assignments to address issues which may have allowed a teacher to choose to stay in the district.

\section{Summary}

In summary, the practitioner setting for this study was analyzed by first looking at the history of education in both the United States and in Missouri. The analysis continued with a look at the organizational analysis of school districts based on Bolman and Deal's (2013) four frames, a leadership analysis, and a discussion of the implications for this research in rural schools. It should be noted that there is a long standing tradition of students being educated in rural schools across the nation, and this practice continues in Missouri. Additionally, each school district within Missouri, while operating under federal, state, and local structures, may look and feel different based on the make-up of the local school board and their school leaders. When analyzing the leadership styles of school leaders, several styles of leadership, including situational, transformational, and 
shared leadership, were explored as the leadership styles in schools vary depending on the individuals serving in those roles.

This study has clear implications for rural school districts, school leaders, and teacher education programs. Findings will be shared to allow school leaders to adjust recruitment and retention programs to better serve the needs of their individual school districts. Additionally, teacher educators will be able to share the findings with preservice teachers to help explain the similarities and differences between the types of school districts. 


\section{SECTION THREE}

SCHOLARLY REVIEW FOR THE STUDY 


\section{Introduction to Scholarly Review}

In the United States, during the 2008-2009 school year, approximately $20 \%$ of students attended a rural school (Strange, Johnson, Showalter, \& Klein, 2012). However, the number of journals specific to rural education number just three: Journal of Research in Rural Education, The Rural Educator, and Rural Special Education Quarterly (Burton, Brown, \& Johnson, 2013).

Since the 1970s, over half the articles included in a narrative analysis of qualitative research conducted specifically on rural teachers were published in these three journals, with just nine articles being found in general education journals (Burton et al., 2013). Burton et al. (2013) contended the lack of research focused on rural teachers in general education journals is of concern, leaving "many education researchers...unaware of issues related to rural education and research in this field" (p. 8).

Hardre (2008) reported as little as six percent of the empirical research in the field of education focuses on rural education. A clear example of the considerable lack of empirical research specific to rural education is evidenced during this review of the literature on teacher retention. In general education journals, teacher retention is a common discussion in the literature. However, using EBSCOhost databases and narrowing the search to return items which specifically discuss teacher retention in rural school districts within the United States significantly drops the number of items returned to less than 100 as of this writing.

Consequently, the studies specific to rural teacher retention often discuss components related to teacher satisfaction. However, there is a lack of research discussing why good teachers choose to teach in a rural school only later to decide to 
leave that position to teach in a larger school district. It is also unclear if the challenges for teacher retention in rural districts are similar to the challenges in suburban and urban districts. Current literature cites the idea that salary and benefits are often lower (Gagnon \& Mattingly, 2015; Monk 2007). Student motivation and achievement are also cited as a significant challenge in rural schools (Hardre \& Hennessey, 2010; Monk, 2007; Ulferts, 2016). Additionally, Monk (2007) and Ulferts (2016) cite challenges with high quality, specific professional development opportunities and access to curriculum and course materials. The history of rural schools, which will be presented in this section, will be followed by scholarly aspects of teacher satisfaction and teacher retention as it pertains to rural schools. Specifically, research from the current scholarly base regarding teacher retention, student achievement as it relates to teacher retention, challenges faced by rural teachers, and challenges faced by rural districts in regard to teacher retention will be presented.

\section{History and Characteristics of Rural Schools}

\section{History of Rural Education in Missouri}

While significant events were happening that affected education nationwide in the early $19^{\text {th }}$ century, Missouri was moving out of the territory category and became a state in 1820. The state's early legislators provided for public education. "Schools shall be forever encouraged in the new State... One or more schools shall be established in each Congressional Township as soon as necessary, and the children of the poor shall be taught free" (Phillips, 1911, p. 6). In the early years of statehood, from 1820-1853, Missouri school districts were governed by Townships, and 25\% of state revenue and dividends were spent on education. Funding was distributed proportionately based on the 
number of students served by the school (Phillips, 1911). During this time, much of Missouri was still a frontier. Families considered survival a higher priority than education. Those students who went to school and who had a teacher often "studied whatever the teacher could teach, or whatever they had books to study" (McGuire \& Phillips, 1929, p. 270). In 1855, there was a push for a more consistent elementary curriculum and textbooks from the state; however, schools and districts did not fulfill the state's wishes (Phillips, 1911).

With the Civil War, education in Missouri faced many challenges. This was the first major funding cut to education in the state, and all funds to schools were eliminated. In 1867, under state superintendent Parker, a new push including taxes for school purposes, teacher qualifications, curricular requirements, and leadership came with the Parker Laws (Phillips, 1911). In 1899, school libraries were recognized, as well as a state course of study for rural schools formalized (Phillips, 1911). Continuing with this forward progress, it was also recognized that any student graduating from any elementary school, including rural schools in the state, would be permitted to attend any high school in the state of Missouri without entrance exams as was previously required (Phillips, 1911). This determination recognized the education received in all Missouri schools, whether in a city or rural area, should be sufficient to prepare a student for the more rigorous educational pursuits in Missouri high schools.

As more schools were needed, so were qualified teachers. As early as 1843 , under State Superintendent Minor, there was a push for schools to prepare teachers for the classroom. In 1855, he "urged Normal [schools] be established without so many limitations and nearer to the people" (Phillips, 1911, p. 76). That same year, it was asked 
that one boy per county be sent to the University to be trained as a teacher at no cost to the student. The student would then be committed to go back to their county and teach for two years (Phillips, 1911). It was recognized that teaching was a stepping stone used by young men as they saved money to go and get further training for a different career or to save until they could open their own business, yet it was not until the late 1860s that the conversation included training women to be teachers (Phillips, 1911). In 1868, under State Superintendent Parker, legislation was laid out to approve six Normal districts as well as the logistics of leadership and administration of these state funded schools (Phillips, 1911). The University of Central Missouri (UCM), which hosts the offices of the Central Regional Professional Development Center (CRPDC), began as one of the state Normal Schools (College celebrates 100-year anniversary and commitment to preparing educators, 2019).

Education in the early years of Missouri history had many problems. At the time Claude Phillips (1911) wrote his book about the history of education in Missouri, he noted there were over 2,000 school districts in the state of Missouri. Many were extremely small, more vocational training was needed, and high school curriculum needed improvement (Phillips, 1911). Additionally, Phillips (1911) stated, "probably more than half of the elementary teachers of the state have had very little pedagogical training and are not high school graduates" (p. 293-294). Fortunately for students of the era, new laws at the time noted after the year 1918, all teachers in the state of Missouri must have at least a high school diploma or the equivalent in training (Phillips, 1911). Even so, this did not address Phillips' pedagogical concerns. 
Schools continued to make progress, and more was put on the shoulders of those working in schools as time went on. A report from the Sedalia public school superintendent to the Missouri school board in 1930 reported the school nurse was vital to the school district and insinuated this was often the only healthcare students received as they noted the incident rates and improvement/cure rates of many health concerns affecting students (The Sedalia Public Schools, 1930). The need for personal finance education, including saving for retirement, was noted, as were the addition of school clerks, special education teachers, and the additional burden of reporting data to the board and the state (The Sedalia Public Schools, 1930). During this time, teachers were typically females who taught an average of three years until they married. Those who pursued teaching as a longer career often took classes at the Normal schools during the summers to improve themselves within their profession (Phillips, 1911).

School consolidation and reorganization was a topic needing attention as the number of Missouri school districts continued to grow. In 1835, a study with the purpose to show how Missouri had outgrown the small district system was presented (Lawrence, 1937). In this study, Lawrence (1937) stated there were 8,931 school districts in Missouri with an average geographical district size of eight square miles. Of these 8,931 school districts, 7,983 were rural schools, and only 769 of these school districts met state standards. In the state, only 948 districts operated a high school, with 387 of these being consolidated districts that shared a high school. Throughout this report, Lawrence used the word inequities often when referring to the quality of both education and facilities for students of Missouri. He noted a need for schools in rural areas as transportation to and from school in rural areas was a concern. Because of this report, elementary districts 
shrunk by nearly 1,000. By 1948, the legislature passed a school district reorganization law (Townsend, 1976). By 1952, the number of school districts in Missouri shrank to 4,537, and by 1958, Missouri only had 2,629 school districts. Missouri continued to work to reduce the number of school districts and, in 1969, required all districts with only three directors (board members) be consolidated. By 1976, Missouri reduced the number of school districts to 563 , which served $1,036,711$ students with 56,407 certificated personnel.

Fast forward to the current structure of schools in Missouri. There are 558 local education agencies (LEA) serving 883,703 students. Of these LEAs, the state of Missouri operates three programs serving students who are blind, deaf, or have significant disabilities (DESE, 2018). Charter school LEAs number 36, and there is one virtual instruction program (DESE, 2018). Currently, 85,563 certificated personnel serve the students in Missouri public schools. Of those certificated personnel, 69,082 are classroom teachers (DESE, 2018). Additionally, when looking at the size of school districts in Missouri, nearly $60 \%$ of the school districts, 332 to be specific, are small districts with total kindergarten through $12^{\text {th }}$ grade enrollment numbering less than 700 students. An additional 57 school districts have a K-12 enrollment between 700 - 1,000 students, 67 school districts have an enrollment of 1,001-2,000 school districts, and 102 school districts serve an enrollment of greater than 2,000 students (DESE, 2019b).

\section{Characteristics of Rural Schools}

While rural schools share many of the same requirements and basic operational needs of their larger counterparts, there are specific characteristics that set them apart (Nelson, 2010; Tobin, 2019). Depending on one's definition of rural, rural schools are set 
apart by geography, size, or a combination of the two (NEA, n.d.; Nelson, 2010; Tieken, 2014). Nelson (2010) defined a community as rural when it has a population of less than 2,500, whereas Tieken (2014) considered rural to be more of a feeling and identification rather than defined by a set number. Either way, rural schools are set apart by common characteristics.

Tieken (2014) discussed the idea that rural education is often defined by two major stereotypes and that both of these fail to truly explain rural schools. The first myth is that rural schools are "backwoods, backwater, and backward; its residents assumed to be ignorant, lawless, and provincial" (Tieken, 2014, p. 7). The second myth is one of "nostalgia...uncomplicated simplicity, with some sort of lost golden age (Tieken, 2014, p. 7). Tieken's (2014) research pointed to something much different. Rural schools do tend to be small, they tend to have smaller class sizes, a smaller facility, fewer course choices, and a smaller number of staff than their larger counterparts (NEA, n.d.; Nelson, 2010; Tieken, 2014). Additionally, staff in rural schools often wear multiple hats, performing duties of multiple roles when compared to suburban or urban districts. (Nelson, 2010; Tobin, 2019). However, rural education in today's world is not backward, nor is it one of uncomplicated simplicity.

Despite their small size, rural schools can leverage their size as an asset. Due to a small administrative team, they often can make decisions quickly (Tobin, 2019). Consequently, they may be able to carry out improvement efforts by relying on the creativity and interests of their teachers (Nelson, 2010). Rural schools tend to tailor school improvement initiatives in a manner that fits their needs, as most programs are 
designed for much larger schools and, at times, written reports on these initiatives may look less formal than their suburban or urban counterparts (Nelson, 2010).

Even so, the above does not paint a complete picture of a rural school. Tieken (2014) took it a step further as she described the image of a packed parking lot and gym on a Saturday night when the community has turned out for a fundraising dinner or a basketball game. The school is not just a school, but the school is the community, and the community is the school (Rural Schools Collaborative. n.d.; Tieken, 2014). The school is often what holds the community together. When a school is consolidated or closes, it is not uncommon for the community businesses to close, and eventually for the community or town to all but disappear (Tieken 2014). The school provides employment, a place for community events, a connection to family (both kin and friends), and sets the tone (Tieken, 2014). A rural school represents "a home, the heart of the community" (Tieken, 2014, p. 151).

\section{Review of the Extant Scholarship}

\section{Teacher Retention}

Of the approximately 3.5 million public school teachers in the United States, approximately $13 \%$ move to a new position or leave teaching altogether (AEE, 2008;

AEE, 2014; NCES, A). Unfortunately, the research emphasis for teacher retention and turnover has been placed on teachers leaving the profession rather than on teachers migrating from one school or district to another (Ingersoll, 2001). Those who move often are seeking better working conditions which may be found in districts that are considered to be wealthy and high-performing (AEE, 2008). It is estimated that "more than one million teachers, including new hires, transition into, between, or out of schools 
annually" (AEE, 2014, p. 2). The National Center for Education Statistics (NCES) (2015) reported during the 2011-2012 school year only $84 \%$ of teachers stayed in their current teaching position. NCES (2016) then separates those not staying in their current position into subcategories, and classifies those who remain in the teaching profession as movers, and those who leave the teaching profession and move on to another career field as leavers. Movers and the leavers each account for eight percent of teachers not staying in their current position (National Center for Education Statistics, n.d.).

Teachers who are classified as movers transitioned within their current district to another public school district or to a private school. From the 2011-2012 school year to the 2012-2013 school year, a majority of the movers (59\%) stayed within their current school district, but $38 \%$ of them moved to a different public school district. A small number of them (3\%) moved to a private school (National Center for Education Statistics, n.d.).

It should be noted that not all teachers who leave the teaching profession do so because they do not like their career. NCES (2016) reports that after the 2011-2012 school year, 38\% of the eight percent of leavers left because they retired, another 29\% left their position as a classroom teacher to continue their career in public education in a different role other than as a classroom teacher. It also appears that teachers with less teaching experience were more likely to move to another school as compared to teachers with more than 20 years of experience (National Center for Education Statistics, 2016).

The reasons teachers move to a different school is tracked to a limited degree. NCES (2015) reports that 70\% of teachers who move to a different school do so on their own terms. Fifty-six percent of these teachers noted the move was for personal reasons or 
factors related to the school. Other reasons cited less often were classroom factors and assignments, salary and benefits, and student performance (National Center for Education Statistics, 2015).

Teacher attrition and migration has a significant impact on student achievement, as discussed below, and has serious implications for school districts, including financial concerns (AEE, 2014; Ingersoll \& Smith, 2003). The Alliance for Excellent Education (AEE) (2014) estimates the monetary cost of teacher attrition to states to be between $\$ 1$ billion and $\$ 2.2$ billion annually. However, "the price tag for recruitment and replacement seriously underestimates the cumulative costs of eroding the caliber and stability of the teacher workforce' (AEE, 2014, p. 3).

AEE (2008) also indicated "job dissatisfaction or the pursuit of another job" (p. 2), along with dissatisfaction with both working conditions and administration, are common reasons teachers migrate from one teaching position to another (Ingersoll \& Smith, 2008). Specifically, salary, limited planning time, workload, student discipline, and student motivation were reported as sources of dissatisfaction. (AEE, 2005; Ingersoll \& Smith, 2003). This, in conjunction with a lack of administrator support and little to no say in policy or decision-making, affects teacher migration (Carver-Thomas, \& DarlingHammond, 2019).

Teachers who are successful in their positions are more likely to continue in their position. AEE (2008) stated, "the key seems to lie in the level of success teachers encounter in raising their students' academic performances" (p. 5). AEE (2008) contended giving teachers supports needed for success will have an impact on teacher retention. Supports include, but are not limited to, mentoring programs, resources, 
professional development, and administrative support (Barley, 2009; Berry, Petrin, Gavelle, \& Farmer, 2011; Burton \& Johnson, 2010; Ingersoll, 2001). Unfortunately, new teachers, without seniority, are often assigned students who struggle with academics or behaviors (AEE, 2005). Consequently, these teachers then require additional supports and resources which may or may not be available. Despite the added challenges, "most new teachers are given little professional support, feedback, or demonstrations of what it takes to help their students succeed" (AEE, 2005, p. 2).

\section{Student Achievement}

According to AEE (2014), high-quality instruction is the number one factor affecting student growth, while having an ineffective teacher over a number of years has a serious negative impact on student learning which persists over time. When teachers leave a position, the students left behind "lose the value of being taught by an experienced teacher" (AEE, 2008, p. 1). It is important to note the problem is not just one of staffing and meeting the requirements set forth by state and federal education agencies, but one of student performance (AEE, 2008; Ingersoll \& Smith, 2003). Ronfeldt, Loeb, and Wyckoff (2013) contended that more research needs to be completed to determine if student achievement suffers due to teachers' leaving, or if teachers leave because of low student achievement.

Teachers who have grown in their craft as teachers are often replaced with newer, less experienced teachers, particularly when teachers leave due to retirement. However, when teachers leave after just a couple of years in a school and are replaced with a teacher who is not as good as the teacher leaving, a negative impact on student achievement is noted (Ronfeldt, Love, \& Wyckoff, 2013). Ronfeldt, Love, and Wyckoff 
(2013) noted the "growing body of evidence" (p. 6) revealing that teachers who champion higher student achievement, as well as those with more experience in education, are more likely to stay in their current position reiterating the idea that successful teachers are less likely to leave education or move to a different position (AEE, 2008). It should be noted that ineffective teachers who leave may positively impact student achievement when a more effective teacher is put into that position (Ronfeldt, Love, \& Wyckoff, 2013). However, the impact of teacher attrition on student achievement seems to be connected to more than just teacher turnover; there is a disruption caused to both the teaching team and the school community (Hanushek \& Rivkin, 2010).

In addition to teachers being able to provide effective, high-quality instruction, teachers also need to have a broad understanding of their students. Teachers who do not have adequate knowledge of their students, including their background and needs, can

actually have an adverse effect on their student's achievement (Burton \& Johnson, 2010). Understanding the rural community in which they teach, as well as the background of their students, is important. When teachers do not understand where their students are coming from and are placed in classrooms with challenges such as low achievement and poverty, teachers can not only grow frustrated with teaching, but also with their students. "In turn, [they] become frustrated with their jobs" (Burton \& Johnson, 2010, p. 377).

\section{Challenges for Rural Teachers}

Beginning teachers in rural schools face challenges specific to the rural school environment in addition to similar challenges to those in larger school districts in suburban or urban areas (Beesley, Atwill, Blair, \& Barley, 2010; Fishman, 2009; Monk, 
2007). As such, the research on teacher retention conducted using participants in suburban or urban schools cannot be generalized to fit the rural context (Burton et al., 2013).

Isolation is a common challenge for teachers in rural schools when compared to those in larger schools (Barley, 2009; Burton, Brown, \& Johnson, 2013; Fishman, 2009). This isolation is not just professional, although it is not uncommon for teachers in rural schools to be a part of a small team who teach the same content or grade level, or even be the only teacher in the school teaching that specific content or grade level (Beesley et al., 2010; Berry et al., 2011; Monk, 2007). In fact, the isolation rural teachers face is professional, geographic, and even social (Baker-Doyle, 2010; Barley, 2009; Beesley et al., 2010; Monk, 2007). When working in a district which can be 50 or more miles from a metropolitan center, options for entertainment and recreation may also be limited.

Baker-Doyle (2010) found a teacher's social networks, both inside the school as well as in the community, play a role in their choice to remain in their position. The support and collaboration between teachers and their teacher friends or team have a significant impact on their choice to remain in a school. Those teachers who are either the only, or one of a few, for a grade or subject level in a school already have limited options as to the makeup of their professional social network. Baker-Doyle (2010) contended these "social networks play a considerable role in shaping teachers' lives and choices throughout their careers" (p. 8).

Teachers have been found to look for positions in communities that are either close to their homes, in communities similar to which they are accustomed, or near the institution they last earned a degree (Boyd, Lankford, Loeb \& Wycoff, 2005). While 
Boyd, Lankford, Loeb, and Wycoff (2005) were focused on urban schools, they do state those who grow up in a rural or suburban community are more likely to seek a teaching position in that type of community. Teachers who are able to connect to the community socially are more likely to stay in their teaching position within the district (Baker-Doyle, 2010).

Unfortunately, teacher education programs, in general, do not adequately prepare students for teaching in rural school districts (Barley, 2009; Burton, 2007). Barley (2009) contended preservice teachers should be aware of the overall nature of rural communities, the fact all rural communities are not the same, and the role rural schools play in their communities beyond the school day. Teachers in a rural school "need to find rural life appealing" (Barley, 2009, p. 10) as community factors play a significant role in teacher satisfaction (Baker-Doyle, 2010). While there is a need to incorporate instruction designed to prepare teachers for these assignments, few teacher education programs offer such to their students (Barley 2009; Monk, 2007).

In addition to isolation, the workload in rural schools can be difficult to manage (Barley, 2009; Monk, 2007; Ulferts, 2016). Teachers will find having more than four different class preparations daily is not uncommon; they may teach multiple grade levels or content areas, may need to be certified in additional content areas, or may teach subjects and content areas for which they do not hold certification (Barley, 2009; Monk 2007). Added to this are extra duties including lunch, committee work, and other meetings (Barley, 2009; Monk 2007). Mentoring programs are often used as a method to induct and retain teachers through support and training when they begin at a rural school (Smith \& Ingersoll, 2004; Yost, 2006). However, because challenges for beginning 
teachers are different in rural schools, teacher induction and mentoring programs need to be tailored to the community and not be generalized across the nation, state, or even the region (Fry \& Anderson, 2011; McConaghy \& Bloomfield, 2004).

Multiple authors state mentoring programs would help beginning rural teachers connect to others both professionally and personally as the isolation and workload experienced by rural teachers can be overwhelming for a beginning rural teacher (Barley, 2009; Beesley et al., 2010; Fry \& Anderson, 2011). As previously stated, rural schools are often the cornerstone of the community, and mentors could help teachers understand how the community functions and how they are going to fit into the community (Barley, 2009; Gagnon \& Hennessey, 2010; Monk, 2007; Semke \& Sheridan, 2012).

Ulferts (2016) discussed rural teachers often cite personal reasons as reasons they either stay or leave a rural district. It can be difficult to make the change from living in a suburb or city to living in a rural community. New teachers must decide if they are going to commute or live in the community (Barley, 2009; Fishman, 2015). Teachers who are not accustomed to living or working in rural settings may struggle with the dynamics of a community where everyone knows everyone, and many are related to each other and know the details of each other's personal lives (Barley, 2009; Fishman, 2015; Monk, 2007). Furthermore, if the teacher moves to a new, rural community, they will not have the connections to friends and family. It may be challenging to make new friends and build new social networks when the number of other young teachers is small (Ulferts, 2016). These teachers also must adjust to the different school-community activities as the requirements to participate extend beyond the school day and the school year. It is commonly expected in rural schools for the teachers to have closer relationships with the 
community, students, and families, which on one hand may provide a connection yet, on the other hand, means breaking old connections and relationships (Ulferts, 2016).

\section{Challenges for Rural Districts}

When discussing teacher retention in rural schools, the research specific to rural school teacher retention and recruitment is limited (Beesley et al., 2010; Ulferts, 2016). Prior to retaining teachers in teaching positions, districts must first consider recruitment and the challenges with hiring highly qualified teachers who are also a good fit for the community. Teacher shortages are a problem for rural districts (Monk, 2007; Ulferts, 2016). Vacancies in rural districts happen at a higher rate. In fact, the teacher vacancies in rural districts are "4\% higher than city, suburban or urban" (Barley, 2009, p. 10), and districts with less than 300 students have the highest turnover rate (Ingersoll, 2001). When openings are posted for a rural teaching position, the teacher candidate pool can be smaller as teachers tend to apply in larger districts which pay more (Barley, 2009; Monk, 2007). Another reason the candidate pool is smaller is because teachers are often not prepared to work in rural districts during their time in college and have completed their student teaching semesters in suburban schools rather than in the rural setting (Barley, 2009; McConaghy \& Bloomfield, 2004; Monk, 2007).

Teacher vacancies "may negatively impact a small or rural school more than a larger school....Due to the limited number of teachers in the district, if one science teacher leaves the district and a replacement is not hired, all students may be lacking a science teacher" (Beesley et al., 2010, p. 1). As it is difficult for districts to find teachers to fill vacancies, rural districts may hire teachers who are less than qualified for the content or grade (Beesley et al., 2010; Berry et al., 2011; Monk, 2007). Some districts 
counter this by using grow your own programs (Beesley et al., 2010; Gagnon \& Mattingly, 2015). Such programs may include teacher aides and paraprofessionals working on their teaching credentials, or graduates of the district coming back to the community to teach once they have earned their certification (Beesley et al., 2010). Alternative certification and having teachers gain additional certifications through testing are also common (Beesley et al., 2010).

Additionally, when districts then configure their schedule of course offerings, particularly in the secondary environment, both the number of teachers and their certifications need to be considered. Monk (2007) stated rural school districts lack the course offerings larger schools have. To offer courses, and to compensate for not needing a full-time teacher in certain areas, rural teachers may need to hold certifications in multiple areas and teach in multiple areas (Monk, 2007). Districts may also need to choose to assign classes to teachers who are not certified in that particular subject area (Barley, 2009; Monk 2007). In fact, teachers in rural districts are twice as likely to be teaching content areas in which they are not certified (Beesley et al., 2010). This practice of assigning courses to less than qualified teachers can create a self-perpetuating cycle which leads to further attrition (Berry et al., 2011). Berry, Petrin, Gravell, and Farmer (2011) used the trend of "hiring of special education teachers with inadequate or inappropriate training appears to be one of the consequences of teacher shortages and recruitment difficulties in rural districts" (p. 8) as an example.

One approach to filling gaps in course schedules is for rural districts to offer a variety of courses via distance learning (Hannum, Irvin, Banks, \& Farmer, 2009). This may involve districts collaborating with each other or districts paying online vendors. 
Either way, rural districts using distance education options would need to ensure both their technology and infrastructure support this delivery method. For this to be successful, teachers need to be well versed in available technology and course delivery methods (Hannum, Irvin, Banks, \& Farmer, 2009). Unfortunately, distance learning instructional strategies, along with rural specific education are not necessarily a part of teacher preparation programs (Barley, 2009).

\section{Summary}

Based on this literature review, more research specific to rural teachers and schools is needed. Ulferts (2016) recently investigated why teachers stay in the smallest rural districts in Illinois. While this gives us current data, Ulferts does not go far enough to find out why teachers originally chose to work in rural districts and then leave the district. Both quantitative and qualitative research has been conducted targeting the challenges of teaching in rural schools, as well as teacher induction and retention. However, none have targeted teachers who were successful in rural schools who chose to leave that environment to work in a larger school district. Research is needed to determine why good teachers are choosing to leave and teach in larger schools

This study is novel as interviewing these types of teachers to determine what, if anything, would have caused them to stay in the rural context for the duration of their career changes the conversation around teacher retention in rural environments (Colquitt \& George, 2011). This type of interview has not been reported in the literature. Generalizable, quantitative data are not sufficient in this case to truly understand the problem of retaining rural teachers. Information beyond what can be gathered in a quantitative analysis is required to understand the perceptions of these types of teachers. 
Considering $20 \%$ of students across the nation attend rural schools (Strange, Johnson, Showalter, \& Klein, 2012), research in this area is needed to assist school leaders in the examination of their current practices in the areas of recruitment and retention and make adjustments as needed. 
SECTION FOUR

CONTRIBUTION TO PRACTICE 


\section{Dissemination of Practitioner Contribution}

The researcher has presented preliminary findings from this study at the National Forum for Rural Education sponsored by the National Rural Education Association (NREA) and Batelle for Kids in October 2019. The researcher also plans to submit proposals to share the findings from this study at the Missouri Association of Rural Education (MARE) Conference. Below is a justification as to why these conferences were targeted by the researcher as well as the slide presentations for the two conferences presented at the NRE Annual.

\section{National Rural Education Association}

According to the NREA's website, 500 individuals attended their convention in 2017 from 44 states (National Rural Education Association, 2018d). The convention takes place annually in October and focuses on both current research specific to rural education as well as issues that affect rural education (National Rural Education Association, 2018e). NREA currently has three focus areas for research and presentations, one of which is Empower (National Rural Education Association, 2019). This study falls under this focus area.

\section{Missouri Association of Rural Education}

MARE also hosts their conference annually in October. MARE's purpose statement includes their focus to ensure rural Missouri students receive a quality education, allowing them to compete globally (Missouri Association of Rural Education, 2018). With MARE's focus on student success in rural Missouri schools, this conference appears to be a good fit at which to share the results of this study. 


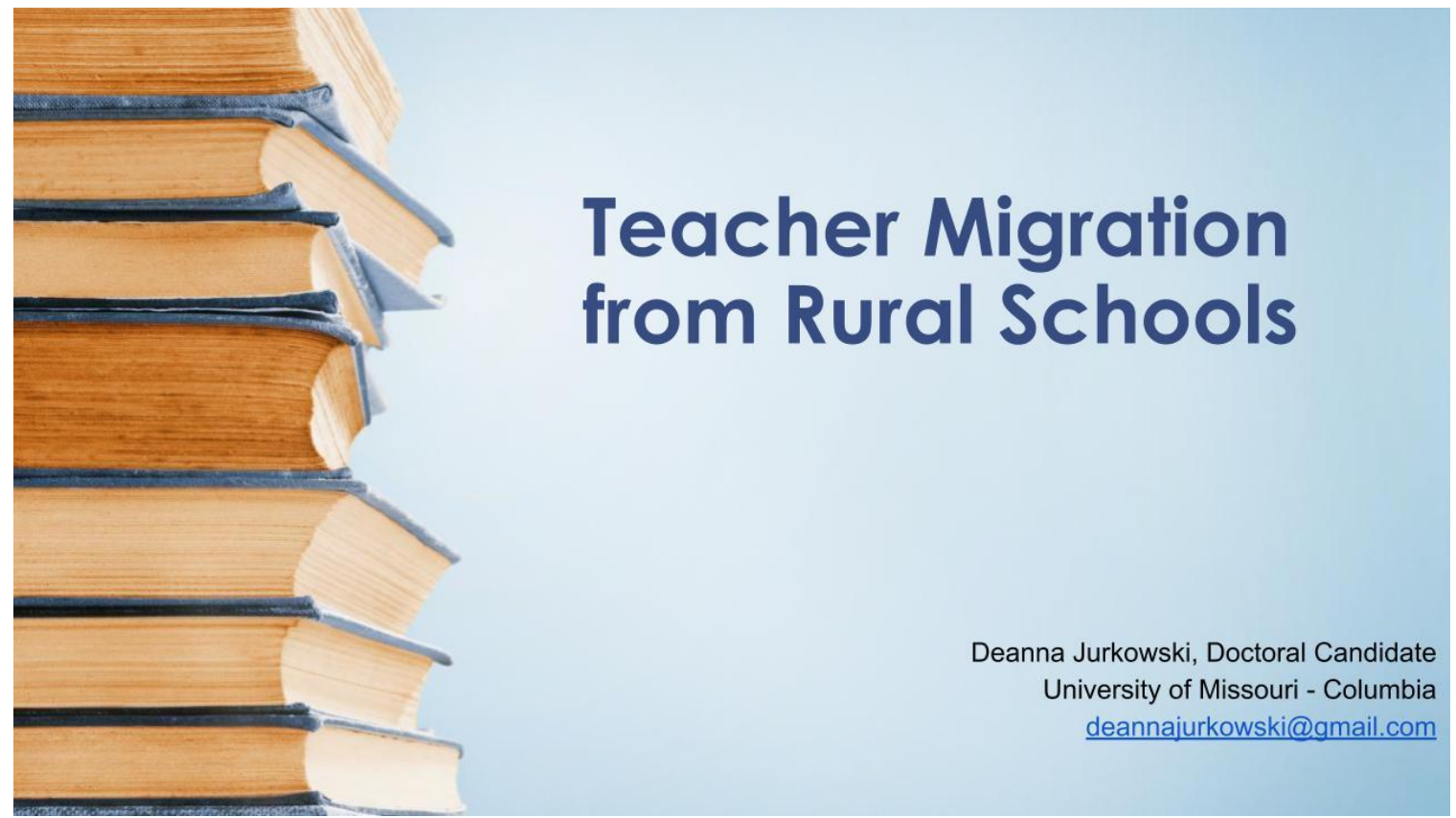

This session is based on data collected for my dissertation and is focused only on research question one. 


\section{Session Overview}

* Guiding Question

* Participant Parameters

* Brief discussion of theoretical lens

* Findings

* What now? - Implications and Recommendations

During this session, we will review the guiding question, the participant parameters, and discuss the theoretical lens of the study. We will then dig into the findings and discuss the implications of this research, as well as recommendations for rural school district leaders. 


\section{Why do teachers leave rural school districts to teach in larger school districts?}

In talking with teachers who have already migrated, will their perceptions be in line with studies limited to teachers in either type of district rather than someone who has experienced both?

The research question guiding today's presentation is "why do teachers leave rural school districts to teach in larger school districts?" Specifically, we are looking at the perceptions of teachers who have already migrated from the rural school district to a larger school district and taught in both types of districts. This is different than what we currently see in the literature, which is teachers who may not have experienced both types of districts. 


\section{Participant Parameters}

* Seventeen Participants

* Taught in a school district with K-12 enrollment of less than 700 in Missouri

* Migrated to and taught in a district with K-12 enrollment of at least 2,000 in the United States

Note: The key is movement from small to large. Participants may have additional districts between small to large, but working as a teacher in the small district and then moving to the large district is key.

Seventeen participants were interviewed for this study. They were required to have taught in a Missouri public school district with K-12 enrollment of less than 700 students for at least one school year. They must have then migrated to a larger school district anywhere in the United States with K-12 enrollment of at least 2,000 students. The key for this study is movement from a small district to the larger school district so the participants can comment on why they made the move to the larger district. 


\section{Herzberg's Motivation-Hygiene Theory}

(1966)

\section{Motivators}

* Lead to job satisfaction due to a need for growth and self-actualization

- These factors include the work teachers do and the impact they make
Hygiene Factors

* Lead to job dissatisfaction due to a need to avoid unpleasantness

- These factors include the environment in which one works, including pay

Herzberg's motivation-hygiene theory is the lens through which this study is

viewed. This particular theory states that individuals may be both satisfied and dissatisfied with their jobs at the same time.

The motivators are what lead to job satisfaction and an individual's need for growth and self-actualization. These are the factors that include the work teachers do and the impact they have on students. This would be what would make a teacher say they love what they do.

The hygiene factors are the factors that lead to job dissatisfaction due to a teacher's need to avoid unpleasantness. These are the factors that include the environment in which one works, including their salaries. 


\section{Herzberg's Motivation-Hygiene Theory}

(1966)

\section{Motivators}

- intrinsic causes of satisfaction

- Achievement

- Recognition

- The actual work itself*

- Responsibility*

- Advancement*

* the most important for a lasting change

in attitude

\section{Hygiene Factors}

- extrinsic causes of dissatisfaction

- Company Policy \& Administration

- Supervision

- Salary

- Interpersonal Relations

- Working Conditions

The list of motivators, or the intrinsic causes of satisfaction, are achievement, recognition, the actual work itself, responsibility, and advancement. Those marked with an asterisk are the most important factors for a lasting change in attitude. The hygiene factors, or the extrinsic causes of dissatisfaction, include company policy and administration, supervision, salary, interpersonal relations, and working conditions. 


\section{FINDINGS - common themes}

* Money and Finances

* Workload

* Family

* Administration and support

* Inevitable

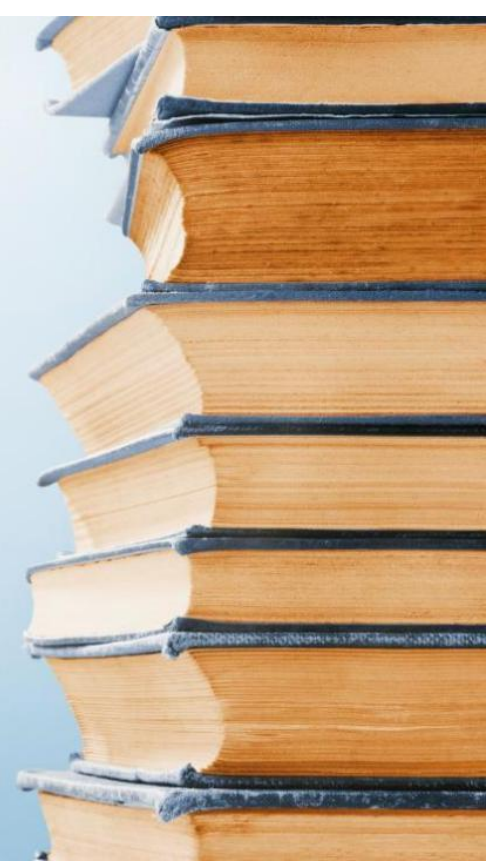

When reviewing the data, the following themes were evident and will be

presented today. Money and finances, workload, family, administration and support, and the idea that the move was inevitable. 


\section{Money and Finances}

* increase in pay moving to larger district

$>$ often fewer responsibilities

$>$ even with cost of living increased, financially better off in larger district

$>$ pay increase for education/experience not as worthwhile in smaller districts

In regard to money and finances, participants reported they had an increase in pay when migrating to the larger district. They also reported that in conjunction with the larger paycheck, they often had fewer responsibilities. They noted that even with a cost of living increase living in a larger city that they and their families were better off in a larger district financially. Participants also discussed the salary increase due to years of experience and/or additional degrees or credit hours was not as worthwhile in the smaller districts as it was in the larger districts. The following slides reflect participant statements supporting these findings. 
"I never would have dreamed,... at any point in my career that I would make this much teaching.

Financially, it's unreal. I got a $\$ 20,000$ raise moving from [small to large district]." 
"Financially, I had to find something close to what I was making [as admin] and I knew the only way that was going to happen was going to a bigger district."

This particular participant made the choice to return to the classroom after working as an administrator and realizing that it was not the best fit for him or his family. Moving back to the classroom in a small district would have been too much of a pay cut for him and his family. 
"We don't have a single teacher in the [larger] district making less than $\$ 40,000$... without any coaching or any other extra duty... I can't even imagine what that would have been like for me as a 21-22 year old making what I would have thought as that much money then." 
"...eventually, because I was like, "Look I can't... This is a struggle for me. They made it where you got that stipend after the season. They wouldn't build it in which was tough because it would have been nice to have that every month. Instead it was a lump sum, and it got taxed like crazy, and I got retirement out like crazy, so...it didn't really add up. 
"Teaching [salary] was a lot more...the rent was a lot more than what our mortgage was on the house [in the small district]. Plus I didn't sell the house...so I was paying rent [in the city] \& mortgage [in the small town]...and I definitely made more... They let me bring in five years on their pay scale. 
"The move went up [in pay]...without the coaching...just because they pay more in general"

"It's an $\$ 8,000$ - $\$ 10,000$ difference just to go to [large district]; that's a lot of money. If those [small] schools could up their pay, they could probably retain teachers better."

As you can see, the larger districts definitely had the potential for a larger paycheck, and this was evident to the participants as they made their choice to migrate to a new district. 


\section{Workload}

- Secondary - in larger districts

$>$ Workload is much lighter (fewer preps, more resources, less isolation)

$>$ Coaching may be an opportunity but is not expected

$>$ Extra-duty is a choice and is compensated

* Elementary - in larger districts

$>$ Grading workload is greater - larger class sizes

$>$ Overall feel is better (teamwork, collaboration, more resources, less isolation

$>$ Extra duty is a choice and is compensated

In regard to the difference in workload, the responses were a bit different between teachers teaching at the elementary versus the secondary level. Teachers at both levels said extra duty was a choice in the larger districts rather than an expectation, as it is in the rural districts, and is compensated.

Secondary teachers reported that in the larger districts, the workload is much lighter than in the rural districts. Teachers have fewer preps, more resources, and less isolation since they are able to collaborate with other teachers who teach the same courses.

Elementary teachers reported the workload is different. In the larger districts, the class sizes are larger, resulting in a greater grading workload. They also report that the overall feeling is better working in the larger districts. Specifically, they discussed teamwork, collaboration, resources, and less isolation overall.

The following slides reflect participant statements supporting these findings. 
I had 12 preps [in the small district] over the year. Every hour I taught something different.

I did 4 sports that first year. Yeah, but I was single and didn't know any better... w would not [want to do it again]. I thought l'd miss coaching more than I do, but I don't. I don't coach anything now. 
And when I got there, they didn't really have curriculum there for me...So I made up a lot as I went because I had to. I had to spend a lot of time there at school getting those done.

I had to rebuild and update everything [instructional materials]. We did not have textbooks [or other resources], and so how I decided to do it was to make PowerPoints and teach by PowerPoint.

Workload includes not just the number of preps a teacher had, but multiple participants reported needing to create teaching materials or rebuild curriculum on their own. 
We did have to do share in gate duty for games and stuff. That's something that I don't have to do in [the large district]...The biggest inconvenience for me was that I just had to stay there. I lived too far away to go home and come back.

The expectation of extra duty outside of the workday was something noted by the participants that was not a requirement in the larger districts. 
But I suddenly now only have one prep. I had four classes a day where one class was a whole 90 minutes with a [90 minute] plan period, oh my gosh, every single day. You had a plan period, which is just amazing. Our teachers have no idea how lucky they are that they have that right, unless they've been in a small school and then they would understand. 
My first two years, I had like 11 preps, each year. And that was tough at 21 years old...Cause I still don't feel like colleges really prepare us...I think a lot of it probably had to do with the fact that I did all of my experiences, observations, student-teaching in bigger schools... I was really only having to prep for 1 prep and that's kinda what I was prepared for...And even when I was at [a smaller district], we got a ton of [preservice teachers]... that would do their student teaching....But even at a school that size, I still only had maybe three preps. So they come in, they see that, Okay, I can get ready for three classes. They go to those smaller schools... where I came from, and it's okay, you need to do this seven times a day...And so I think a lot of it is that we put so many of our kids that are going through education programs in the bigger schools, 'cause that's what's available... and then they get thrown in something completely different with their first job. 


\section{Family}

* Money, Workload, Family connect

* Less time spent at work means more time with family

* More money, less responsibility and extra duty means more time with family

* Work/Life balance is a priority that cannot be met as well in the smaller districts

Family was a common theme as the data were reviewed. When talking about their decision to leave the rural district to migrate to the larger district, participants talked about how the move benefitted their families. Money, workload, and family all connected through this conversation. Participants noted they spent less time at work in the smaller district, allowing them to spend more time at home with their families. The work/life balance is one participants felt could not be met as well in the small, rural districts. The following slides reflect participant statements supporting these findings. 
So when I found out last September that I was pregnant...I talked to [my administrator] about the fact that I would still technically be on maternity leave when school started next year and how I really was uncomfortable with coaching [volleyball]... just don't think that I can do that. I'm going to have a newborn at home and it's going to be hard enough for me to go back to work as is, let alone being a Head Coach gone six days a week. And my [administrator] basically told me, "I'll give you this year off, I'll try to get the Head Coach to stay for a year, but you're going to have to help her, and do some things. You don't necessarily have to go to the games and stuff, but you're going to be required to help in terms of paperwork and things like that." But then after this year...your rehire is going to be dependent on you coaching again. I expect you to coach. That's why we hired you to begin with." 
My husband and I were about to start a family. We wanted to have kids. Thinking about childcare, and how long my kids would be at childcare if I was commuting, compared to being five minutes away from school...my biggest thing was really starting our family and being close to home with the kids. If they got sick, I can go, you know, I'm closer...it was more of a time with the kids thing. 
I was pregnant during $V B$ season and I knew that being a mother was gonna be a priority for me...I knew that coaching was not gonna happen anymore; there was just no way I was gonna be able to do that. I knew I was gonna step away from that and then I really hated the idea of having a baby and leaving it ...and driving 30 minutes away...I've never taught MS honestly at that point. I was like, "I really don't know that I wanna teach middle school, but I do know that I don't wanna have to coach anymore... and at that point, honestly, in a small school, I think that was gonna be the expectation that we really need you to coach, right? 
I was putting [my daughter] to bed, and we had a late, late, late basketball game at a tournament...so I went home and put her to bed and said, "Honey, I gotta go, I got basketball game tonight" ...and she said, "You're always leaving me to go to basketball." I said, "Nope, not anymore, l'm done" ... And that was the motivating factor for me to get out of basketball. I retired from that. It's like, okay, what's next?

Time with family was not a response voiced solely by the female participants. This father made the choice to reduce his workload by moving to a larger district after this conversation with his young daughter. 
I was so busy, and I think that was part of it. I was gone six nights

a week, a lot of those weeks for preparation [classes and

coaching] and stuff like that. I didn't see [my wife] on a Saturday

for the entire month of January and half of February...'cause basketball. 


\section{Administration and support}

* Participants were mixed in regards to administrative support and other support, such as that from mentors and other teachers

* When it was a reason they left the rural school district, they were not shy about the negative feelings they had toward administration

The role of administration was also a clear theme in the data. Participants had mixed reviews of the support from mentors, other teachers, and administration. When it was good, it was highlighted by the participants. However, when it was a reason they left the rural school district, they were very vocal about the negative feelings they had toward administration. The following slides reflect participant statements supporting these findings. 
I felt like there wasn't an expectation level to do our best. And for me as a person, if I'm going to do something I'm going to do it the best I possibly can and put everything into it. And I felt from day one the administration didn't have that expectation of the teachers, because they didn't want to put in the time. And so the teachers don't put in the time. 
I mean, the shortage of teachers is going to be crazy. Even I'm thinking, I've done 15 years, so I'm technically halfway through, and all I can think is, "I don't know if I can make it $\mathbf{1 5}$ more to retirement." I know the retirement's really good, and that's definitely an incentive. Also, I don't know if it's going to be there when I'm done in 15 years. So, just support your teachers, just be there for them. Back them. Listen to them. Listen to what they say, like little things, even. 
The calendar for this year was, in my opinion, awful. Almost all the teachers said that, and the administration, the board still said, "We're going to go with this calendar," and the teachers are like, "Then why'd you ask?"

Just support your staff. And don't ask for the advice or send out surveys to your staff and then don't listen to them. Why send it out? I get it, you guys are the bosses, principals and them, so if you're just going to make a decision, just make a decision. Tell us, "This is it." But don't pretend like we have a say in it and then don't listen, because that just kills our morale. 
He [the principal] didn't support the teachers very well, and it was a struggle for a couple years... I mean, it was bad at times. Like, teachers were in tears at the end of days and things like that, it was crazy. Like there was not much support from him with the teachers. 
We weren't real happy in [the small district] with what was going on with the school. School board-wise, administration-wise, we weren't happy, really. She [my wife] wasn't really happy with her principal, I wasn't happy with mine, we weren't happy with the board at all...

So, we didn't have a kid at the time, it's easy, "Let's talk about leaving." All right, no problem, then. So I start looking around first for jobs. 
It was a bunch of the good old country boys that were on the board when we got there for the first four or five years, and then their kids graduated, so they got off the board, and then the new ones that got on were just different. It seemed like a lot of them had an agenda, and it wasn't quite as comfortable around there as it was before [in the small district]. And I know that happens at every district, and you might have seen it. You have experience also, so you might have seen it at places yourself, where board members are getting on with agendas, not necessarily to help the school in general, just something specific that they want to get done. So that started happening and it didn't make me and my wife very comfortable at times.

It should be noted that this participant viewed the good old country boys as a positive influence on the district and it was the incoming new board members he viewed as having individual agendas. 
And we had all of these programs in place that [the former principal] had set up and had hand picked teachers to lead, and stuff like that. The person that came in... just had to really maintain it to get his feet wet [in the small district], and he didn't maintain it, he didn't really wanna keep that going. So for me, seeing that, seeing how good [the district] was and then seeing where it was going, that's kinda what made my move.

This individual had a very positive experience with his principal who left and did not appreciate the path taken by the new principal. He only stayed one year with the new principal. 
So in my first year, ...I was observed one time...actually, in March, he came to me and said, "Do you have a day this week that you're doing discussion with your kids?" "Cause my classes are normally project based. So he always tried to avoid doing observations, 'cause it's hard to observe anything at that point. "Do you have anything discussion that you're doing so I can come observe because the board meeting is this week and I need to recommend you for rehire, but I need to have an observation to do that." 
We had one Principal, was never in my classroom ever. And even my observation, gave almost no feedback on what I needed to be doing. I scored really high, which I think I genuinely deserve those scores. Obviously I think I'm a good teacher, but I think that there could've been some feedback provided on why you scored this or what you could've done to score next higher, and none of that was ever really provided. 
I didn't have issues with classroom management in terms of needing kids sent to the office for any kind of reprimands. But I did have lots of reports on bullying that I would turn in and nothing was ever done for those students being bullied in order to assist the students. 
I specifically had one student who was consistently bullied by a classmate. I consistently wrote reports and turned that student's reports in, and that student was never punished for his bullying, even though it was consistent... And [the student] even admitted several times like, "I don't like her, so I don't really care." He was never punished. There was never anything done about it. Just very lazy.

These two slides reflect a participant who felt there was no support for students who had ongoing issues with bullying in the small district. She no longer wanted to work for that administrator. 


\section{Inevitable}

* Some teachers knew from the beginning they were going to move on from the smaller districts

$>$ they lived in the larger district

$>$ family was closer to the larger district

$>$ they wanted to teach at their alma mater

Even before taking a position in the small rural district, some participants knew they would only be there for a short time. They felt the move to a larger district was inevitable because their home was in the larger district, their family was far away, and they wanted to move closer meaning they would end up in a larger district, or they wanted to have the opportunity to teach at their alma mater. The following slides reflect participant statements supporting these findings. 
It was probably inevitable but looking back, I wish I could have spent more years there because... It was so much fun...

I remember telling my boss, "If you could just move the [smaller HS] to the [bigger town], I would stay, and that was the truth.

There was nothing that I dislike about that experience and that is the sad part, right.

... there are parts of our lives that you're not gonna change. So for mine, for example, it was me coming back to my hometown, my family's here, and all of that, even though like I said, the best experience teaching l've ever had. 
I was always wanting to come back to my alma mater

eventually. I did not want to come back here right away when I was a young kid out of college, because I would have known too many of them, and they might have been little brothers or sisters of people I went to high school with, still.

Honestly, I was not looking for a job and then somebody told me, ... there was a job in[my hometown] that had come open. I told my wife,... "I'm not looking to leave, but..." She was like, "You always wanted to go back to [hometown], might as well apply." So that was the only place I applied that year... 
I think moving to [larger district] was inevitable.

Inevitable. Honestly, one of my best friends is here

teaching and coaching. We've been friends since

elementary school, and one of our things was we wanted

to coach together at some point and he's the head

basketball coach for boys and I'm the assistant

basketball coach for boys. 
[The larger district] was my long term goal.

I wasn't disgruntled with anything here, it was just an opportunity to go back to my alma mater. 


\section{So now what?}

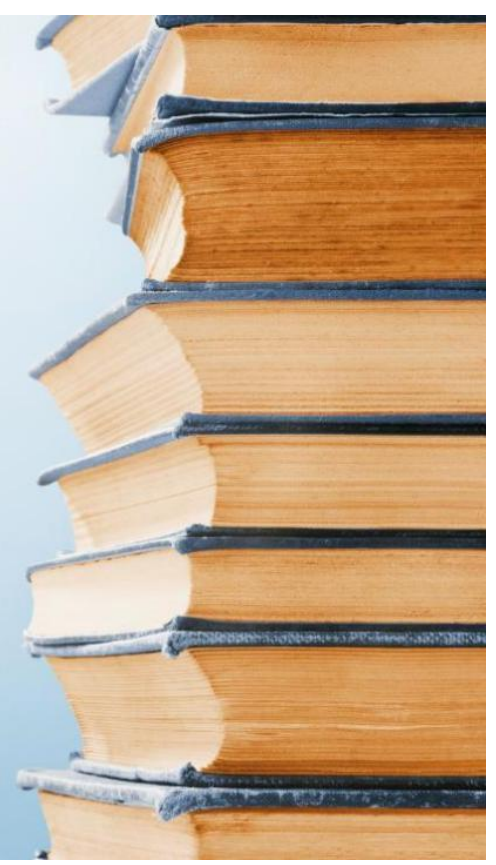

Now that we have this data, what do we do with it? 


\section{How do we use this information now?}

\section{- Hire the right people}

$>$ Find out why they want to work in your district. Individuals with community ties may be more likely to stay.

First, leaders in rural school districts need to work to hire the right people. Ask questions as to why applicants want to work in your district. Do they have ties to your community? If so, they may be more likely to stay as you may not have concerns with them migrating to move closer to family or friends. 


\section{SUPPORT TEACHERS}

* Provide resources, rework budgets to allow spending in areas to better equip teachers to promote student growth

* Have high expectations

* Rework schedules to provide as much time to work on preparation as possible. Look for ways to increase plan time, use additional subs, hire more clerical staff or teacher aids

* Create an environment where family comes first

* Examine hiring practices for coaches and compensate for extra duty (gate,etc.)

It is critical rural school leaders ensure their teachers have not just adequate support but that they ensure teachers have the support needed to excel at their work. Rural school leaders should provide the necessary resources for teachers. This may mean they need to rework budgets to allow spending in areas to better equip teachers to promote student growth.

Administrators in rural districts should have high expectations and hold their teachers to these. They should work to create schedules to provide as much time as possible to work on preparation. This may take some creativity and include increasing plan time, using substitutes, or the hiring of more clerical staff or teacher aids. While there may be a minimum required amount of plan time based on the state in which you live, across the board, participants discussed the discrepancy in preparation required in the smaller districts, especially at the secondary level.

Additionally, rural school leaders should create an environment where family comes first so teachers feel as if they can have a work/life balance that is manageable. 
Finally, rural school leaders should support their teachers by examining hiring practices for extra duty positions including compensation and whether it is optional, encouraged, expected, or required as a condition of employment as a teacher. 


\section{Spread the word}

* Share concerns about compensation \& workload with school board and legislators

* Advocate for your district

Rural school leaders also need to be advocates for their teachers. They should share concerns about compensation and the workload of their teachers with both their school board and legislators. As leaders in the school district, they need to be an active advocate and spread the word about what teachers need to stay in the rural district and work to improve student achievement. 


\section{Areas for further research}

* Further examine the differences in perceived workloads between large and small school districts in regard to elementary vs. secondary teachers.

* Look into partnerships with rural schools and university teacher ed programs to allow pre-service teachers to see the benefits of a rural school and what it really looks like from the inside

* Using a large number of participants, conduct a study to quantify the answer to the questions surrounding teacher migration from small rural districts.

There are still areas where further research is needed. Research needs to be conducted to examine further the differences in perceived workloads between small and larger school districts in regard to elementary versus secondary teachers.

Partnerships between rural schools and university teacher education programs should be investigated. Would it make a difference if pre-service teachers had more opportunities to learn about the benefits of teaching in a rural school and get to actually see what it looks on a day-to-day basis from the inside?

Finally, as this is a qualitative study reflecting the experiences of a small number of teachers in Missouri, quantitative research should be conducted to explore the many findings of this study with a larger number of participants. Quantifying the results in addition to telling the stories of teachers will give a broader perspective to the answers to the research questions. 


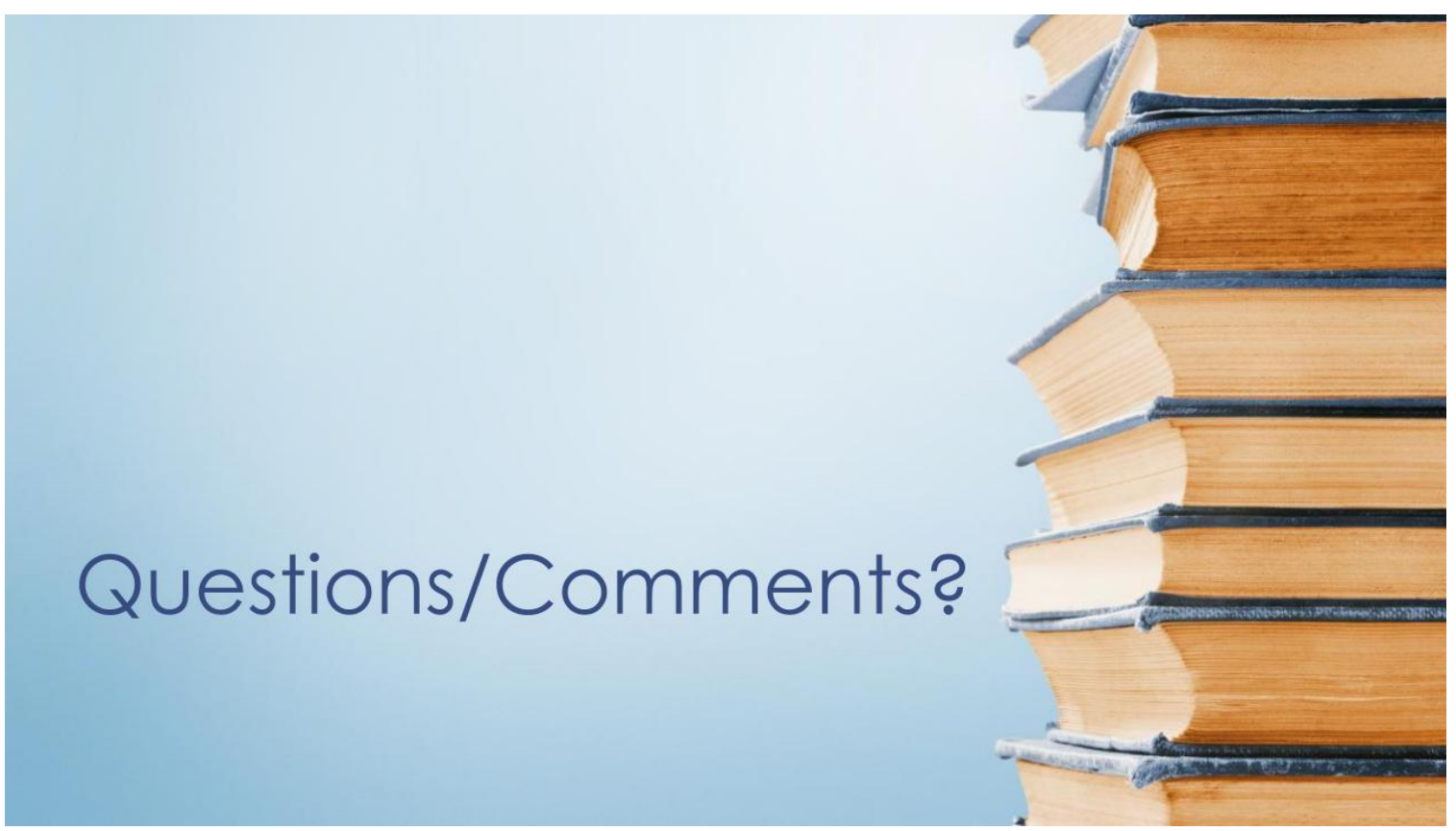

Thank you for your time today. I would now like to open the floor to any questions or comments. 


\section{SECTION FIVE}

CONTRIBUTION TO SCHOLARSHIP 


\section{Contribution to Scholarship}

\section{Target Journal}

"The Rural Educator is the official journal of the National Rural Education Association (NREA)" (National Rural Education Association, 2018a). The journal is published three times each year, is peer-reviewed, and focuses on issues related specifically to rural schools (National Rural Education Association, 2018b). The journal is hosted by the Mississippi State University Library, and articles are available online through the NREA website as well as in print form. The Rural Educator publishes research articles, reviews of research, and Promising Practices, which are described as "practices that show promise to support teaching and learning in rural education settings" (Mississippi State University Libraries, 2018).

\section{Rationale for this Target}

This journal was chosen by the researcher as it was the journal in which much of the specific research related to rural education was found for this study's literature review. As one of the few peer-reviewed journals specifically geared toward rural education, The Rural Educator not only publishes articles based on practices in the rural education setting and review of research, but it also publishes original research. The Missouri Association of Rural Education is a member of the NREA Advocacy Coalition. This fact connects rural schools in Missouri, specifically in the area selected for this study, to rural education nationwide. The NREA has published a list of ten research priorities, of which teacher/leader recruitment and retention is one (National Rural Education Association, 2018c). The targeted audience for this journal matches the targeted audience likely to be interested in the results of this study. 


\section{Journal Article}

Teacher Migration from Rural Schools: Teachers' Reasons for Making the Move Deanna Jurkowski

University of Missouri - Columbia 


\begin{abstract}
This qualitative study examines why teachers migrate from small, rural school districts to teach in larger districts by interviewing teachers who have already made the move and who have taught in both environments. Findings reveal teachers primarily leave small rural districts for financial concerns and enjoy a smaller workload at the secondary level in the larger districts. Workload at the elementary level seemed to be similar. Recommendations for small rural school district leaders are presented.
\end{abstract}

Key Words: Rural education, rural schools, teacher retention, teacher migration, rural teachers, rural teacher recruitment, rural teacher retention

When discussing rural teacher retention, the research specific to teacher recruitment and retention in rural districts is limited (Beesley et al., 2010; Ulferts, 2016). The literature states teacher shortages are a problem for rural districts (Monk, 2007; Ulferts, 2016) and vacancies in rural districts happen at a higher rate. In fact, teacher vacancies in rural districts are "4\% higher than city, suburban or urban" (Barley, 2009, p. 10), and districts with less than 300 students have the highest turnover rate (Ingersoll, 2001). These teacher vacancies "may negatively impact a small or rural school more than a larger school" (Beesley et al., 2010, p. 1). As it is difficult for districts to find teachers to fill vacancies, rural districts may hire teachers who are less than qualified for the content or grade (Beesley et al., 2010; Berry et al., 2011; Monk, 2007). This practice of assigning courses to less than qualified teachers can create a self-perpetuating cycle leading to further attrition (Berry et al., 2011). 
Consequently, the studies specific to rural teacher retention often discuss components related to teacher satisfaction. However, there is a lack of research discussing why good teachers choose to teach in a rural school only later to decide to leave that position to teach in a larger school district. It is also unclear if the challenges for teacher retention in rural districts are similar to the challenges in suburban and urban districts. Current literature cites the idea that salary and benefits are often lower (Gagnon \& Mattingly, 2015; Monk 2007). Additionally, Monk (2007) and Ulferts (2016) cite challenges with high quality, specific professional development opportunities and access to curriculum and course materials. Teachers in rural schools face isolation when compared to those in larger schools, and this isolation is often geographic as well as professional (Burton et al., 2013; Fishman, 2009; Monk, 2007). At the same time, the workload in rural schools can be difficult to manage (Monk, 2007). A secondary teacher will find having more than four preps daily is typical in a rural school, and it is not uncommon to have added to this extra duty, including lunch, committee work, and other meetings (Barley, 2009). Recently, Ulferts (2016) investigated why teachers stay in the smallest rural districts in Illinois. While this study provided current data, Ulferts did not find out why teachers originally chose to work in rural districts and then leave the district. Admittedly, both quantitative and qualitative research has been conducted targeting the challenges of teaching in rural schools as well as teacher induction and retention. Research cited in the literature review for this study regarding rural teacher retention often discuss components related to teacher satisfaction. However, there is a lack of evidence and discussion as to why teachers choose to teach in a rural school only later to decide to leave that position to teach in a larger school district. It is also unclear if the challenges regarding teacher 
retention in rural districts are similar to the challenges in suburban and urban districts. Even with Ulferts' (2016) recent study, research specific to rural school teacher retention and recruitment is quite limited.

\section{Purpose of the Study}

The purpose of this study was to gain an understanding of why teachers leave small, rural schools to teach in larger school districts. By interviewing teachers who have experienced working in a rural district and who then chose to continue their teaching career in a larger school district, the researcher hoped to change the conversation from being just about the challenges and benefits of teaching in a rural district to one that looks at perspectives of those who have worked in both environments. Ideally, the researcher thought an understanding of why teachers migrate to a larger district would give insight to small, rural district administrators. In turn, rural districts may be able to adjust their hiring practices to better recruit teachers who are likely to remain in a small, rural district. Additionally, understanding why teachers are leaving rural districts may also allow rural districts to examine their current working conditions, employment policies, and climate to retain teachers currently employed. This article focuses on the following research question: Why do teachers leave rural school districts to teach in larger school districts?

\section{Theoretical Framework}

The study was viewed through the lens of Herzberg's (1966) motivation-hygiene theory. Herzberg (1966) found "five factors stand out as strong determiners of job satisfaction - achievement, recognition, work itself, responsibility and advancement - the last three being of greater importance for lasting change of attitude" (p. 72-73). These more intrinsic factors relating to job satisfaction are also referred to as motivators. On the 
other side, Herzberg (1966) referred to hygiene issues or factors that are more extrinsic and causes of dissatisfaction, which include "company policy and administration, supervision, salary, interpersonal relations, and working conditions” (p. 72).

Much of the work done by teachers, no matter where they work, is similar when one considers they instruct students with the goal of growth and achievement. According to Herzberg et al. (1959), individuals need to like their work for them to continue the work. This factor, along with recognition and achievement, is long-lasting when it comes to job satisfaction. This may be why teachers in rural areas talk about what they like about their teaching jobs (Burton \& Johnson, 2010). Conversely, job dissatisfaction, in regard to items tied to the working conditions, leadership, and salary, are included in the number of items stated as challenges for rural teachers.

Herzberg et al. (1959) determined "the factors...that made people happy with their jobs turned out to be different from the factors that made people unhappy with their jobs" (p. 111). Unhappy feelings about the job were connected to the working conditions, whereas happy feelings are connected to the work itself. For example, teachers may love what they do, but may not be happy in their current position, school, or community.

Herzberg (1966) expanded the analysis of his theory and suggested "the hygiene or maintenance events led to job dissatisfaction because of a need to avoid unpleasantness; the motivator events led to job satisfaction because of a need for growth of self-actualization" (p. 75) resulting in the two factor theory. "A 'hygienic' environment prevents discontent with a job, but such an environment cannot lead the individual beyond a minimal adjustment consisting of the absence of dissatisfaction. A positive 'happiness' seems to require some attainment of psychological growth" 
(Herzberg, 1966, p. 78) leading this researcher to consider the opposite to be true for teachers in rural schools.

Herzberg's two factor theory has still been used as a lens for research in different disciplines. Maidani (1991) conducted a quantitative study to determine what differences in aspects of job satisfaction were evident between public and private sector employees. Interestingly, public sector employees were higher on the side of extrinsic or hygiene issues than private sector employees, while both private and public sector employees value intrinsic or motivators. As teachers in rural school districts work in the public sector unless employed by a private school, Herzberg's two factor theory is an appropriate lens for research regarding teacher retention.

\section{Study Design}

\section{Setting}

The setting for this study began with the 558 school Missouri districts. Within this, 332 school districts meet the small, rural definition. Further, the primary focus was on the Central Regional Professional Development Center (CRPDC) region, which includes 77 school districts, of which 56 meet the researcher's definition of small rural school district, and nine meet the researcher's definition of a larger school district. Additionally, when looking at the size of school districts in Missouri, nearly $60 \%$ of the school districts, 332 to be specific, are small districts with total kindergarten through $12^{\text {th }}$ grade enrollment numbering less than 700 students. An additional 57 school districts have a K-12 enrollment between 700 - 1,000 students, 67 school districts have an enrollment of 1,001-2,000 school districts, and 102 school districts serve an enrollment of greater than 2,000 students (DESE, 2019). 
Small rural school districts are defined as a public school district with total kindergarten through twelfth grade (K-12) student enrollment of 700 or fewer students. Larger school districts will be defined as public school districts with total kindergarten through twelfth grade (K-12) student enrollment of at least 2,000 students in the same school year. Enrollments were based on data on the Missouri Department of Elementary and Secondary Education (DESE) website for the 2018 school year (DESE, 2019).

\section{Participants}

Seventeen participants were selected for interviews using a snowball approach as a purposeful sampling method (Hatch, 2002; Merriam \& Tisdell, 2016). Primary participants were found based on recommendations from principals and other employees of the CRPDC and community members living in the region. Prospective participants with whom the researcher had worked were not eligible as participants for this study.

Participants, between the 2008-2009 school year and 2018-2019 school year, must have taught a minimum of one full school year in a small, rural school district within the state of Missouri. They must have then migrated to a larger school district anywhere in the United States. No exclusions were made for multiple migrations, moves to administration during their career, or migrations to medium size school districts as there is a potential for a variety of teaching experiences with the connecting factor being teaching in a small, rural district and then migrating to a larger district.

This study included six male teachers and 11 female teachers. During their teaching careers, five participants taught only elementary students, and nine taught only secondary students. The final participants have taught at both the elementary and 
secondary levels. All participants are certified teachers in Missouri, and all but one either hold a master's degree or are working on a master's degree, with three holding an educational specialist, one a doctorate, and one working on their doctorate.

\section{Data Collection}

Data analysis began concurrently with data collection (Merriam \& Tisdell, 2016; Seidman, 2013). The researcher's thoughts, reflections, and observations regarding the interviews were recorded while analyzing what the participants shared.

The researcher utilized a process of coding to find themes and patterns in the data (Hatch, 2002), specifically open coding to make initial notes and designate potential segments of interest and axial coding to narrow down the patterns and themes emerging from the data (Merriam \& Tisdell, 2016). Additionally, the lens of the study, hygienemotivation theory, was used to create categories in which to present the findings (Merriam \& Tisdell, 2016).

\section{Findings}

Teachers participating in this study report several reasons for their choice to migrate to a larger district. For some, the move was made primarily for financial reasons, while others discussed the workload as a precipitating factor. Many participants talked about their family and doing what was in the best interest for their interpersonal relationships. Administration, as well as perceived support, were also topics connected to their decision to migrate to a larger district. Career advancement and opportunities prompted some individuals. For some participants, they knew the move was inevitable due to some other singular and personal specific reason. It should be noted, however, that most participants did not cite just one reason. 


\section{Money and Finances}

Teachers reported leaving rural school districts to teach in larger school districts for an increase in pay. Even with the often increased cost of living associated with moving to a larger town or city, the pay increase left participants better off financially. Participants also noted that the pay increase for education and experience was not as worthwhile in smaller districts.

Cassie was able to point directly to money in regard to her decision to migrate to a larger district. She discussed how she and her best friend had followed similar paths in their careers. Whitney spoke about her situation very directly. "I was looking for pay. It was money, just an increase in pay. It was actually going to be less travel time and more money...just absolutely to pay the bills." Albie was also very clear when it came to compensation and clarified the difference in pay just moving an hour down the road to a larger district from one year to the next. "When I left the small district, I got a $\$ 20,000$ pay raise...I never would have dreamed, starting out or whatever, at any point in my career that I would make this much teaching. Financially, it's unreal."

Daniel and Greg both moved from teaching in a small district to administrative positions. When choosing to leave administration and go back to the classroom, both had to consider the financial implications for their families. Greg spent two years as a rural school administrator prior to deciding to go back to the classroom. He said, "Financially, I had to find something close to what I was making and I knew the only way that would happen was going to a bigger district."

Kelsey added that with an increase in pay there was an increase in expenses. Her situation was a bit different in that she made a move from a larger school district and took 
a $\$ 14,000$ pay cut to move closer to family so grandparents could help care for her children while she and her husband worked. They made the choice to move back to the larger school district several years later and made these comments about the financial implications of that move. "I want to say it was close to $\$ 20,000$ when we moved back." Ken added to the storyline of teachers migrating due to financial considerations. When asked if anything would have made him stay in the small district, he said, "Well, you know I'd like to not say money, but if I had made enough money, I could've tried [to stay]. The school doesn't have that; school doesn't work that way even if they did have that much money."

It was not just base pay that came up during the interviews. Long term compensation is also on the mind of the participants. Annabelle and Hannah commented that getting their advanced degrees in the smaller district would not have led to a large enough jump in salary to justify the cost of the degree program. Hannah said, "I didn't realize how much more money I'd be making, just in general, once I got my master's. It went up significantly." Annabelle commented her administrator in the small district also let her know if she got her advanced degree, there would not be as much of a pay raise.

\section{Workload}

Workload is another reason teachers migrate from small, rural districts to larger districts. They were clear that the workload was too much in a rural district.

Teachers were very open about the number of preps they had in the small districts. Leann said, "I had 12 preps over the year. Every hour I taught something different." Daniel discussed his hiring process for his first-year teaching. In addition to teaching 7-12 social studies with something different each class period, he said, 
I coached varsity softball for four or five years. I coached junior high basketball for three years. I coached varsity boys' basketball for two years. I was an assistant for the boys and the girls' varsity basketball teams before I took over as head coach for one year for the girls and two years for the boys.

Daniel shrugged as he finished that part of his story with, "Yeah, but I was single and didn't know any better." When asked if he would ever want to do that again, his answer was an emphatic "NO! I thought I'd miss coaching more than I do, but I don't. I don't coach anything now."

Mac was a K-12 music teacher in his small, rural district. Regarding the workload he said, "I was the only music teacher for the entire school district. So, I did high school band and middle school band and high school choir and middle school choir and all the elementary music classes. It was just too much.” Mac talked about having to shift his mindset from high school students to early elementary classes during the passing period. He said he knew at the beginning of the 2nd semester of his first year it was time to start looking for a position where he would only be responsible for teaching band.

Overall, participants reported that in secondary settings, the workload is much lighter with fewer course preps, more resources available, and collaboration as a part of a team sharing the load reduces the feeling of isolation in the larger school districts. Ken said, "it was a no-brainer. It was a quality of life thing, and so I just had to go," when talking about the workload. He said his workload was lighter, "I got more money, it was closer to home, and I went from six preps to two." He continued by stating, "I needed to be away from the workload that I had in the small district. I loved the people, but the job was rough." 
In addition to the number of course preps, teachers discussed the workload involved when resources such as curriculum were either unavailable or out of date. Molly said, "When I started I was given no curriculum besides my course title." Daniel's situation was similar. "When I got there, they didn't really have curriculum there for me. The curriculum binders they have were from the early 2000's and I started doing this in $2012, \ldots$ And then the grading aspect of it is something that they don't really tell you about as much."

Contrast the above statements to what it was like once they left to go to larger districts. In Sabrina's case, "I suddenly now only have one prep. I had four classes a day with one period as a whole 90 minutes of plan, oh my gosh, every single day. Our teachers have no idea how lucky they are."

Participants also reported coaching may be an opportunity but is not expected in the larger districts. Extra duty is a choice in these situations and not a condition of employment. Two female participants commented extensively regarding starting a family and coaching responsibilities. Both felt coaching was a condition of employment, with Leann's administrator making it very clear,

I talked to [my administrator] about the fact that I would still technically be on maternity leave when school started next year, and [he]...basically told me, "I'll give you this year off, ...But then after this year, you are going to coach again and your rehire is going to be dependent on you coaching again. I expect you to coach. That's why we hired you to begin with."

In the elementary setting, the workload is primarily reported two ways. Some said it is easier in the larger districts. Others say it is about the same level of difficulty with 
prep time being less time consuming and grading taking more time, meaning their workload is just flipped from what they had in the small district. Elementary teachers did not report leaving primarily due to the workload.

\section{Family}

As participants spoke about their reasons for migrating from small districts to larger districts, when talking about their reasons related to family, it was very much interconnected with money and workload. Family tied closely back to those other two reasons. When teachers spend less time at work and their workload is lighter, they can spend more time at home with their families. When they earn more money, have fewer responsibilities and extra duties, they have more money they can spend on family activities and, in turn, more time with their families. Participants are reporting that they cannot meet the work/life balance as well working in the small districts.

Two participants, Molly and Whitney, got divorced while teaching in the small districts. This impacted their decision to move to a larger district. For Whitney, she was looking at her choices from a monetary perspective. However, Molly stated her divorce was why she moved. "Had that not happened, I was fine teaching there."

Children were also a major reason for some of the female participants' migration. Sabrina did not want to leave a baby in childcare and drive 30 minutes to work, and Hannah had similar thoughts. She shared,

My biggest reason was my husband and I were about to start a family. Thinking about childcare, and how long my kids would be at childcare if I was commuting compared to being five minutes away from school was my biggest [reason for leaving the small district]. 
The male participants were also family oriented as they voiced why they decided to migrate to a larger district. Mac made the choice to move closer to where his girlfriend, and now wife, was living and working. That decision ended up pulling him out of the classroom and into an aide position for two years, followed by him leaving teaching for two years to work in a job that allowed him to earn more money. Eventually, he was able to move back into a teaching position, but this time in special education rather than music. Greg's choices had to do with the fact that he had left a teaching position in a small district to pursue an administration job in the small district from which he had graduated. He stated, "[I] ran into the situation that the kids that were in school were kids of people that I went to school with, and when I had to say no, they were remembering me [from high school]. They would come to me with things like I was their buddy from high school."

Greg chose to move his family rather than have problems in the community. Cody's decision revolved around the fact they did not yet have children. When things were not going well for him and his wife in the small district, he said, "So, we didn't have a kid at the time, it's easy. [He and his wife said], 'Let's talk about leaving."' Albie also had family on his mind when making career decisions. He had made a career out of moving to coach basketball.

One day when we had a late, late, late basketball game at a tournament at a larger district, so I went home and put [my daughter] to bed and said, Honey, I gotta go, I got a basketball game tonight. She was four at the time, and she said, "You're always leaving me to go to basketball." 


\section{Administration and Support}

Participants discussed the perceived support from administration as well as other teachers as reasons they made the decision to migrate to a larger district. Poor support sometimes included administration, school boards, co-workers, and community. There were several who spoke highly of the support they had and told the story of how hard it would be to leave a district, as they had a positive experience in this area.

Leann did not have a positive experience with her administrators in the small district. She felt as if she did not get feedback regarding her teaching and that she was there to be a coach first rather than a teacher. This was not in line with what she wanted to do.

Daniel had the opposite experience with his first administrator in his small district. Daniel had such a favorable experience, that the problems for him started when the first principal left and a new one came in. He shared, "And so then I started [thinking about leaving] about the time my first principal left...I kind of started getting the itch to... Maybe I should leave too."

Cody was another teacher who made his choice to leave because of district leadership. He referred to good old country boys in a positive manner when he shared, "things started going downhill with the board...so we started to talk about leaving. We weren't real happy in the small district with what was going on with the school."

Vicki's situation is somewhat tied to administrative support. However, her reasons 
for leaving have to do primarily with a toxic relationship with her grade level teammate who should have been a support rather than someone who made Vicki's life difficult. Vicki explained it as follows,

When you're spending your first year with a very toxic person that you can't collaborate with, you can't reason with ... I mean, there was nothing I could do...The fact that there weren't any other positions and nobody else wanted to move with her; it just came down to, "Okay, well then I need to step away."

Overall, when asked what advice participants would give principals to help them retain teachers, participants talked about administration supporting teachers, listening to them, and building relationships. Sabrina summed it up by saying, "So as far as retaining teachers, it's all about relationships...Those relationships with them are super important. Because you've got to find a reason to make them want to stay."

\section{Opportunity}

For several of the participants, opportunities arose that made them leave the district. Participants voiced wanting to grow in their careers. Mia wanted to work for and learn from other administrators. "I thought that if eventually administration is the field that I want to go into, that I should really go and gather some different experiences, work with different people. I feel like sometimes the best learning is being in it with them.” Greg's situation was similar. He reported he was recruited by the superintendent from his home town district and could not pass up that opportunity. Kelsey's situation was more thought out than Greg's, as she had been thinking and planning for some time. She pursued her education and realized there was no room for advancement in the type of job 
she wanted in the small district. She explained, "My ed specialist was in curriculum...I just knew the small district didn't have something like that. So I started looking."

\section{Inevitable Migration}

In a few situations, no matter how positive the experience was in the small district, the participants said it was inevitable that they would have made the switch to the larger district. Sabrina stated, "It was probably inevitable. I wish I could have spent more years there because I loved it. It was so much fun, but it was probably inevitable really based on my family being in the larger district." Cody was another teacher who said, "Honestly, I would've stayed there if the job had not come open, but I was always wanting to come back to my alma mater eventually."

\section{Discussion}

Looking through the lens of Herzberg's (1966) motivation-hygiene theory to take into consideration job satisfaction, and the idea that an individual may be both satisfied and dissatisfied with their job at the same time, it was found that teachers are satisfied with the motivation factors of their job in small school districts while citing hygiene factors as the primary reasons for making the decision to migrate to a larger school district. Teachers reference aspects of their job that fall into Herzberg's (1966) motivation factors as what they often liked about their job. Specifically, teachers referenced the work of teaching students in the classroom, building meaningful relationships, and making a difference in the lives of students as reasons they loved, not just liked, their time in a small school district. Conversely, teachers referenced aspects of their job that fall into Herzberg's (1966) hygiene factors as to why they chose to leave the small district and opted for a larger district. On this topic, they specifically referenced 
extrinsic aspects of their jobs such as monetary compensation, administration and policy, and working conditions including overall workload and extra duties.

\section{Financial Compensation}

Teachers leave small, rural districts primarily due to financial reasons. Small school districts should strongly consider working to move their salary schedule to be closer in line to those districts to which they often lose teachers. While it may not be possible to pay the same as larger districts, school districts should consider the potential cost to the district in the areas of finances, time, and student achievement of not working to adjust the salary schedule. At the very least, districts should look at the salary schedules of neighboring small districts and their conference schools when making decisions for upcoming years. When doing this, districts should not just consider the base pay and the amount of increase per step, but whether or not the district is encouraging teachers to further their education by paying a reasonable increase for earning graduate credits and completing advanced degrees. Teachers consider these long term salary prospects when looking at whether or not it is financially reasonable for them to stay in a small district, especially if they are pursuing a degree they feel strongly will help them be a better teacher for their students.

\section{Workload}

Secondary teachers leave small school districts due to the overwhelming workload. While more elementary teachers will talk about the workload being similar or somewhat more in the small districts, the consensus of secondary teachers, as well as K12 teachers, is that there is a disparity in workload between small and larger districts. The workload was noted to be significantly less in the larger districts. This, combined with 
having coworkers who teach not only the same grade level students, but also the same content, was cited as a benefit of migrating to a larger district.

Monk's (2007) statements about workload are confirmed by this study's findings. Teachers in small districts with up to six preps a day do not have enough time during their planning period to adequately prepare lessons, collaborate with other teachers, grade papers, contact parents, and attend student meetings. Unfortunately, the workload disparity between different size districts is unlikely to go away. However, small districts, particularly at the secondary level, should take stock of the amount of work they expect of their teachers and consider what can be let go. If there are tasks assigned to teachers for reasons other than because they are truly important and impact student achievement and wellbeing, it may be time to have conversations as to whether it is time to let this go. Likewise, when adding a new initiative, program, or practice, small districts should consider what they can first take off a teacher's plate before adding something new. Small district leaders could work with their teachers to brainstorm ways to help teachers manage the workload in small districts. Creative scheduling to maximize teachers' plan and work time might become a pivotal practice in small districts to retain teachers.

\section{Administration and Support}

While relationships with administration and good leadership are important, it does not seem to be specific to school districts based on their school size. Participants chose to leave districts of both sizes during their career due to a lack of support. However, a negative experience with administration in a small district can cause the district to lose a teacher faster than in the larger district, as teachers do not often have a wide variety of colleagues to choose from to get the support they need to grow as a professional. 
Conversely, those teachers who had positive experiences with administrators, stayed longer and agonized a bit more over their decision to leave. These teachers cited other reasons as the ultimate reason for leaving and wanted to be clear it was not due to the leadership in the small district.

It is not enough for small, rural districts to hire and work to retain high quality teachers, but it is important they work to hire and retain high quality school and district leaders. The findings are clear in that when teachers felt they worked for a good administrator they stayed longer, or at least considered staying. When the administrator was not perceived as good, teachers tried to leave as quickly as they could. Administrators in small, rural districts should have an understanding of what it means to teach in this environment. They should pursue professional development to help them support their teachers and students in this environment in addition to the many professional development opportunities they need to manage all aspects of their position.

\section{Other Causes for Migration}

Even if small school districts were to address all of the above, there are reasons teachers choose to leave that cannot be mitigated by the small district. Teachers leave the small rural district to move closer to home. It is not uncommon for a teacher to take the first job opportunity available to them once they graduate from college and then teach in the small district until they find a job in a district closer to their hometown. While a small district cannot fix this, school leaders can work to incorporate these transplant teachers not just into the school, but into community life as well. Teachers who experienced this reported staying in the small district longer than those who reported feeling like an 
outsider but, ultimately, they knew when they started teaching in a small district that it was inevitable they would move to a larger district.

Finally, teachers report a lack of opportunity for advancement in the small school districts and leave to pursue career opportunities such as instructional coaching, administration, and teacher leadership such as department chair, that are not available in the small district. Teachers who want to become a principal may have the opportunity to move into that role in the small district. However, there is often only one administrator per building and, if the timing and fit are not right, they must move to another district for this type of position. Small, rural districts may not be able to mitigate this, but they can utilize the skills of these teacher leaders in their district.

\section{Recruitment, Hiring, Orientation, and Induction}

Small, rural school leaders may want to consider adjusting their practices in the area of recruitment, hiring, orientation, and induction. This begins long before there is an opening in the building by building relationships with teacher education programs in the region. Building this relationship and encouraging teacher education programs to allow rural school leaders to participate on panels to talk about the positive nature of working in a small district, as well seeking out preservice teachers to complete observation hours and student teaching in the small district will allow more preservice teachers to get their feet wet in the small district and hopefully see the many benefits of working in this environment.

Small school district leaders should also consider reviewing their interview protocol to ensure they are asking the right questions to determine if a candidate is a good fit not only for their district and team, but for small schools in general. Gaining 
information about an applicant's background and experience without asking those questions that are both inappropriate and illegal in interviews can be an art. However, the information may make the difference between hiring a candidate that seems to be a good fit and needs little coaching over one who may also be a good fit, needs a bit more coaching, but in the long run will stay longer in the district. This is worth strong consideration as student achievement can suffer with teacher turnover (AEE, 2008). Orientation and Induction are also areas that are worth reviewing. Teachers who are connected to mentors, their teaching team, administration, and the community are more likely to register this hygiene factor as positive rather than negative. Teachers who felt like they are successful and connected are more likely to stay in a small district, or at least strongly question if it is time to migrate to a larger district. By supporting teachers, it is conceivable a small district could hold on to a teacher for a bit longer than if they were not supported.

Not only will rural school leaders across the region be able to use this information, the researcher's institution will be able to use the data and findings to make adjustments to hiring practices, including interview protocols. Additionally, improvements could be made to mentoring programs and possibly duty assignments to address issues that may have allowed a teacher to choose to stay in the district. In regard to compensation, the researcher's institution will have data to support salary schedule change proposals to the school board. By adjusting practices based on the data and findings in this study, a rural school may be better able to not only recruit and retain high quality candidates as well as the teachers currently on staff. 


\section{Recommendations for Further Research}

While this study adds to the current body of literature regarding small, rural schools, the findings point to a need for further research in the following areas.

1. Quantitative research should be done to explore the many findings of this study with a larger number of participants.

2. Research should be conducted to determine the financial compensation package threshold needed to attract, recruit, and retain teachers, staff, and administrations in small rural districts.

3. More research should be done in the area of workload disparity not only between small and larger districts, but also of secondary teachers as compared to elementary teachers.

4. Look into partnerships with rural schools and university teacher education programs to allow pre-service teachers to see the benefits of a rural school and what it really looks like from the inside throughout their time in college.

\section{Limitations}

Limitations of this study included the fact participants were limited to have taught in small, public, rural schools in Missouri, preferably one region of Missouri.

Additionally, as this is a qualitative study, the findings are not generalizable and cannot be interpreted as the perspective of all teachers (Creswell, 2014; Merriam \& Tisdell, 2016). Instead, the data collected are the perceptions of a small group of teachers in Missouri whose perspectives add to the discussion of teacher retention in rural school districts. 
Due to the study design, including the collection of both interview and observational data, limitations for this study also include the bias of the researcher. The researcher is open about currently working as an administrator in a small, rural school in the CRPDC region while her children attend school in a larger school district. The researcher is aware of this bias and has been careful to reduce any impact this had on the data collection and analysis process.

In regard to the data collected, the interviews recorded the perspectives of individuals rather than objective data. Without getting multiple perspectives such as the teacher, administrator, and peers regarding the same teacher migrating from one school district to another, there may be missing pieces to the story. Further, this study is also limited by the fact all participants had previously chosen to leave teaching positions in small, rural school districts. There was no participation of teachers who had chosen to stay in a small, rural school district and there was no participation of teachers who taught in schools other than public school districts.

\section{Assumptions}

Assumptions for this study include the researcher trusting participants gave honest answers from their individual perspective. In regard to artifacts, the researcher assumed publicly available documents and information were accurate and were not altered for this study.

\section{Summary}

The reasons teachers leave small, rural districts to teach in larger districts are varied and personal. Depending on their circumstances, the combination of reasons they give have to do with money, workload, and their families. Administration, leadership, 
and peer support also affected their decisions. When it was not positive, it made the participants look to other positions. When the administrative support was positive, other reasons for leaving were given. Advancement and opportunities were also given as reasons for leaving the small districts, and at times, teachers realized the opportunity, such as an administrative position, was not a good fit. This had them looking for a teaching position that would pay similar to their administration level resulting in them working in a larger district. Finally, for some individuals, their goal is to work in a particular district. If that is the case, the migration to the larger district will be inevitable no matter how much they like the small district.

This qualitative study adds to the body of research regarding rural schools and teacher retention. The study explains why teachers migrate from small, rural schools to larger school districts. Ideally, this information may allow leaders in rural school districts to adjust their recruitment, hiring, and induction practices to better retain teachers.

\section{References}

Alliance for Excellent Education. (2008, February). What keeps good teachers in the classroom? Understanding and reducing teacher turnover (Issue Brief). Washington, DC: Author.

Barley, Z. A. (2009). Preparing teachers for rural appointments: Lessons from the midcontinent. The Rural Educator, 30(3), 10-15.

Beesley, A. D., Atwill, K., Blair, P., \& Barley, Z. A. (2010). Strategies for recruitment and retention of secondary teachers in central U.S. rural schools. The Rural Educator, 31(2), 1-9. 
Berry, A. B., Petrin, R. A., Gravelle, M. L., \& Farmer, T.W. (2011). Issues in special education teacher recruitment, retention, and professional development: Considerations in supporting rural teachers. Rural Special Education Quarterly, 30(4), 3-11.

Burton, M., Brown, K., \& Johnson, A. (2013). Storylines about rural teachers in the United States: A narrative analysis of the literature. Journal of Research in Rural Education, 28(12), 1-18.

Burton, M. \& Johnson, A. S. (2010). "Where else would we teach?”: Portraits of two teachers in the rural south. Journal of Teacher Education. 61(4), 376-386.

Creswell, J. W. (2014) Research design: Qualitative, quantitative, and mixed methods approaches. (4th ed.). Los Angeles, CA: Sage.

Fishman, D. (2015). School reform for rural America. Education Next, 15(3). Retrieved from https://login.cyrano.ucmo.edu/login?url=http://search.proquest.com/docview/1683 512565 ?accountid=6143

Gagnon, D. J., \& Mattingly, M. J. (2015). State policy responses to ensuring excellent educators in rural schools. Journal of Research in Rural Education, 30(13), 1-13.

Gill, S. J. (2010). Developing a learning culture in nonprofit organizations. Los Angeles, Ca: Sage.

Hatch, J.A., (2002). Doing qualitative research in education settings. Albany, New York: State University of New York Press, Albany.

Herzberg, F., Mausner, B., \& Snyderman, B.B. (1959). The motivation to work (2nd ed.). New York, New York: John Wiley \& Sons, Inc. 
Herzberg, F. (1966). Work and the nature of man. Cleveland, OH: The World Publishing Company.

Ingersoll, R. (2001). Teacher turnover and teacher shortages: An organizational analysis. American Educational Research Journal, 38(3), 499-534.

Maidani, E. A. (1991). Comparative study of Herzberg's two-factor theory of job satisfaction among public and private. Public Personnel Management, 20(4), 441.

Merriam, S. B, \& Tisdell, E. J (2016). Qualitative research: A guide to design and implementation (4th ed.). San Francisco, CA: Jossey-Bass.

Missouri Department of Elementary and Secondary Education. (2019). District enrollment 1991-2018. Retrieved from https://apps.dese.mo.gov/MCDS/home.aspx

Monk, D. H. (2007). Recruiting and retaining high-quality teachers in rural areas. The Future of Children, 17(1). Retrieved from https://login.cyrano.ucmo.edu/login?url=http://search.proquest.com/docview/1519 298645 ?accountid $=6143$

Ulferts, J. D. (2016). A brief summary of teacher recruitment and retention in the smallest Illinois rural schools. The Rural Educator, 37(1), 14-24. 


\section{SECTION SIX}

SCHOLARLY PRACTITIONER REFLECTION 
By nature, I tend to take time to reflect on significant events in my life, goals, both met and unmet, and the processes that I have used over time. As a part of this dissertation in practice, the program requires a formal reflection of how the dissertation has impacted me as both an educational leader and how the process has impacted me as a scholar. Of all the steps toward the completion of my dissertation, this reflection is by far the easiest for me to complete as it would have been done whether or not it was required.

\section{Influence of Dissertation on Researcher's Practice as an Educational Leader}

As an educational leader, I can honestly say that the influence of this dissertation has not all been positive. To be fair to myself, I think it is important to disclose the challenges of the process, but end with the positive impact the dissertation in practice has had on me.

As I sit here writing this reflection, it is not easy to concentrate as the multitude of tasks needing my attention at school keeps working its way into my consciousness. I know finishing this dissertation in practice and graduating with my EdD will feel as if a great burden has been lifted off me, both physically and mentally. However, finding time to complete dissertation research, and be both a mom and a wife, is challenging on its own. Add that to working full time as a first-year high school principal, and the balancing act becomes more precarious. It has been overwhelming at times to make sure I carve out time to not only learn my new district and position, ensure that both my students and staff are well cared for, be visible at events to interact with the community, collect and analyze data, and still find time to take care of my family and myself.

Even before the COVID-19 pandemic, completing a dissertation was a challenging undertaking. I have listened to friends and colleagues discuss both the ups 
and downs of their process, and knew my dissertation would take a mental, emotional, and physical toll on me. Nevertheless, I knew I was up for the challenge. I am a leader who wants to give my all to everything I do. My kids deserve the best mom I can be, and my school deserves the best principal I can be. I did not know how to ensure there was a sufficient balance between home, work, and research and, with this, I struggled. It was hard to admit I could not always be there for others. As a school leader, my priorities were easy. At work, I was at work. While my hours were long, I was able to carve out time on the weekends and some evenings to work on my research, yet there still were not enough hours in the day.

Cue the pandemic, and it felt as if I was at work $100 \%$ of the time. Suddenly, there were no boundaries. I ate, slept, and breathed coronavirus news and decisions. I had to learn how to prioritize with six people needing the internet at home, student and teacher needs coming in at all hours, and trying to quickly figure out what it meant to be an educational leader during a pandemic. I made a choice to shelve my dissertation for a while, knowing I was needed more by my staff and students.

As an educational leader, my doctoral program, including my dissertation, has instilled in me the necessity of being one who uses data to drive decisions. I value those lessons more now than I ever realized I would. Daily the information would change, and it seemed like daily we would have to adjust our decisions and plans for both instruction and meal service in the district. As an educational leader in a rural district, I was involved with this process more than what it seemed my principal colleagues in larges districts were. I was a participant in the conversations surrounding what was in the best interests of people during our closure, stay-at-home orders, and planning for those significant 
events like graduation, summer sports, and reopening in the fall. All of these decisions required us to review the available data constantly.

Once things settled down a bit into a pattern of a new normal, I was able to carve out time to work again on my dissertation. The lesson I learned is that as an educational leader, at times, it is necessary to but those things on the back burner that are not as timesensitive. While it would have been nice to have finished a semester earlier, other more important and pressing needs required my time and attention. As I complete this dissertation days before my students walk in their modified graduation ceremony, I now get to be one of many individuals who will look back and say they completed their doctoral program despite a pandemic. I do not know if this is something to be proud of or something that will make me think I was crazy not to stop and really take a break.

At the beginning of this reflection, I noted I would end with what I see as the positive impact of this dissertation on me as an educational leader. First, I am more thoughtful. An example of this is understanding the importance of taking the time needed to look at all angles rather than making decisions without all the relevant data. Working through the data, finding patterns, and figuring out what it means is something we do as educational leaders in the field daily. We may not always do it on such a large scale as a research study with IRB approval, but we do it with discipline data, attendance data, and conversations with students and teachers, which is yet another type of data. I am better at this due to the dissertation process. Second, I am a better writer. The amount of writing I do on the job is minimal when compared to this dissertation, but my writing is more effective. I am no longer concerned when I put letters out to the public that I will be misinterpreted or embarrassed by large errors. I am thankful for the growth in my writing 
skills, especially as I write updates to my students and families about changes and cancellations due to COVID-19. I feel confident when I work on handbooks and procedure manuals and know I have the skills to communicate effectively. Third, I am able to handle almost anything that comes my way on any given day. Once this process is done, I think my stress levels will be more balanced, and the everyday stress of a rural school principal, even during the pandemic, will be more easily managed. While I cannot see the future, I often think about how next year I will do my job that much better. I will not be new to the district or my position, and I will not have the task of scheduling interviews and evaluating data that does not directly apply to my work as interesting as it might be.

Finally, I look forward to new challenges and projects. As an educational leader, I imagine the projects I will have the opportunity to tackle in the future. They may take the form of grant writing, research, and problem-solving in general! This dissertation has impacted me as an educational leader as I am so much more confident in my ability to seek out information, consult the literature, and ask experts for their opinion and assistance. This also helps as I present information and proposals to my superintendent and school board with confidence that will benefit my students, my staff, and my community. I know the process to be a change agent. I know how to make decisions based on the information at hand, and I am confident in my ability to gather and analyze new data.

\section{Influence of Dissertation Process on Researcher as a Scholar}

As a scholar, the process of this dissertation has first and foremost forced me to actually me see myself as a scholar and a researcher. They say is something I have heard 
for decades when people talk about what research says. For example, they say humans need air, food, and water to survive. It has taken me a great deal of time to come to the realization that when talking about teacher migration from rural schools that I am a part of the they. My research matters and has a place to help improve the quality of education for students in rural America.

Additionally, I had the opportunity to submit two sessions, and both were accepted at The National Forum to Advance Rural Education. This was not only a great honor and validated my research topic, but from the questions asked by those attending the session, I realized this information needs to be disseminated, and more research should be conducted in this area. The voices of this study's participants can make a difference, and I am qualified to speak on this topic.

Overall, the influence of the dissertation process has given me confidence as a researcher and has lit a fire to begin new research adventures in the future. Completing this research allowed me to dig into what has been published about my topic, and to realize there are so many more questions and gaps in the literature than there are answers at times. Additionally, when looking at the available research and historical sources, I fell in love with the special collections rooms at the universities' libraries. I had the pleasure of reading primary sources highlighting the beginnings of rural schools in Missouri. Had I not started my doctoral journey, I would not have the knowledge I do today about the rich history of Missouri schools. I would not have an understanding of the research process, nor would I believe myself capable of participating in research.

As a scholar, I want to learn more, not just about the past but about what current researchers are putting forth. I respect the work of the authors published in journals, and I 
hope to join their ranks, sharing the stories of my participants who entrusted their experiences to the research process. It takes many of us to continue the research needed to have a positive impact on students in our world, and I hope to be a part of it! 
APPENDIX 


\section{Appendix A}

\section{Interview Protocol}

1. Tell me about yourself.

Where did you grow up? What was your major? Hobbies/Interests? Why did you become a teacher?

2. Tell me about your career path.

Which school districts have you taught in? Grade levels? Content areas? Did you test in to multiple certifications?

3. Tell me about your experience working in a small, rural school district.

What was the job hunt and hiring process like? What did you like/dislike? What was your workload like (extra duties, etc.)? Did you live in the community or commute? Admin/teacher support?

4. Talk to me about your decision to leave the rural school district.

What were some of the precipitating factors? What was the final straw? How was the search process? How did it feel to leave?

5. Tell me about your experience working in the larger school?

What do you remember about how it felt on your first few days? What did you like/dislike? What was your workload like? Did you live in the community or commute? Admin/teacher support?

6. What were some of the similarities between the small school and the larger school? Differences?

Probe for compensation, duties, instructional practices, relationships with students/staff/community, professional growth, social life 
7. In hindsight, tell me about your thoughts on your move from the small to large school.

Is there anything that would have made you stay in the small school or delay your departure? Did you ever think about moving back to a small district? Any regrets about the move?

8. Looking back, what advice do you have for teachers trying to decide if they want to take a job in a rural district or if they are considering moving to a larger school district?

9. What advice would you like to give school administrators in small schools/large schools?

10. Looking back, how do you feel about your decision to move to a larger school?

11. Anything else you would like to add? 


\section{Appendix B}

\section{Interview Questions Linked to Research Questions}

\begin{tabular}{ll}
\hline Interview Question & Research Questions \\
\hline 1 & 2 \\
2 & $1,2,3,4$ \\
4 & $3,4,6$ \\
5 & $2,5,6$ \\
6 & $3,4,5,6$ \\
7 & $3,4,6$ \\
8 & 5 \\
9 & $2,5,6$ \\
10 & $1,5,6$ \\
11 & 5,6 \\
\hline
\end{tabular}




\section{Appendix C}

\section{Individual Interview Consent Form}

\section{CONSENT FORM TO PARTICIPATE IN A RESEARCH STUDY}

\section{Researcher's Name(s): Deanna L. Jurkowski \\ Project Number: 2016724}

Project Title: Is the grass really greener? A qualitative study of teacher reflections on their decision to migrate from small rural districts to larger school districts

\section{STUDY SUMMARY}

You are being asked to participate in a research study that I am doing to investigate the experiences of teachers who have migrated from a small rural school district to a larger school district. When you are invited to participate in research, you have the right to be informed about the study procedures so that you can decide whether you want to consent to participation. Please ask me any questions you have as we go through this form. If you decide to take part in this study, you will receive a copy of this form

Your participation in this study is voluntary. You do not have to be in the study if you do not want to. You may refuse to be in the study and nothing will happen. If you do not want to continue to be in the study, you may stop at any time without penalty.

\section{WHAT AM I BEING ASKED TO DO?}

You will be asked to answer questions during an interview with the researcher about your experiences working in both a small rural school district as well as a larger school. During the interview, I will take notes and use an audio recorder to record the interview. Interviews will last approximately 30-60 minutes and you may be contacted for follow up questions in the weeks following the interview.

\section{WHO DO I CONTACT IF I HAVE QUESTIONS, CONCERNS, OR COMPLAINTS?}

You may ask questions, voice concerns or complaints to the researcher, Deanna Jurkowski, deannajurkowski@gmail.com. Additionally, you may contact Sandy Hutchinson, Dissertation Chair, Hutchinson@ucmo.edu if you have questions about the research.

If you have any questions regarding your rights as a participant in this research you may contact the University of Missouri Institutional Review Board at (573) 882-3181 or rb@missouri.edu.

If you have any questions right now, I'd be happy to answer them. 


\section{Appendix D}

\section{Introductory Email to Teachers}

\section{Dear Teachers,}

I am a doctoral candidate under the supervision of Dr. Sandy Hutchinson (hutchinson@ucmo.edu) at the University of Missouri and seeking participants to fulfill degree requirements for my study titled: Is the grass really greener? A qualitative study of teacher reflections on their decision to migrate from small rural districts to larger school districts. I am researching to understand the perceptions of teachers who have left a teaching position in a small rural school to teach in a larger school and their thoughts on their decision and experience after having taught in both environments.

I am looking for teachers who have taught at least one year in a school district with K-12 total enrollment of 600 students or less in the Central Regional Professional Development Center region of Missouri who then migrated to a school district with K-12 enrollment greater than 2,000 students anywhere in the nation and have taught in this environment at least one year.

Participants will be invited to partake in an individual interview lasting approximately 40 to 60 minutes. Confidentiality will be kept by removing any personally identifiable information from both the data collection process and data analysis. There are no anticipated risks in participating in this study. The benefits of participating in this study are you may enjoy the opportunity to express your experiences teaching in both a small rural school district as well as compared to a larger school district. You may enjoy the opportunity to participate in a research study focused on rural education. You may withdraw from the study at any time. This has been approved by the University of Missouri Institutional Review Board.

If you are interested in speaking about your experiences as a teacher who migrated from a small rural district to a larger district, I hope you will please consider participating in this study. Please contact me, Deanna L. Jurkowski, via email at djurkowski@concordia.k12.mo.us or by phone XXXXXXXXXX to participate and/or with any questions. Thank you for your time and consideration. I look forward to hearing from you.

\section{Deanna L. Jurkowski}




\section{Appendix E}

\section{Introductory Email to Administrators in the CRPDC Region and}

\section{CRPDC Employees}

\section{Dear [Contact],}

I am a doctoral candidate under the supervision of Dr. Sandy Hutchinson (hutchinson@ucmo.edu) at the University of Missouri and seeking participants to fulfill degree requirements for my study titled: Is the grass really greener? A qualitative study of teacher reflections on their decision to migrate from small rural districts to larger school districts. I am researching to understand the perceptions of teachers who have left a teaching position in a small rural school to teach in a larger school and their thoughts on their decision and experience after having taught in both environments.

I am looking for teachers who have taught at least one year in a school district with K-12 total enrollment of 600 students or less in the Central Regional Professional Development Center region of Missouri who then migrated to a school district with K-12 enrollment greater than 2,000 students anywhere in the nation and have taught in this environment at least one year.

Participants will be invited to partake in an individual interview lasting approximately 40 to 60 minutes. Confidentiality will be kept by removing any personally identifiable information from both the data collection process and data analysis. There are no anticipated risks in participating in this study. The benefits of participating in this study are you may enjoy the opportunity to express your experiences teaching in both a small rural school district as well as compared to a larger school district. You may enjoy the opportunity to participate in a research study focused on rural education. You may withdraw from the study at any time. This study has been approved by the University of Missouri Health Sciences Institutional Review Board.

If you know of a teacher who may be interested in speaking about their experiences as a teacher who migrated from a small rural district to a larger district, I hope you will please share their contact information with me or forward my contact information and this letter on to them. Please contact me, Deanna L. Jurkowski, via email at djurkowski@concordia.k12.mo.us or by phone XXXXXXXXXX to participate and/or with any questions. Thank you for your time and consideration. I look forward to hearing from you.

Deanna L. Jurkowski

Appendix D

Individual Interview Consent Form 


\section{Appendix F}

\section{Institutional Review Board (IRB) Approval}

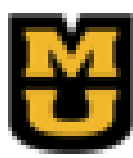

\section{Institutional Review Board} Unimerity of Misouri-Columbla

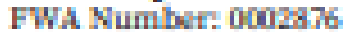

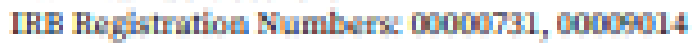

4R2 MeEgndaly Hall

Colum bit, MD 65211

573-867-3161

irhoniscourisdu

September 13, 2019

Principal Tementigator: Menna L. Jurhomai [MU.Shuded|

Dwarment: Educational Ladership-EDD

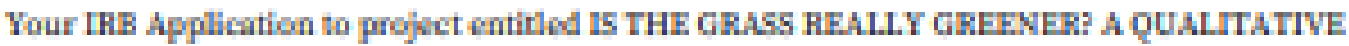
STUDY OF TFACHEF REFLECTINS ON THEIH DECLION TO MIGRATE FEOM SMALI RURAL DISTRICTS TO LAFCEE SCHOOL DISTRICIS wan rviewed aed apponed by the MU Teqitutional Hewkw Bowd aceodieg to therm tend sonditbon dowitud below:

IHE Projot Number

IHB Hewhw Number

Initial Appliatine Apprown Dat:

IHE Expiration Date

Lowl of Roniew

Frojoctsutu

Empt Cumgoris IRnibud Common

Eule!

Eisk Lowel
2016725

구녿

Stptomber 13, 1019

Sptomber 13, 2 no

Exempt

Hothe - Fwapt

43 CFH $46.104 d[2]$

Minimal Eisk

The principal inwstigator (Fi is responsibk for all kpets and coeduct of this study. The PI must somply wh the fatoning conditom of the epprowl:

1. Wo subject may be inwolwd is any study procedure priar io the IRE approwel date or affer the opiration date.

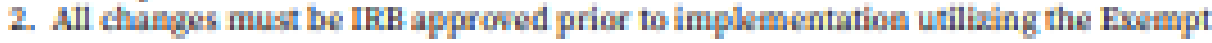
Amendmant Form.

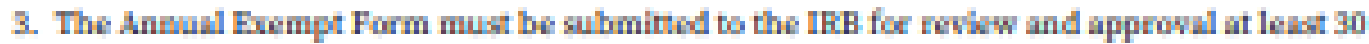

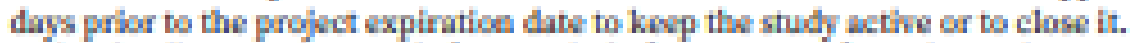

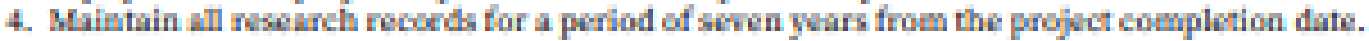

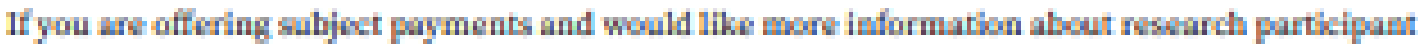

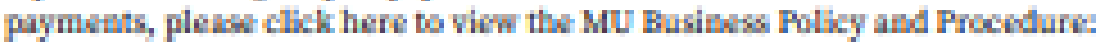

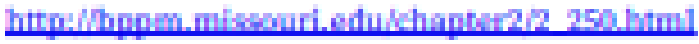

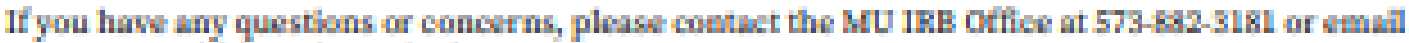
to murowrchingmisuri.adu.

Thank you,

MU Insthutbonal Ronisw Bônd 
Qtubsir 10, 2019

Principal Tenestightor: Dewna L. Jurkowai (MU-Studest)

Department: Educational Ladership-EDD

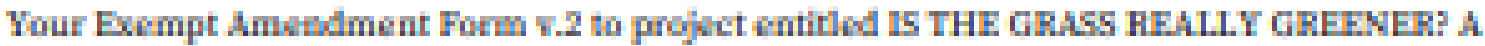
QLALITATIVE STUDY OF TEACHEE HEFLECTONS ON THEIH DECLION TO MIGRATE FROM.

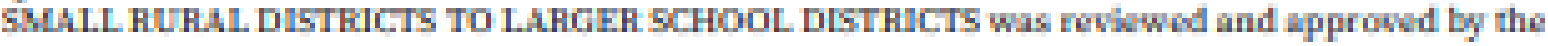

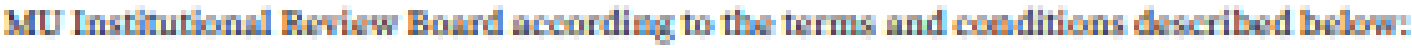

$\begin{array}{ll}\text { IHE Projot Number } & 2016724 \\ \text { IHE Hewhw Numbur } & 254752\end{array}$

Inital Applikation Approwa Datw September 13, 2019

Approval Date of thit Hewwy otobst 10, 2019

IRE Expiration Date September 13, 2000

Lewl of Renies Ewapt

Froject Status active- Erempt

Eikk Lowel Misimal Hist

The principal inwstigator (F) is repansibu for all apects and cosduct of this study. The PI must comply with the folbeirg conditons of the sppowl.

1. No subjects may be inwolwd is any study procedure prior to the IRE approvel date of after the cyiration dake.

2. All changes must be IFB approned prior to implumentation utilizing the Ewapt Amendment Form.

3. The Ansud Erempt Form must be submired to the IFB for rewww and approved at lewe 30 days poibo to the project wpiratioe dat to kwp the study kthe of to clow it.

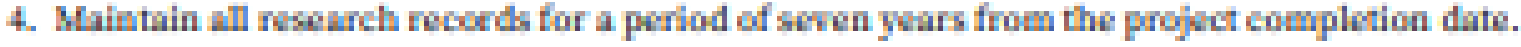

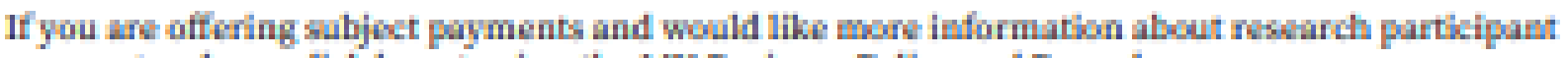
piymats, pleww clkk here to viow the MU Busiess Rolky aed Procedure

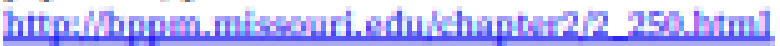

If you haw wny questons or concerns, plosw costut the MU IRE office at 573-62-318L of wan to murewarchirLGmissuri.oblu.

Thank you,

MU Institutbond Roniww Bowd 


\section{REFERENCES}

A\&E Television Networks. (n.d.). Horace Mann biography. Retrieved from https://www.biography.com/scholar/horace-mann

Alliance for Excellent Education. (2005, August). Teacher attrition: A costly loss to the nation and to the states (Issue Brief). Washington, DC: Author.

Alliance for Excellent Education. (2008, February). What keeps good teachers in the classroom? Understanding and reducing teacher turnover (Issue Brief). Washington, DC: Author.

Alliance for Excellent Education. (2014). On the path to equity: Improving the effectiveness of beginning teachers. Washington DC: Author.

Baker-Doyle, K. (2010). Beyond the labor market paradigm: A social network perspective on teacher recruitment and retention. Education Policy Analysis Archives, 18(26), 1-14.

Barley, Z. A. (2009). Preparing teachers for rural appointments: Lessons from the midcontinent. The Rural Educator, 30(3), 10-15.

Beck, D., Maranto, R., \& Shakeel, M. D. (2016). Does rural differ? Comparing parent and student reasons for choosing cyber schooling. The Rural Educator. 37(3), 112

Beesley, A. D., Atwill, K., Blair, P., \& Barley, Z. A. (2010). Strategies for recruitment and retention of secondary teachers in central U.S. rural schools. The Rural Educator, 31(2), 1-9.

Berry, A. B., Petrin, R. A., Gravelle, M. L., \& Farmer, T.W. (2011). Issues in special education teacher recruitment, retention, and professional development: 
Considerations in supporting rural teachers. Rural Special Education Quarterly, $30(4), 3-11$.

BlackPast. (2014, February 18) (1890) Second Morrill Act. Retrieved from https://www.blackpast.org/african-american-history/second-morrill-act-1890

Bolman, L. G. \& Deal, T. E. (2013). Reframing organizations (5 ${ }^{\text {th }}$ ed.). San Francisco, CA: Jossey-Bass.

Burton, M., Brown, K., \& Johnson, A. (2013). Storylines about rural teachers in the United States: A narrative analysis of the literature. Journal of Research in Rural Education, 28(12), 1-18.

Burton, M. \& Johnson, A. S. (2010). “Where else would we teach?”: Portraits of two teachers in the rural south. Journal of Teacher Education. 61(4), 376-386.

Carver-Thomas, D., \& Darling-Hammond, L. (2019). The trouble with teacher turnover: How teacher attrition affects students and schools. Education Policy Analysis Archives, 27(36). http://dx.doi.org/10.14507/epaa.27.3699

Central Regional Professional Development Center. (n.d.). Retrieved from https://www.ucmo.edu/offices/central-regional-professional-developmentcenter/index.php

College celebrates 100-year anniversary and commitment to preparing educators. (2019, April 10). Retrieved from https://www.ucmo.edu/news/universitynews/posts/2019-04-10-ucm-college-of-education-celebrates-100-yearanniversary-and-commitment-to-preparing-educators.php

Colquitt, J. A. \& George, G. (2011). Publishing in AMJ-part 1: Topic choice. Academy of Management Journal, 54(3), 432-435. 
Creswell, J. W. (2014). Research design: Qualitative, quantitative, and mixed methods approaches (4th ed.). Los Angeles, CA: Sage.

Diamond, J. \& Acosta, J. (2016, November 24). Betsy DeVos picked for Trump's education secretary. Retrieved from https://www.cnn.com/2016/11/23/politics/betsy-devos-picked-for-educationsecretary

Doering, C. (2015, October 24). Obama plan limits standardized testing to no more than $2 \%$ of class time. Retrieved from https://www.usatoday.com/story/news/2015/10/24/obama-schools-test/74536886

Flavin, B. (2016). The ultimate guide to 13 different types of schools across America. Retrieved from https://www.rasmussen.edu/degrees/education/blog/types-ofschools/

Fishman, D. (2015). School reform for rural America. Education Next, 15(3). Retrieved from https://login.cyrano.ucmo.edu/login?url=http://search.proquest.com/docview/1683 512565 ?accountid $=6143$

Fry, S. W., \& Anderson, H. (2011). Career changers as first-year teachers in rural schools. Journal of Research in Rural Education, 26(12), 1-15.

Gagnon, D. J., \& Mattingly, M. J. (2015). State policy responses to ensuring excellent educators in rural schools. Journal of Research in Rural Education, 30(13), 1-13.

Gill, S. J. (2010). Developing a learning culture in nonprofit organizations. Los Angeles, Ca: Sage. 
Grocke, V. (n.d.). Compulsory education. Retrieved from https://www3.nd.edu/ rbarger/www7/compulso.html

Gruneberg, M. M. (Ed.). (1976). Job satisfaction - A reader. New York, New York: Macmillan Press.

Hannum, W. H., Irvin, M. J., Banks, J. B., \& Farmer, T. W. (2009). Distance education use in rural schools. Journal of Research in Rural Education (Online), 24(3), 115.

Hanushek, E., Rivkin, S. (2010). Constrained job matching: Does teacher job search harm disadvantaged urban schools? (Working Paper No. 15816). Cambridge, MA: National Bureau of Economic Research.

Hardré, P. L. (2008). Taking on the motivating challenge: Rural high school teachers' perceptions and practice. Teacher Education and Practice, 21, 72-88.

Hardré, P. L., \& Hennessey, M. N. (2010). Two rural worlds: Differences of rural high school students' motivational profiles in Indiana and Colorado. Journal of Research in Rural Education, 25(8), 1-32.

Hatch, J.A., (2002). Doing qualitative research in education settings. Albany, New York: State University of New York Press, Albany.

Herzberg, F., Mausner, B., \& Snyderman, B.B. (1959). The motivation to work (2nd ed.). New York, New York: John Wiley \& Sons, Inc.

Herzberg, F. (1966). Work and the nature of man. Cleveland, OH: The World Publishing Company.

Huysman, J. T. (2008). Rural teacher satisfaction: An analysis of beliefs and attitudes of rural teachers' job satisfaction. The Rural Educator, 29(2), 31-38 
Indiana Historical Bureau. (n.d.). Land ordinance of 1785. Retrieved from https://www.in.gov/history/2478.htm

Ingersoll, R. (2001). Teacher turnover and teacher shortages: An organizational analysis. American Educational Research Journal, 38(3), 499-534.

Ingersoll, R. M. \& Smith, T. M. (2003). The wrong solution to the teacher shortage. Educational Leadership, 60(8), 30-33.

Ingersoll, R. M., \& Smith, T. M. (2004). Do teacher induction and mentoring matter? National Association of Secondary School Principals. NASSP Bulletin, 88(638), 28-40.

Kingsville R-1. (2017). Comprehensive school improvement plan. Retrieved from https://www.kingsville.k12.mo.us

Krueger, R. A., \& Casey, M. A. (2015). Focus groups: A practical guide for applied research (5th ed.). Los Angeles, CA: Sage.

Lawrence, B.I. (1937). Some fundamental considerations concerning reorganizing school units in Missouri (Doctoral dissertation). University of Missouri, Columbia, MO.

Levi, D. (2014). Group dynamics for teams ( $4^{\text {th }}$ ed.). Los Angeles, CA: Sage.

Lowe, J. M. (2006). Rural education: Attracting and retaining teachers in small schools. The Rural Educator, 27(2), 28-32.

Maidani, E. A. (1991). Comparative study of Herzberg's two-factor theory of job satisfaction among public and private. Public Personnel Management, 20(4), 441. Maslow, A.H. (1943). A theory of human motivation, Psychological Review, 50(4): 37096. 
McConaghy, C., \& Bloomfield, D. (2004). Beyond the line/beyond the self: Flirting with rural teaching. Journal of Curriculum Theorizing, 20(3), 93-112.

McGuire, E., Phillips, C.A. (1929). Adventuring in young America. New York: MacMillan.

Merriam, S. B, \& Tisdell, E. J (2016). Qualitative research: A guide to design and implementation (4th ed.). San Francisco, CA: Jossey-Bass.

Millward, R. E. (2015). Gettysburg's lesson on situational leadership. School Administrator, 72(1), 12-13.

Mississippi State University Libraries. (2018). The Rural Educator. Retrieved September 26, 2018, from http://epubs.library.msstate.edu/index.php/ruraleducator/index Missouri Association of Rural Education. (2018). MARE is a service organization. Retrieved September 26, 2018, from https://www.moare.com/vnews/display.v/ART/43e0cb7829cc8

Missouri Department of Elementary and Secondary Education. (2019a). About the state board: Facts about the Missouri state board of education. Retrieved from https://dese.mo.gov/state-board-education/about-state-board

Missouri Department of Elementary and Secondary Education. (2019b). District enrollment 1991-2018. Retrieved from https://apps.dese.mo.gov/MCDS/home.aspx

Missouri Department of Elementary and Secondary Education. (2018). 2017-2018 Statistics of Missouri public schools. Retrieved from https://apps.dese.mo.gov/MCDS/FileDownloadWebHandler.ashx?filename=3bce 62f9-3da4Missouri\%20School\%20Statistics.pdf 
Missouri NEA. (2019). About MNEA. Retrieved from

https://www.mnea.org/Missouri/mission.aspx

Missouri Revised Statutes: Mo. Rev. Stat. § 160.0111 (2018).

Missouri School Boards' Association (MSBA). (2018). So you want to be a school board member?. Retrieved from https://ams.embr.mobi/Documents/DocumentAttachment.aspx?C=ZfON\&DID=G

\section{GLJI}

Missouri school funding inadequate. (2019). Herald Whig. Retrieved from https://www.whig.com/20190117/missouri-school-funding-inadequate

Missouri State Teachers Association (MSTA). (2019). Advocacy. Retrieved from https://www.msta.org/advocacy/

Mo.gov. (n.d.). Department of elementary and secondary education. Retrieved from https://www.mo.gov/government/guide-to-missouris-government/department-ofelementary-and-secondary-education/

Monk, D. H. (2007). Recruiting and retaining high-quality teachers in rural areas. The Future of Children, 17(1). Retrieved from https://login.cyrano.ucmo.edu/login?url=http://search.proquest.com/docview/1519 298645 accountid=6143

National Center for Education Statistics. (n.d.). Fast facts. Retrieved from https://nces.ed.gov/fastfacts/display.asp?id=28

National Center for Education Statistics. (2015, November). Teacher turnover: Stayers, movers, and leavers. Retrieved July 26, 2019, from https://nces.ed.gov/programs/coe/indicator_slc.asp 
National Center for Education Statistics. (2016). Teacher turnover: Stayers, leavers and movers. In The condition of education. Retrieved from https://nces.ed.gov/programs/coe/pdf/coe_slc.pdf

National Center for Education Statistics (NCES). (2019). Public school revenue sources. Retrieved from https://nces.ed.gov/programs/coe/indicator_cma.asp

NEA (n.d.). Rural Schools. Retrieved from http://www.nea.org/home/16358.htm

National Governors Association Center for Best Practices \& The Council of Chief State School Officers. (n.d.). Common core state standards initiative. Retrieved from http://www.corestandards.org

National Rural Education Association. (2019). 2019 National Forum to Advance Rural Education, $111^{\text {th }}$ NREA Convention and Research Symposium, Call for Proposals. Retrieved from https://drive.google.com/file/d/1aNfqZVvunJh1ibQCET4HnJhJ_fBYkTjW/view

National Rural Education Association. (2018a). Retrieved from https://www.nrea.net National Rural Education Association. (2018b). The Rural Educator. Retrieved from https://www.nrea.net/The_Rural_Educator

National Rural Education Association. (2018c). National Rural Education Association (NREA) Research Agenda - 2016-2021. Retrieved from https://drive.google.com/file/d/0B6jy__ymJ61PcEhlbmxPZU5XLTg/view

National Rural Education Association. (2018d). 2018 National Forum to Advance Rural Education, $110^{\text {th }}$ NREA Convention and Research Symposium, Call for Presenters. Retrieved from https://drive.google.com/file/d/1aNfqZVvunJh1ibQCET4HnJhJ_fBYkTjW/view 
National Rural Education Association. (2018e). NREA annual convention. Retrieved from https://www.nrea.net/Convention_and_Research

Nelson, S. (2010). Leveraging the unique features of small, rural schools for improvement. Lessons Learned, 1(5). Retrieved from https://educationnorthwest.org/sites/default/files/resources/lessons\%20learned_rur al.pdf

Nick, D. (2014). Indiana drops common core education standards. Retrieved from http://time.com/36779/indiana-drops-common-core-education-standards

Northam, A. (2019). 63 years after landmark Brown v. Board case, segregated classrooms persist. Retrieved from https://www.usatoday.com/story/news/investigations/2019/04/05/segregatedclassrooms-mississippi/3347927002

Northouse, P. G. (2016). Leadership: Theory and practice ( $7^{\text {th }}$ ed.). Los Angeles, CA: SAGE.

Pendola, A., \& Fuller, E.J. (2018). Principal stability and the rural divide. In E. McHenry, Sorber \& D. Hall (Eds.), The diversity of rural educational leadership [Special issue]. Journal of Research in Rural Education, 34(1), 1-20.

Phillips, C.A. (1911). A history of education in Missouri. Jefferson City, MO: Hugh Stephens Printing Company.

Rogers, P. \& Blenko, M. (2006). Who has the D?. In Harvard Business Review (Ed.). (2013). HBR's 10 must reads on making smart decisions (pp. 95-114). Boston, MA: Harvard Business Review Press. 
Ronfeldt, M., Loeb, S., \& Wyckoff, J. (2013). How teacher turnover harms student achievement. American Educational Research Journal, 50(1), 4-36. https://doi.org/10.3102/0002831212463813

Rural Schools Collaborative. (n.d.). The rural advantage: What does it mean to you? Retrieved from http://ruralschoolscollaborative.org/our-work/the-rural-advantage

Sass, E. (n.d.). American educational history: A hypertext timeline. Retrieved from http://www.eds-resources.com/educationhistorytimeline.html

School board may adopt rules and regulations, Mo. Rev. Stat. § 171.011 (1963).

Seidman, I. (2013). Interviewing as qualitative research (4th ed.). New York, NY: Teachers College Press.

Semke, C. A., \& Sheridan, S. M. (2012). Family-school connections in rural educational settings: A systematic review of the empirical literature. School Community Journal, 22(1), 21-47.

Smiley, G. (n.d.). Great depression. Retrieved from http://www.econlib.org/library/Enc/GreatDepression.html

Smith, T. M., \& Ingersoll, R. M. (2004). What are the effects of induction and mentoring on beginning teacher turnover? American Educational Research Journal, 41(3), $681-714$.

Spangler, T. (2017, February 7). Betsy Devos confirmed Education secretary; Pence casts deciding vote. USA Today. Retrieved from https;//www.usatoday.com

Strange, M., Johnson, J., Showalter, D., \& Klein, R. (2012). Why rural matters 2011 2012: The condition of rural education in the 50 states. Washington, DC: The Rural School and Community Trust. Retrieved from ERIC database (ED528634). 
The National Center for Public Policy Research. (n.d.). Brown v. Board of Education, 347 U.S. 483 (1954) (USSC+). Retrieved from https://nationalcenter.org/brown.html

The Sedalia Public Schools. (1930, April). The Sedalia Public Schools Special Report of the Superintendent of Public Schools. Sedalia, MO.

Tieken, M. C. (2014). Why rural schools matter. The University of North Carolina Press: Chapel Hill, North Carolina.

Tobin, P. D. (2019). A rural superintendent's challenges and rewards. Retrieved from https://www.aasa.org/SchoolAdministratorArticle.aspx?id=9414

Townsend, R. (Ed.). (1976) Education in Missouri: an informal history. Jefferson City, Missouri: Missouri Department of Elementary and Secondary Education.

Ulferts, J. D. (2016). A brief summary of teacher recruitment and retention in the smallest Illinois rural schools. The Rural Educator, 37(1), 14-24.

United States. National Commission on Excellence in Education. (1983). A nation at risk: The imperative for educational reform: A report to the Nation and the Secretary of Education. Retrieved from https://www2.ed.gov/pubs/NatAtRisk/risk.html

U.S. Department of Education. (2017, May 25). The federal role in education. Retrieved from https://www2.ed.gov/about/overview/fed/role.html

US. Department of Education. (2010). An overview of the U.S. department of education. Retrieved from https://www2.ed.gov/about/overview/focus/what.html U.S. Department of Education. (n.d.). No child left behind. Retrieved from https://www2.ed.gov/nclb 
Varsity Tutors. (n.d.). Northwest ordinance. Retrieved from https://www.varsitytutors.com/earlyamerica/milestone-events/northwestordinance

Versland, T. M. (2013). Principal efficacy: Implications for rural "Grow Your Own" leadership programs. The Rural Educator, 35(1), 13-22.

Wamsley, L. (2018, February 22). West Virginia's teachers walk off the job, protesting low pay and benefit cuts. Retrieved from https://www.npr.org/sections/thetwoway/2018/02/22/588086091/west-virginias-teachers-walk-off-the-job-protestinglow-pay-and-benefit-cuts

Yan, H. (2019, January 14). Los Angeles teachers are on strike leaving 600,000 students in limbo. Retrieved fromhttps://www.cnn.com/2019/01/14/us/los-angelesteachers-strike/index.html

Yang, Y. (2014). Principals' transformational leadership in school improvement. The International Journal of Educational Management, 28(3), 279-288.

Yost, D. S. (2006). Reflection and self-efficacy: Enhancing the retention of qualified teachers from a teacher education perspective. Teacher Education Quarterly, 33(4), 59-76. 
Deanna L. Jurkowski was born in 1975 as her parents were stationed at Clark AB in the Philippines. Like others in her family, Deanna would later begin college with a dream of being a member of the US Air Force. After graduating high school in 1993, she attended the Illinois Institute of Technology on an AFROTC schedule and majored in business. During her second semester of college, she changed her major to accounting. As all great love stories go, boy met girl, boy and girl fall in love, and boy and girl get married. Deanna married the love of her life, Odin, in 1995, and they began their family. After her first child was born, Deanna was no longer able to meet the medical qualifications and was honorably discharged from the AFROTC program. At that point in time, Deanna and Odin made the decision to put her college on hold while she was a stay at home mom.

Deanna became active in La Leche League International, an organization dedicated to providing information and support to breastfeeding women as her family was growing. During this time, Deanna became an accredited leader and held leadership roles at the state level for the organization in both Illinois and Missouri.

When the time was right, Deanna chose to go back to college to pursue her bachelors' degree, this time in Maternal and Child Health with a concentration in human lactation. Odin was also working on his doctorate at this time. Deanna and Odin's family kept growing, and in 2002, their fourth child passed away less than three weeks after she was born. Soon after Amelia's death, their family moved to Missouri where Odin taught at the University of Central Missouri, and Deanna put her education on hold again. Deanna then began working part-time as a Children's Ministry Coordinator at her church, gave birth to two more children, and soon shifted to working at the church preschool. 
In 2009, Deanna made the decision to go back to college with the goal of earning her bachelor's degree to set an example for her children that education is a priority for both men and women. Seeking a degree in Family and Consumer Sciences Education was the fastest path to a degree. Deanna never intended to teach or even work full time as five living children kept her busy enough. However, Deanna was contacted regarding a fulltime FCS position with the Kingsville R-1 school district while student teaching. She accepted the position and began teaching when her youngest child entered Kindergarten, and her eldest was in 10th grade.

Deanna stayed in the Kingsville R-1 district for eight years. During her second year, she moved into the special education department part-time and taught FCS parttime and began working on her master's degree in secondary administration. During her third year, she became the district's process coordinator. Deanna then became the district's special education director and continued to teach part-time during her fourth year as she added on coursework for certification in the area of special education administration. This was about the time she began her doctoral journey through the Statewide Collaborative EdD in Educational Leadership and Policy Analysis at the University of Missouri. In her sixth year in public education, Deanna moved into the role of K-12 Assistant Principal/Special Education Director in Kingsville. She stayed in this position until she moved to the Concordia R-2 District in 2019 to become their 7-12 Principal. Her husband has lovingly stepped into the supportive role as she has taken on new educational and career opportunities.

Deanna has had a long and winding journey to get to the point where she is completing her dissertation. Prior to this program, she never viewed herself as a leader, 
nor sought out leadership roles. Instead, the roles seemed to fall in her lap. Throughout her coursework and this dissertation process, she learned to see herself as a leader, seek out new opportunities, and continue to do what is right for both her own children as well as her students at school. Deanna hopes to have a long career working toward improvement by doing what is right for students and families in public education.

Deanna and Odin have been married for nearly 25 years and have six children. Their eldest, Kalina, is a teacher and lives with her husband, Marvin, in San Lucas, Guatemala. Their son, Byron, is pursuing a degree in Computer Science at the University of Central Missouri. Their daughter, Acacia, is pursuing a degree in both Biology and Chemistry at Missouri State University. The youngest two children, Cordelia and Valen, are both still in public school. Cordelia is considering a career in physical therapy, and Valen currently wants to be an actor. Both the younger children are actively involved with dance and theater at their local performing arts studio. The Jurkowski household is always on the go and always busy. Deanna strives to be a role model, setting an example and demonstrating to her children and her students that they can be anything in this world with hard work and determination. 